$\infty \quad$ AL.2.1987-497

c. 2

?

Horse Handling Facilities

Q

$\checkmark$

s

(n)

5
$\frac{5}{d}$
$\mathbb{L}$

Shei

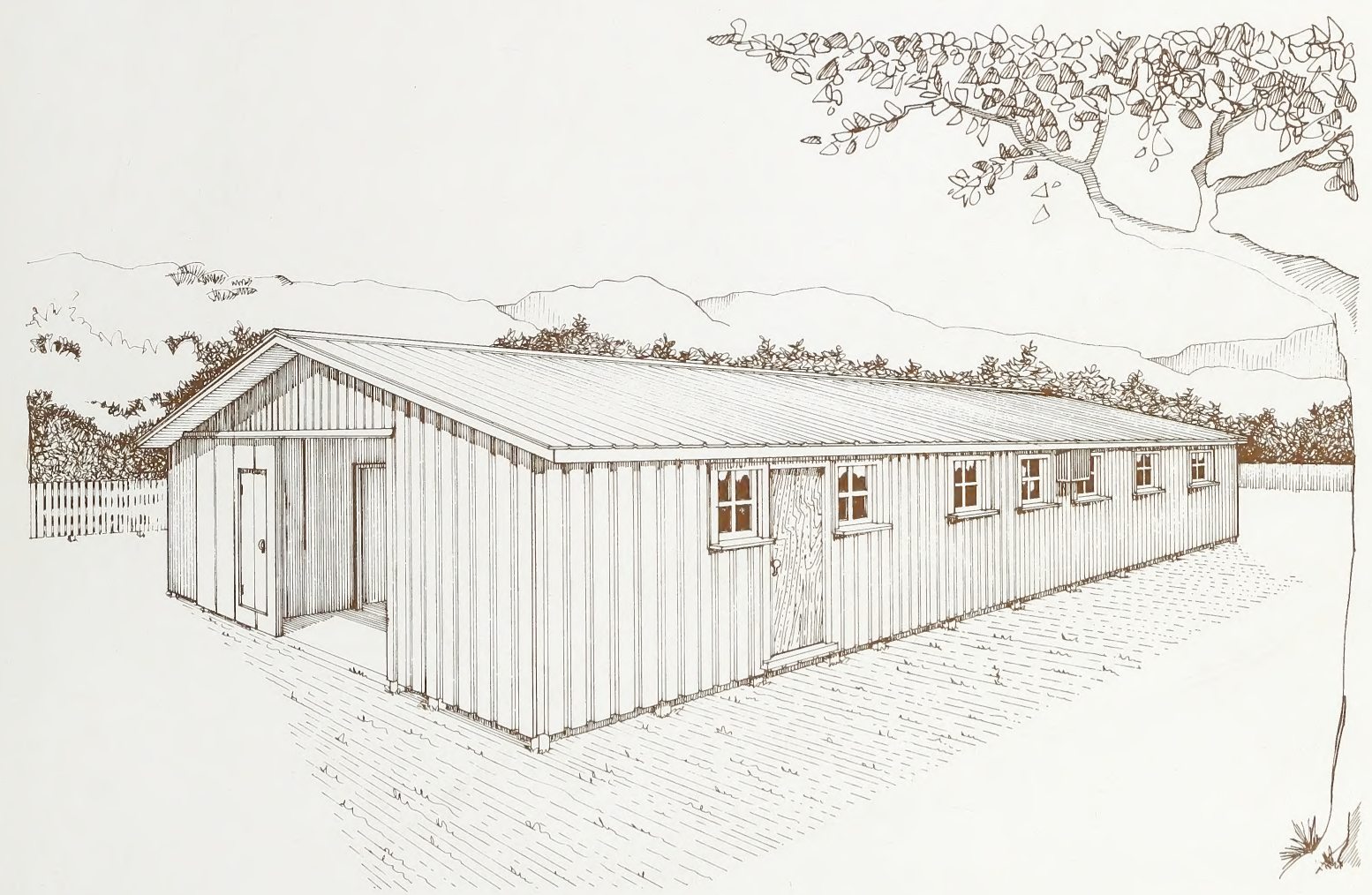


Copies of this publication may be obtained from

Print Media Branch

Alberta Agriculture

7000 - 113 Street

Edmonton, Alberta T6H 5T6

OR

Alberta Agriculture's district offices

198510 5M Revised 


\section{HORSE HANDLING FACILITIES}

PRAIRIE JUNIOR HIGH SCHOOL LIBRARY MEDIA CENTRE

Written By:

Alan Kidd

Engineering Assistant

Wayne Winchell

Regional Agricultural Engineer

Barrhead

L. Burwash

Horse Industry Branch 


\section{CONTENTS}

INTRODUCTION $\ldots \ldots \ldots \ldots \ldots \ldots \ldots \ldots \ldots \ldots \ldots \ldots \ldots \ldots \ldots \ldots$

SITE PLANNING FOR HORSE FACILITIES $\ldots \ldots \ldots \ldots \ldots .3$

SHELTER FACILITIES $\ldots \ldots \ldots \ldots \ldots \ldots \ldots \ldots \ldots \ldots$

PLANNING THE STABLE $\ldots \ldots \ldots \ldots \ldots \ldots \ldots \ldots \ldots, 6$

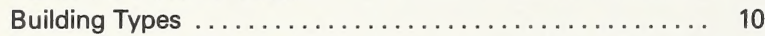

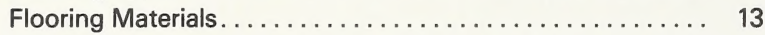

Box Stalls .............................. 14

Tie Stalls ............................. 17

Lighting .............................. 20

Watering Systems ....................... 21

HEATING AND VENTILATION $\ldots \ldots \ldots \ldots \ldots \ldots \ldots \ldots 22$

Natural Ventilation ........................ 22

Forced Air Ventilation $\ldots \ldots \ldots \ldots \ldots \ldots \ldots \ldots \ldots \ldots, 26$

Heated Facilities ...................... 28

MANURE HANDLING $\ldots \ldots \ldots \ldots \ldots \ldots \ldots \ldots \ldots \ldots, 30$

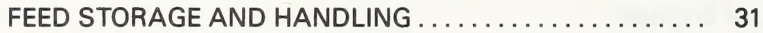

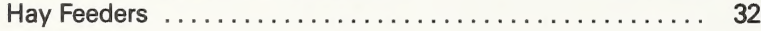

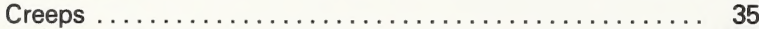

Mineral Feeders ......................... 37

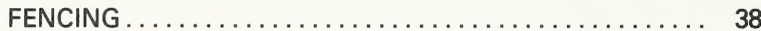

Corral Housing ...................... 40

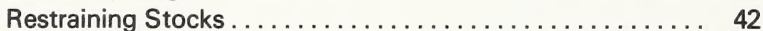

Teasing and Breeding Facilities $\ldots \ldots \ldots \ldots \ldots \ldots \ldots \ldots 43$

ARENA CONSTRUCTION ................... 47 


\section{INTRODUCTION}

This publication presents information on horse barn designs and recommended methods of construction. It includes chapters on site planning, horse shelters, corral and fence construction, and riding arenas.

The largest costs incurred in maintaining and managing a horse operation are feed and labor. Therefore, all planning should aim at minimizing feed loss and labor. 


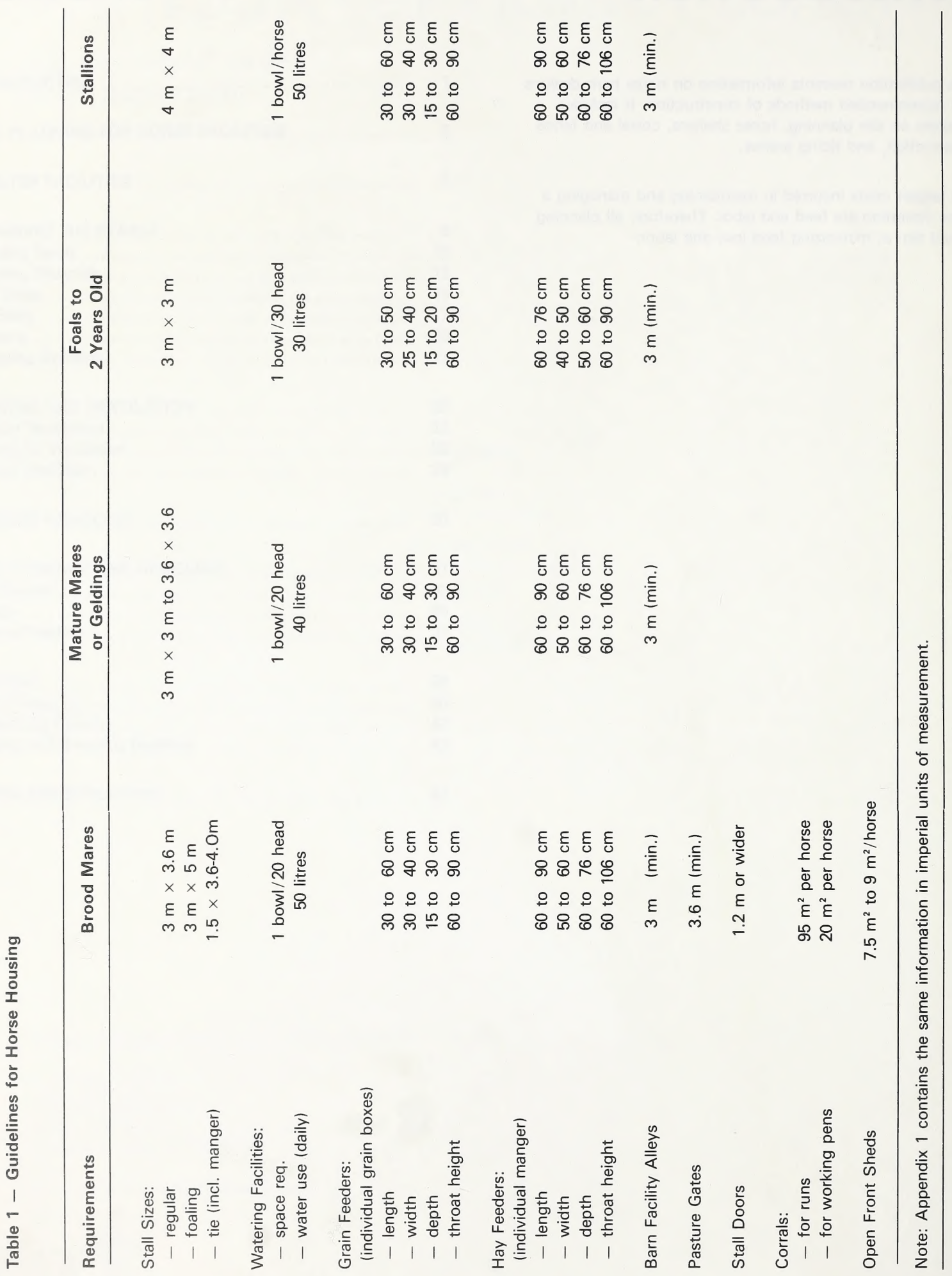




\section{SITE PLANNING FOR HORSE FACILITIES}

The planning of a horse facility is the most important step in the construction process. Much thought and attention are needed to ensure a successful venture. Future problems can be avoided by considering the following points:

- Location - The location should be easily accessible and have good drainage. Water and electrical hookups should also be considered. Barns and corrals should be located some distance $(100 \mathrm{~m})$ from the residence. Allow ample space for parking and turning trucks and trailers.

- Zoning - Check local regulations.

- Flexibility - The possibility of expansion or conversion of the facility should be considered, not only in the building design, but in the choice of site.

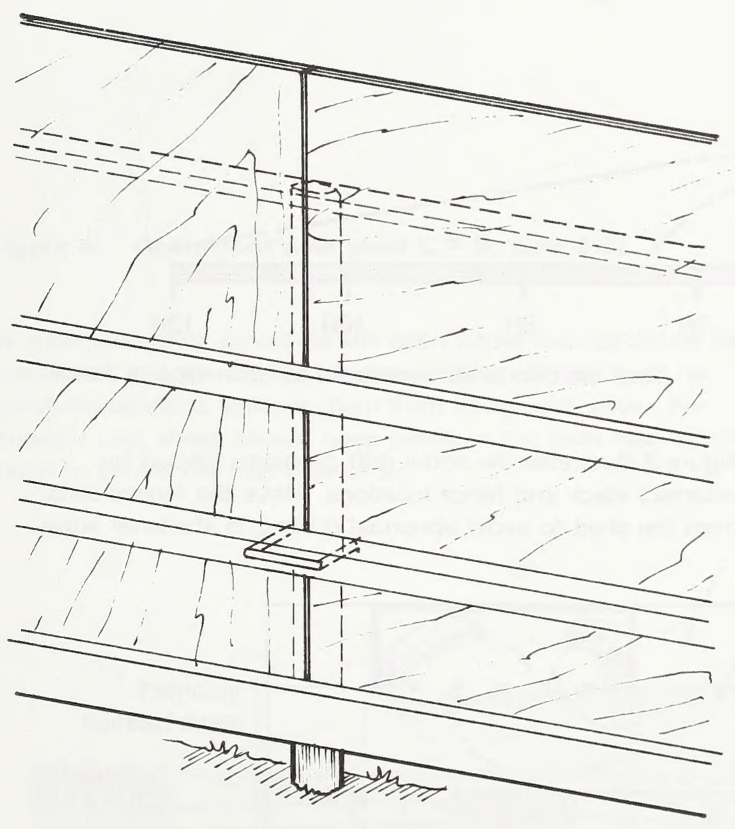

Solid Fence

Figure 1: Construction of snow and windbreak fences
- Environment - Proximity to neighbors and pollution potential.

- Appearance - The actual appearance of a stable is also important. An attractively designed and efficient building can increase the property value of an operation significantly.

- Snow and Wind Control - Snow and wind are unquestionably part of Alberta's climate. The wind lowers the actual temperature and animals react by increasing their feed intake. They also suffer from stress and discomfort in the cold. In still air conditions, there are very few days when the temperature drops below a mature animal's comfort zone. Therefore, windbreaks are useful.

Natural windbreaks provide the best means of wind protection. Where natural ones are not available, artificial windbreaks such as fences can be effective.

Designs for solid or porous fences are shown in Figure 1.

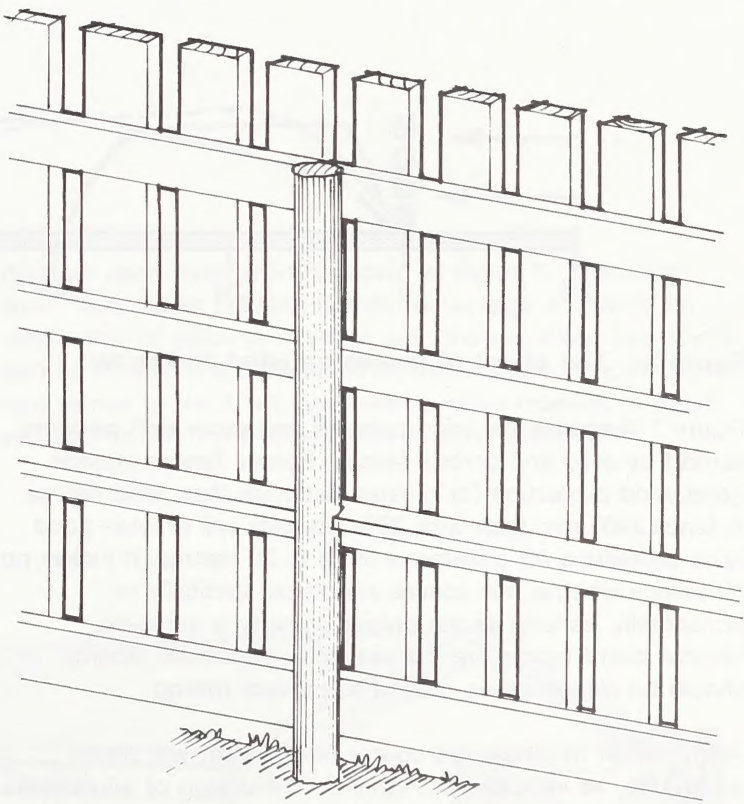

$20 \%$ Porosity Snow Fence 
Solid fences are effective for snow control over a limited area, but are ineffective for wind control because of high turbulence

(Figure 2).

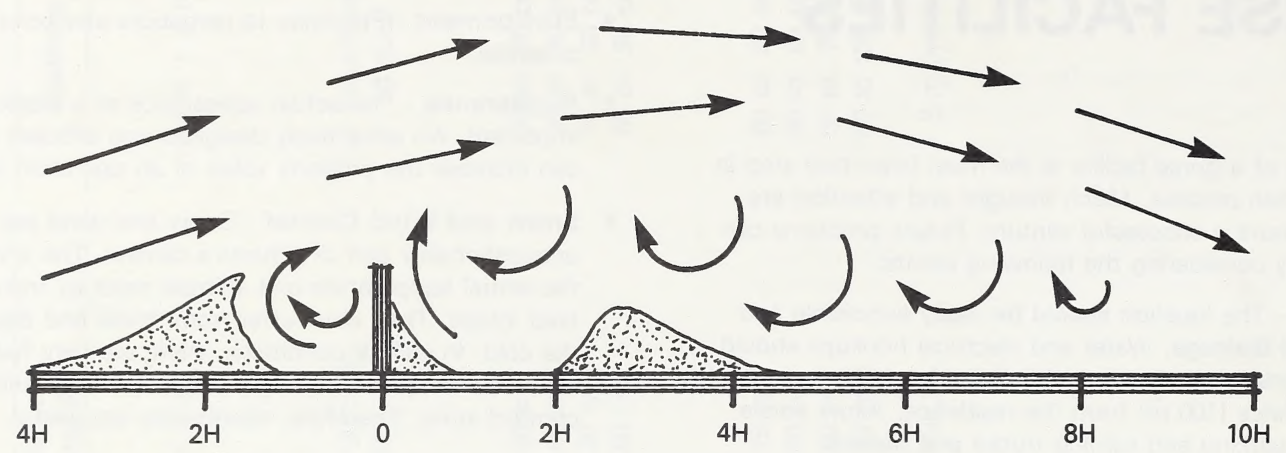

$H=$ height of windbreak fence

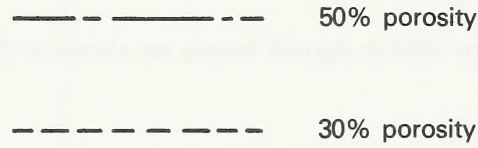

$15 \%$ porosity

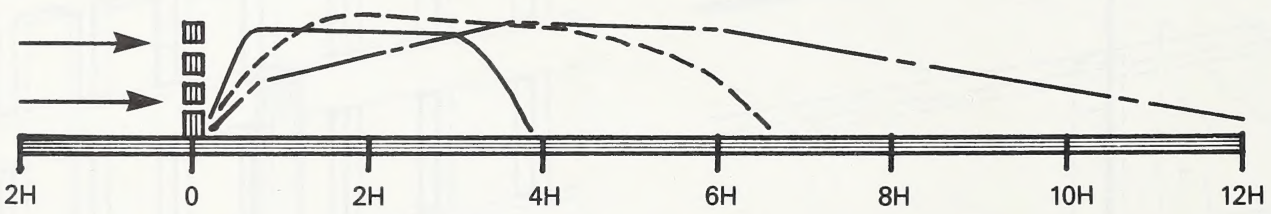

Figure 2: The effect of fences on wind and snow

lines indicate areas protected by each type of fence

Figure 2 illustrates the wind patterns and snow drift patterns caused by solid and porous fences. Porous fences provide good wind protection for greater distances than solid fences. A fence $2400 \mathrm{~mm}$ high with $20 \%$ porosity will provide good wind protection for a distance of 24 to 30 metres. It makes no difference whether the spaces are placed vertically or horizontally, as long as the proper porosity is achieved. Vertical board fences are the easiest to construct. Boards should be placed above ground to prevent rotting.

Any attempt to hinder the course of the wind will create snowdrifts, as indicated in Figure 3. The design of windbreaks must deal with this potential snow drifting problem. The location of sheds, machinery, feed stacks and other buildings is also important. Careful placement will cause the snow to settle in unused areas. Just as windbreaks have certain air flow characteristics, they also have peculiar snow drift patterns which depend on the density of the windbreak. Space must be allowed for snow drifts as well as the resulting drainage. Poorly placed buildings and equipment will cause drifting in lanes and corrals and may cause the building to fill with snow.
Figure 3 illustrates the snow drift problems caused by incorrect stack and fence locations. Move the fences away from the shed to avoid abnormal drifting in sheltered areas.

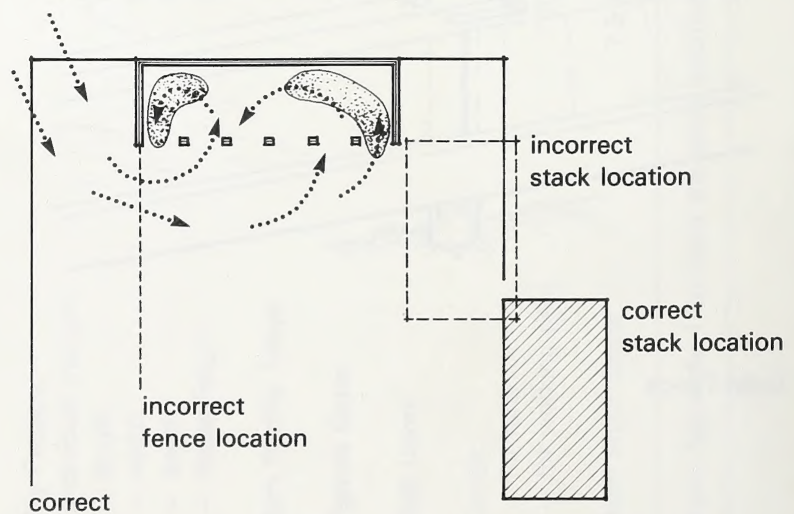

fence location

Figure 3: Snow accumulation in corrals 
Your shelter and attached corrals should be carefully planned to ensure that the finished horse facility meets your needs. One building option is a single sloped, open-front shed (Figure 4). This facility provides good wind and moisture protection at a low cost.
A shelter such as this should be located on well drained land allowing about $8 \mathrm{~m}^{2}$ per horse. Maximum depth of the shed should be $8 \mathrm{~m}$. Shallow sheds with an east or south exposure are usually preferred but sheds should be faced away from the prevailing winds. If hay feeders are placed in the shed, they should be put at the back wall. This will prevent horses from loitering in the entry and blocking access to the feeder for other horses. All wood should be treated once a year with creosote to limit wood chewing.

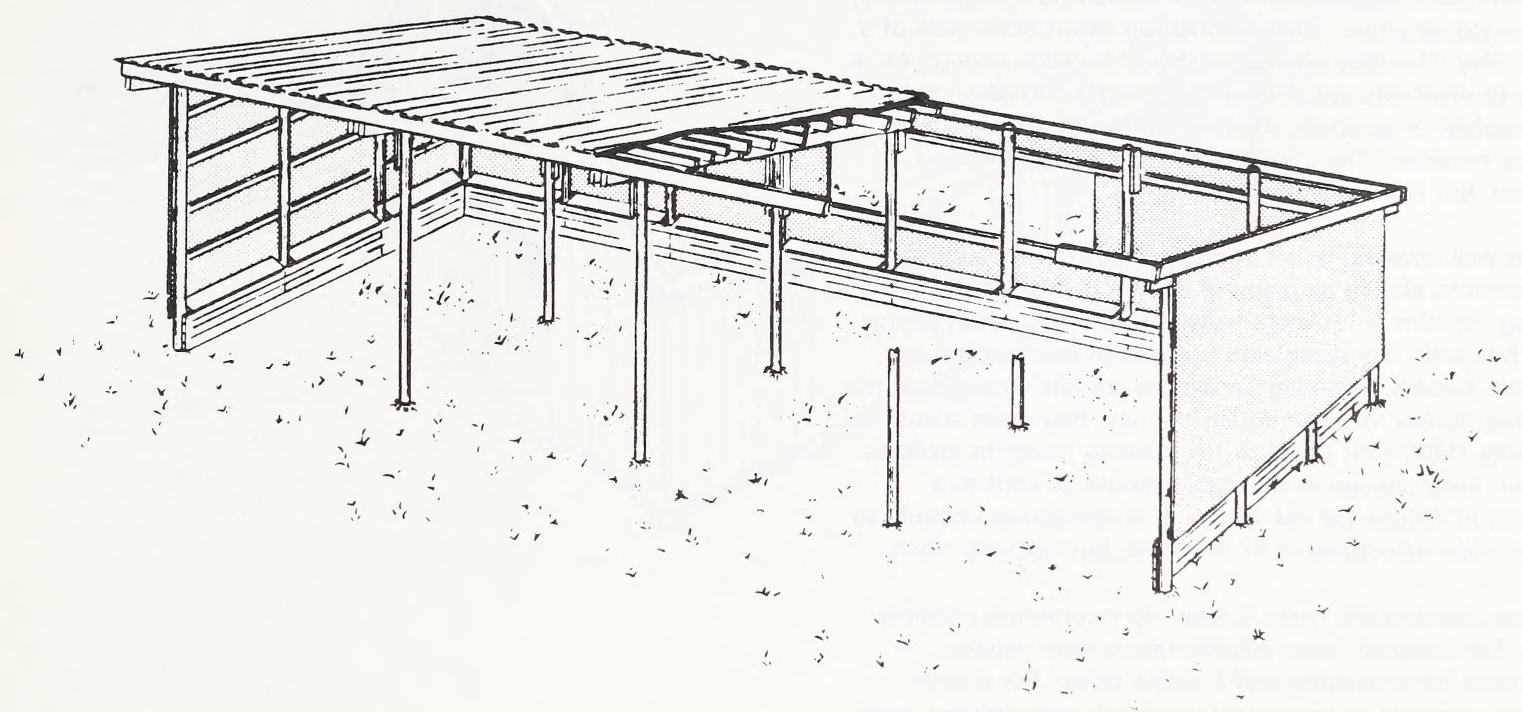

Figure 4: Open-front pole shed C.P.S. plan 8162

A continuous slot should be left open under the rear eaves for ventilation and the control of snow drifting. Sheds must be carefully placed to prevent them from filling with snow. For summer use, sheds should have panels in the back wall which open to permit the free flow of air.
Another open front shed is shown in Figure 5. This clear span, truss rafter building has the advantage of having no centre row of poles to interfere with manure clean-out. It can also be closed in and insulated at some future date. Since the roof slopes to the front, an eavestrough is required to avoid wet and muddy conditions at the front of the shed.

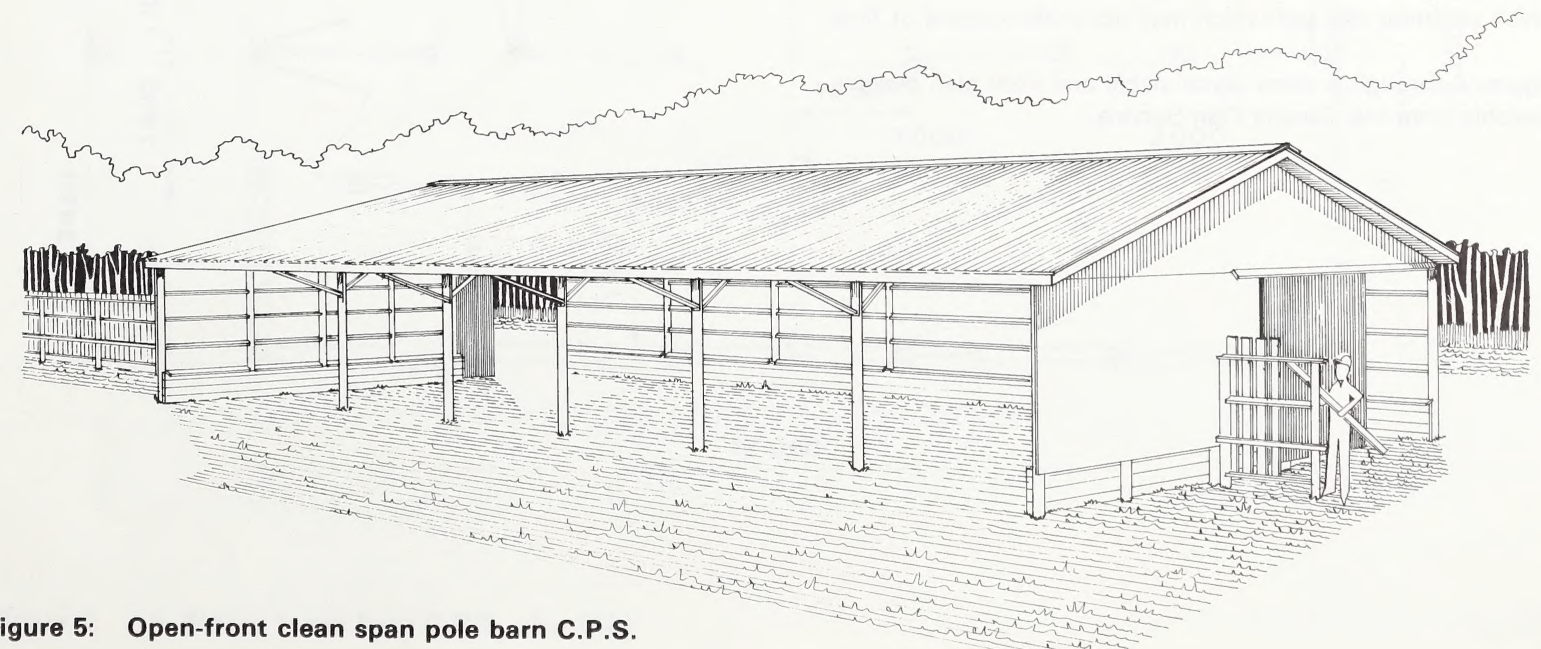




\section{PLANNING \\ THE STABLE}

While there are several options as to style and type of facility presented in this chapter, there is a recommended stable which is ideal for new construction. This stable represents maximum utility at minimum cost. It should be a single storey, gable-ended structure. Stalls should run down either side of a central alley. The alley and doors should be wide enough for a vehicle to drive through. Floors of the stalls and alley can be either asphalt or concrete. Planned ventilation of some type must be provided. The structure should be draft free and insulated, but heating is unnecessary.

Outside wall covering is not important, but inner walls and stall partitions should be made of $38 \mathrm{~mm}$ ( 2 inch) thick planking, or $19 \mathrm{~mm}(3 / 4$ inch) plywood with adequate framing. Tie or box stalls are acceptable and should include mangers and grain feeders. Watering appliances are not necessary if the horse has access to water during the day. Box stalls should have wide $(1200 \mathrm{~mm})$ doors or full opening fronts to facilitate cleaning. Feed storage in the stable should be kept to a minimum to reduce the risk of fire. It is sometimes possible to remodel older structures to fit this ideal, but not very often.

Advance planning will make it easier to incorporate personal details. For instance, large establishments may require washrooms for employees and a stable office. For a large breeding operation, a permanent washrack with optional opensided restraining stocks is almost a necessity. Careful planning before building will ensure an efficient functional structure.

Practicality of the building itself is very important. It should be easy to clean and maintain. Remember that feeding and cleaning are chores, and a simple system can reduce labor requirements. Ample space for storage, wide doors, and alleys are important.

Large amounts of feed and dust in a stable increase the possibility of fire. Materials and designs should be chosen which minimize risk and which may aid in the control of fires.

Figures 6 through 8 show some stable and floor plan designs available from the Canada Plan Service. 

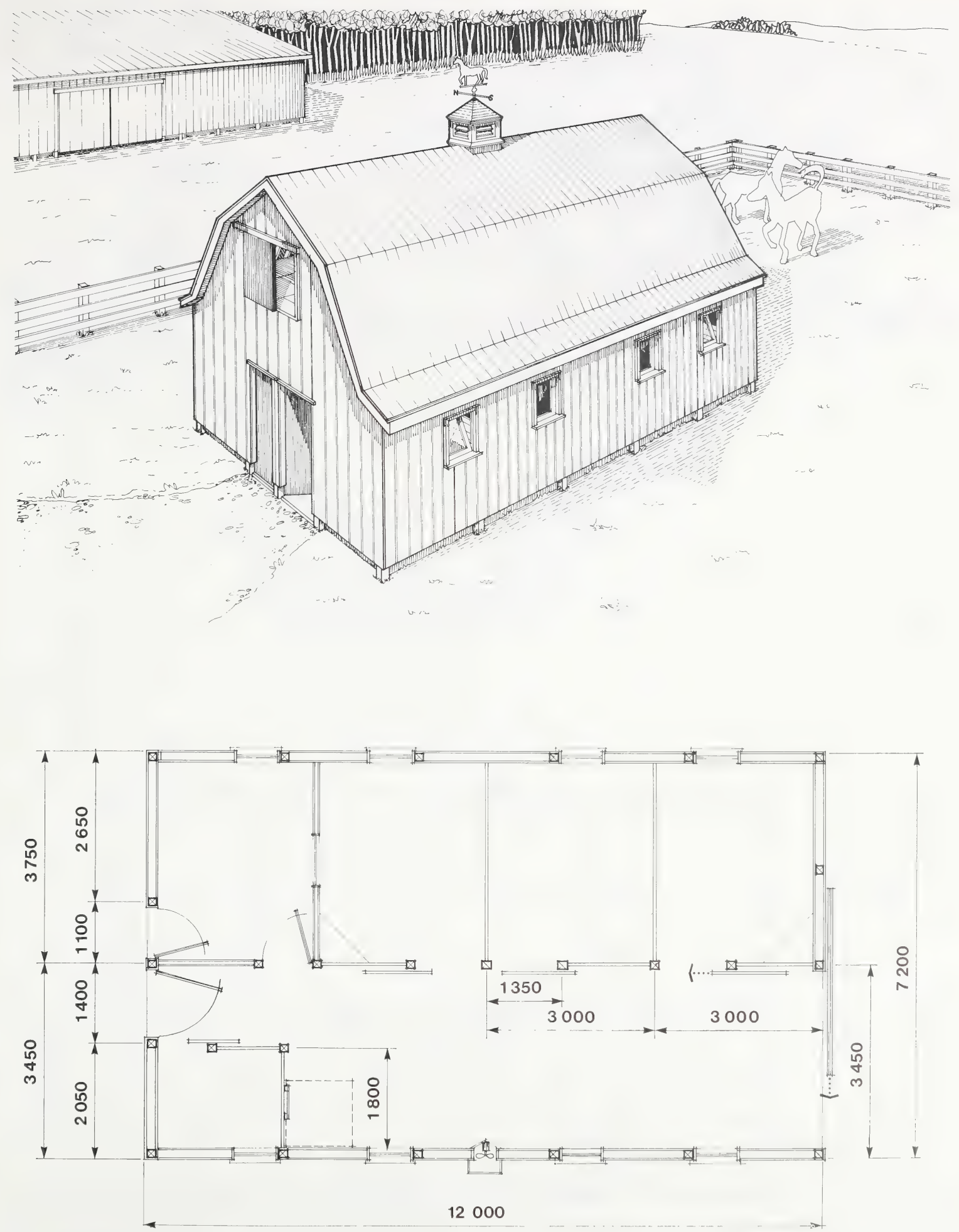

Figure 6: $\quad 1 \frac{1}{2}$ Storey horse barn C.P.S. plan 8204 

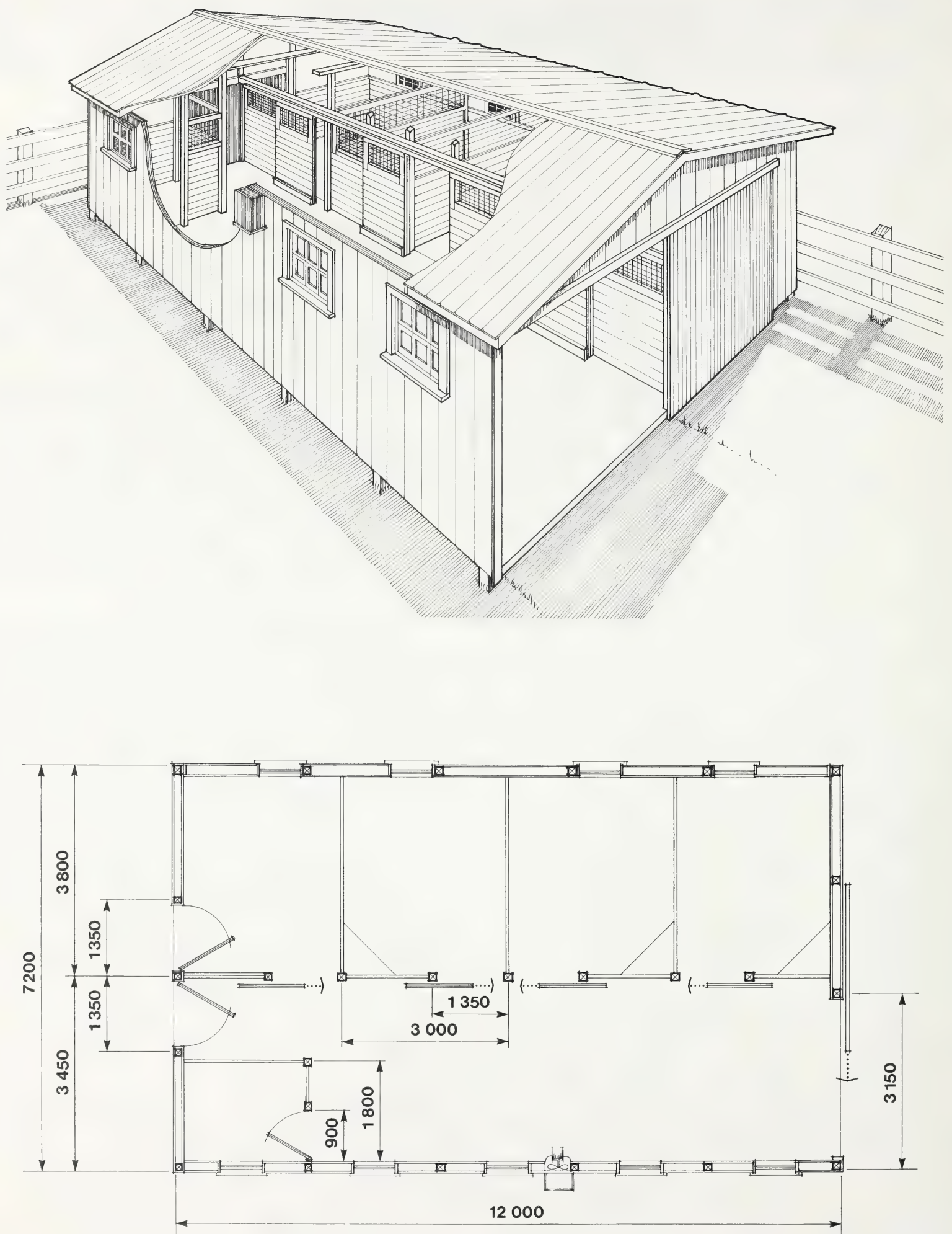

Figure 7: Horse barn C.P.S. plan 8201 

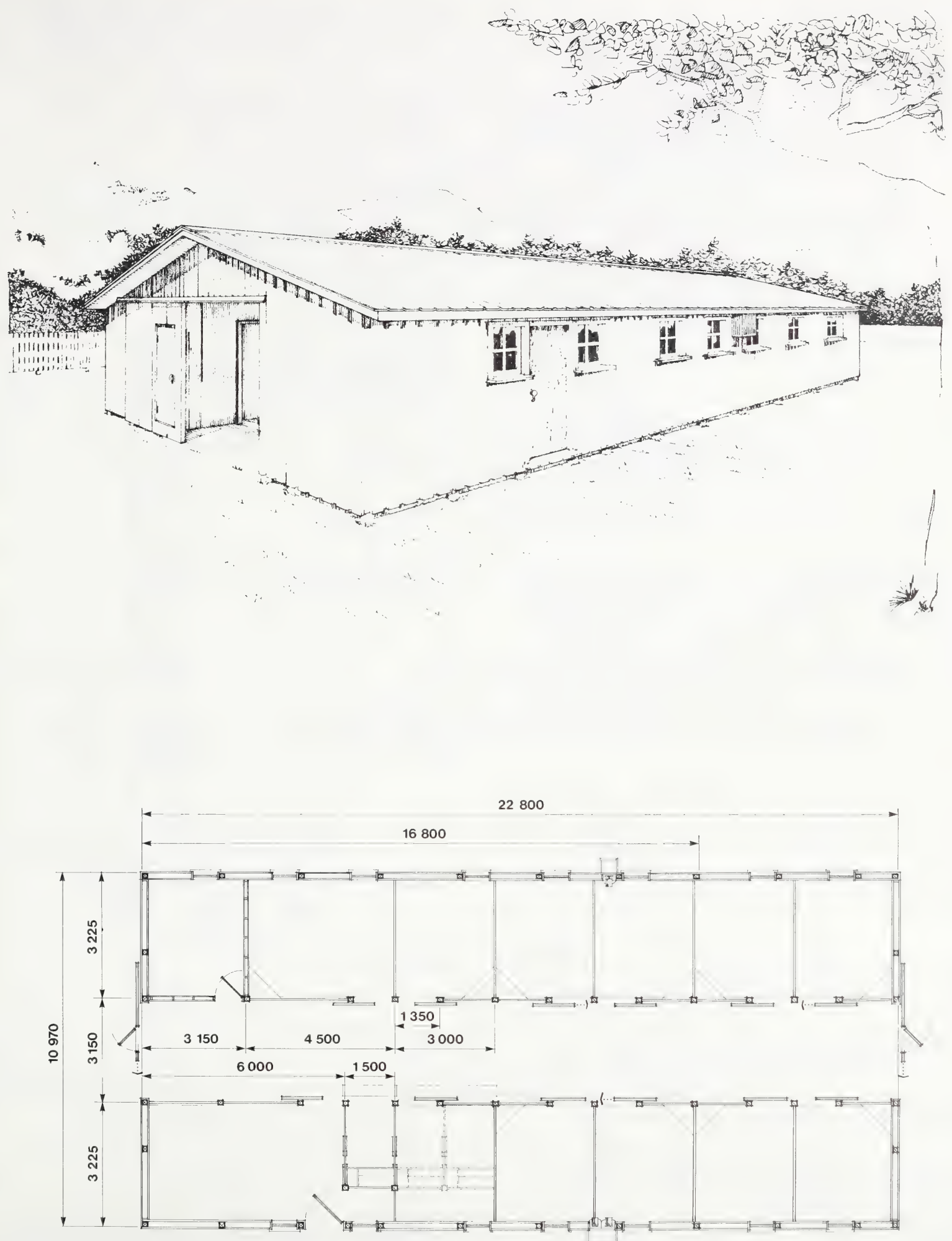

Figure 8: Horse barn C.P.S. plan 8202 


\section{BUILDING TYPES}

There are three common shapes among modern farm structures: gable ended (with perpendicular walls), arch type, and flat roofed type (with slanted walls). The gableended structure is built mainly with wood framing; arch buildings can be either wood or metal; and the flat-roofed type usually has a two-hinged steel frame structure.

Gable ended structures are most readily adapted for use as horse stables. They are easy to insulate, service and finish on both the interior and exterior. Doors and windows can be placed on side and end walls. The outside can be finished to match existing structures. Square pole (Figures 9 and 10) or traditional framing techniques (Figure 11) can be used.

Wooden trusses up to $18 \mathrm{~m}$ in length are less expensive than steel trusses and give a large range of sizes at a reasonable cost. Gable ended structures are usually the least expensive to erect.

Another wooden framed structure that is readily adaptable for livestock housing is the rigid frame (Figure 12). Such buildings are comparable in price to those of standard frame construction and are easy to insulate and sheath on the interior. Putting ventilation slots in the side walls and installing a baffle can be difficult depending on the design of the rigid frame.

Arch type buildings (Figure 13) have some drawbacks when used as stables. The slanted walls will reduce the usable floor area in low buildings. This is especially true for outfacing tie stalls. If the building is tall enough to have a reasonable vertical wall height, overhead space is wasted. A loft can be put in, but this adds to labor and is not recommended. It is possible to put doors and windows on side walls, but not as easily as in a standard frame building. Building and attaching stalls can be difficult.

Wooden archrib buildings are relatively easy to service and insulate. Metal ones are difficult as well as expensive to insulate. Horses will chew any sprayed-on insulation, so the inside of the structure must be strapped and sheeted to at least 8 feet. Most of the sprayed on insulations absorb moisture and are therefore not recommended for livestock buildings.

Two-hinge metal frame structures may have slanted side walls, which make side doors more difficult to install. The inside of the building must be strapped to protect the insulation.

Enclosed, uninsulated metal buildings lose excessive amounts of heat and will "sweat" badly in the winter, even when heated. Adding interior structures may be difficult. Metal quonsets and metal framed buildings generally cost more than wooden structures, especially those with shorter spans, and are generally not recommended for livestock housing.

Inner walls and partitions should be faced with $38 \mathrm{~mm}$ lumber, or suitably framed $19 \mathrm{~mm}$ plywood. Outer surfaces can be dressed to match existing structures. Wooden siding may be defaced by horses and it may be necessary to restrict horses' access to it. Aluminum siding is prone to dents and tears. Metal sheeting is more rugged. Painted plywood or chipboard is subject to chewing. Usually it is necessary to protect the outer walls from the horses. Horses may chew at shingles used to clad archrib buildings. All lead-based paints are poisonous and must not be used on livestock facilities.

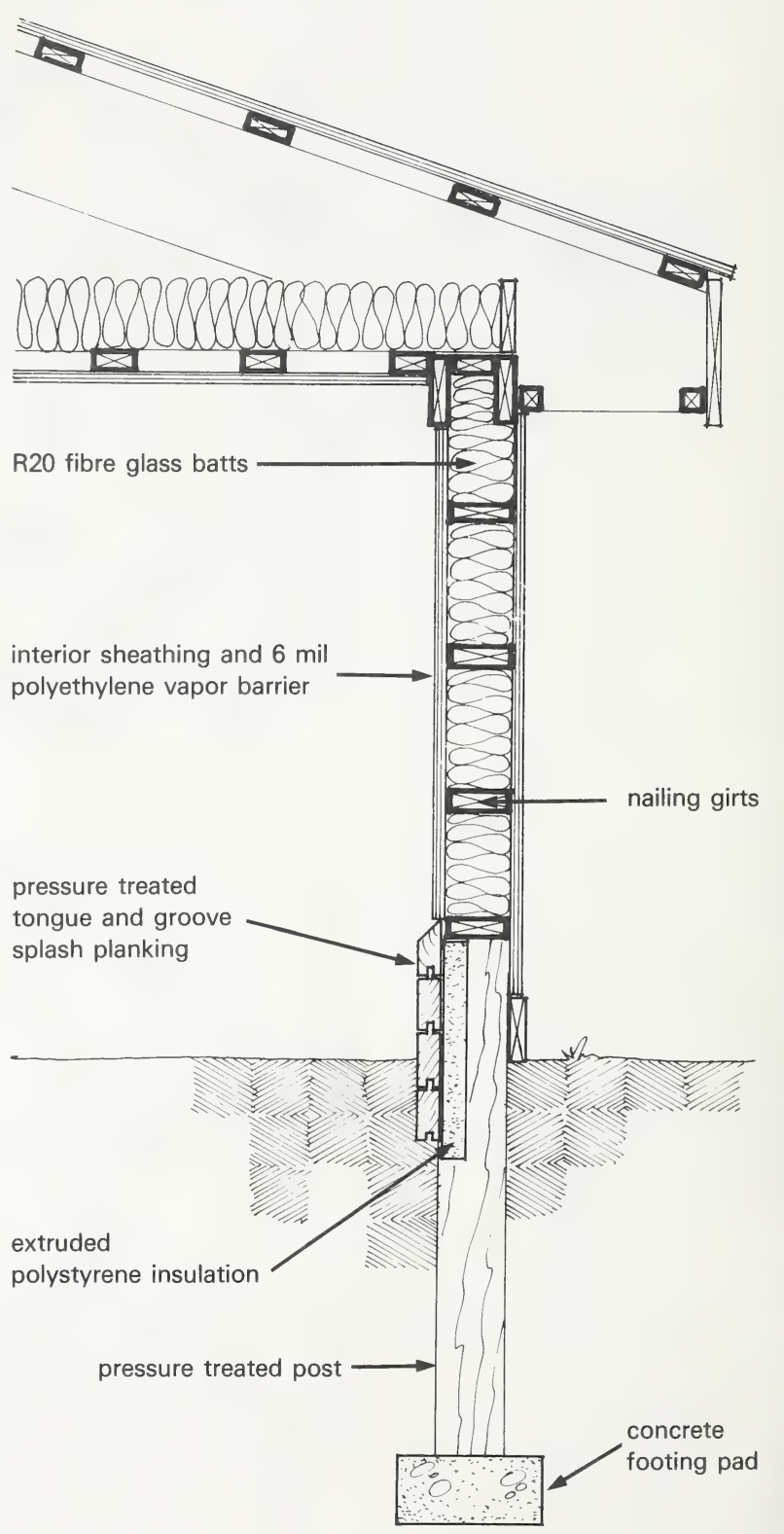

Figure 9: Insulated post frame construction (flat ceiling) 


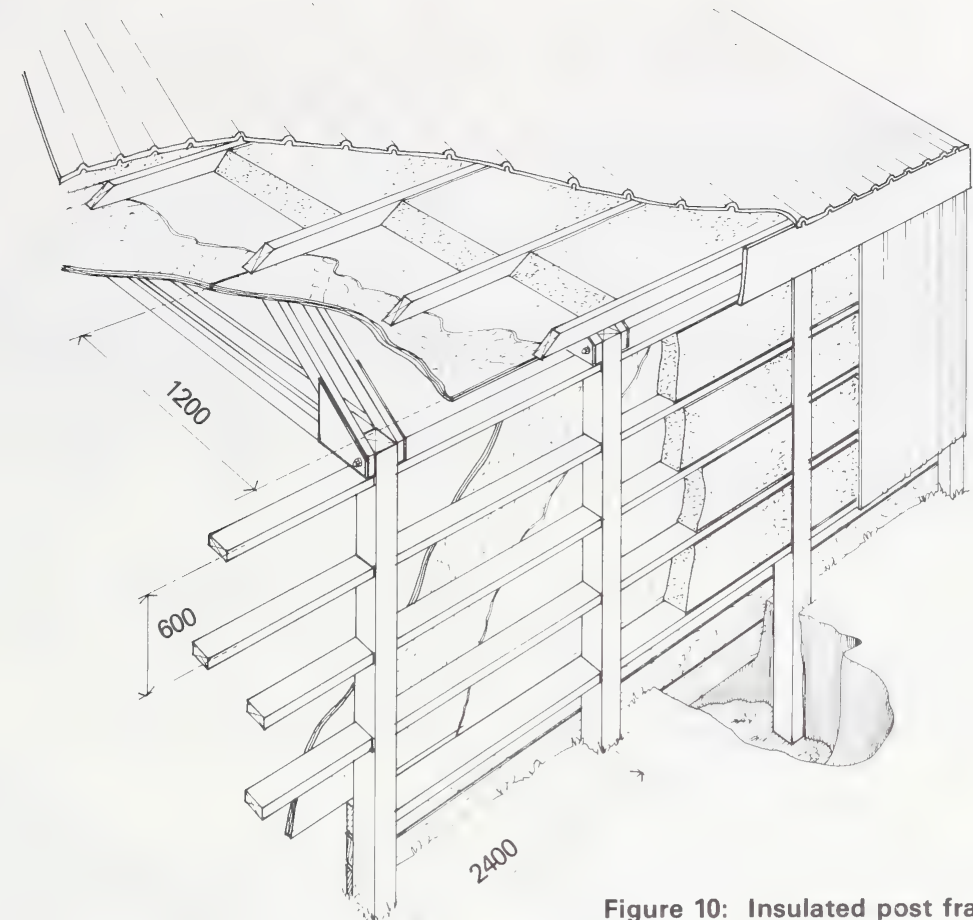

Figure 10: Insulated post frame construction (insulated roof deck)

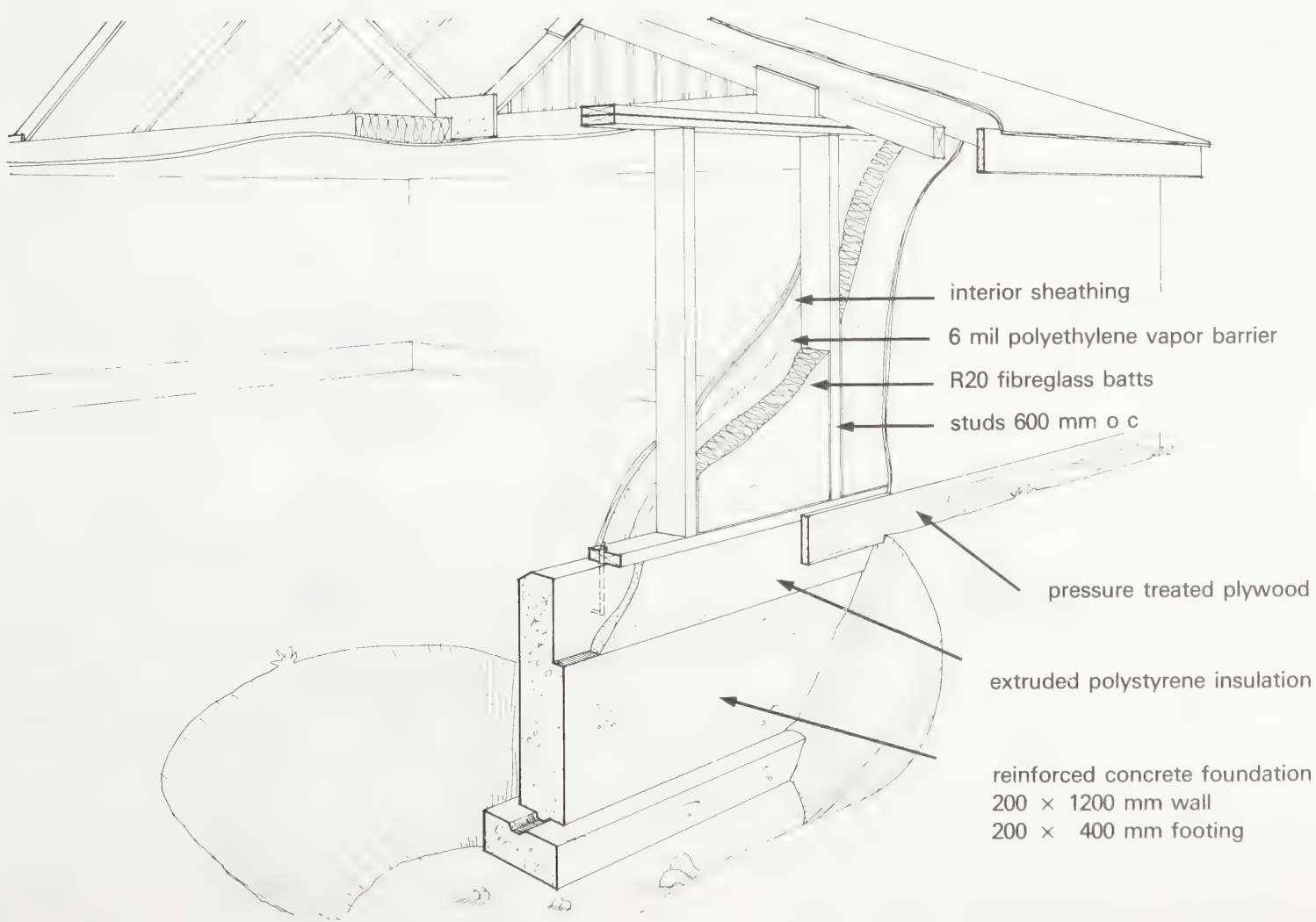

Figure 11: Insulated stud wall construction 


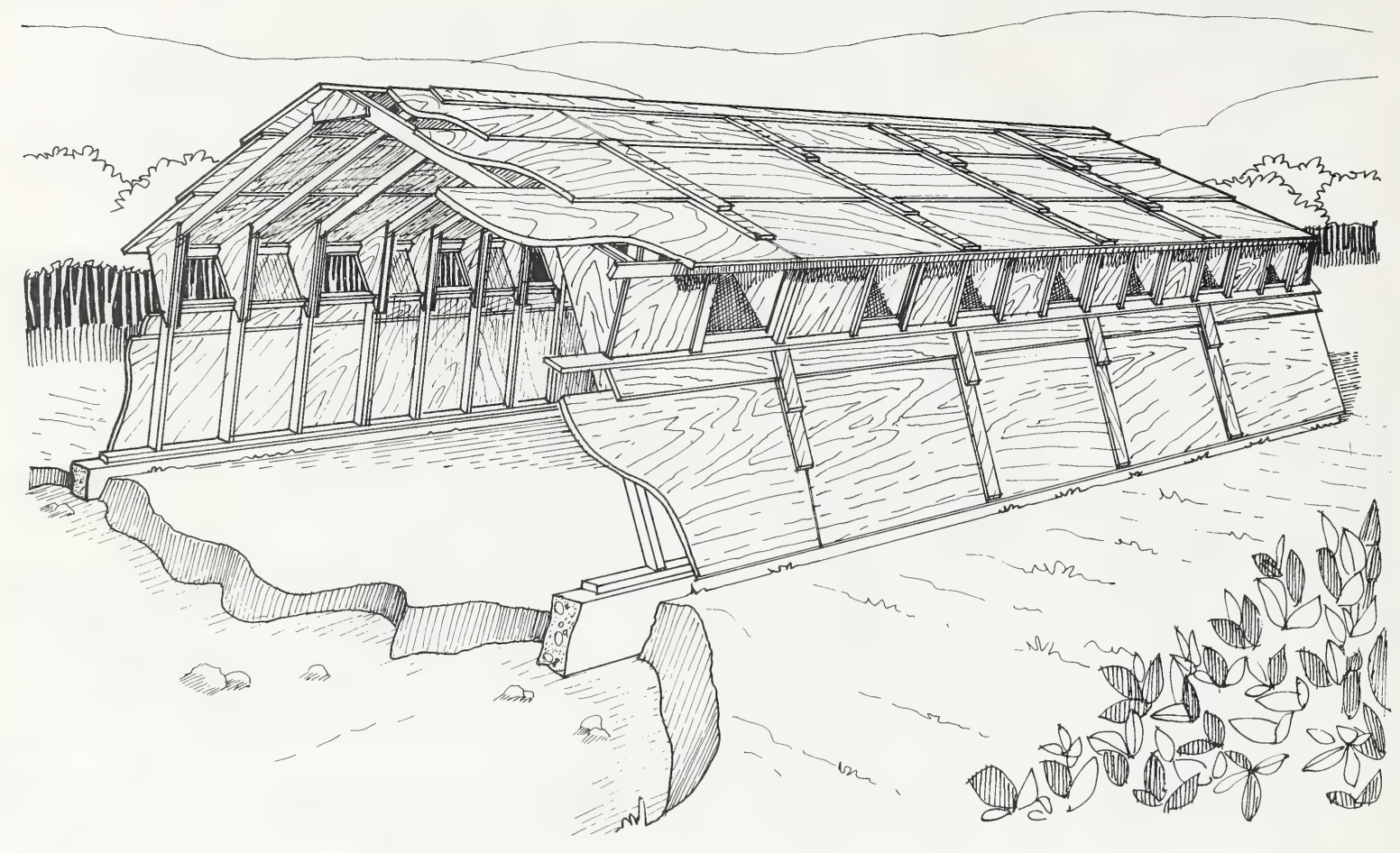

Figure 12: Rigid frame construction

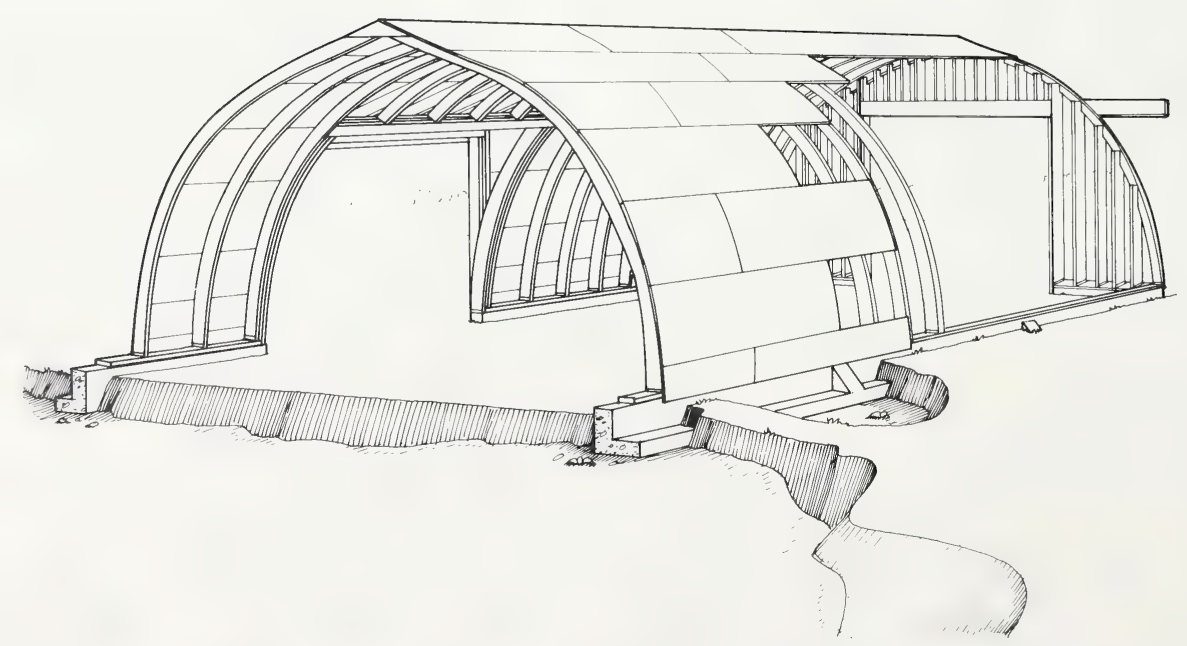

Figure 13: Wooden arch construction

12 


\section{FLOORING MATERIALS}

The ideal floor should be elastic and firm; smooth but not slippery. It should be absorbent, but not retain odors, and it should drain well. An ideal floor has not yet been found.

A stable floor need not be made entirely of one material. A common plan is to have a concrete alley, with earth in the stalls. Alleys need to be able to support heavy equipment. Asphalt mixes from stall to alley may be varied to provide a harder alley floor. Alleys may be crowned, and stalls sloped with a gutter installed to improve drainage. Maximum stall slope should be 1:50. Floors drains are a possibility but they plug easily. They can cause more problems than they are worth. Safety, comfort and utility are major considerations when choosing a floor.

The use of concrete, asphalt or brick in stalls may require more bedding than clay or dirt floors. This is particularly true for young horses that spend considerably more time lying down. Extra bedding will reduce the incidence of scraping of the hocks on rough flooring when getting up and also reduce the loss of body heat from the foal when it is lying down.

\section{CLAY}

Clay or earth floors are advocated by many. They are inexpensive and not slippery when wet. However, these floors do not dry easily, and are dusty when they are dry. Earth and clay are easily pawed and pitted and need frequent replacement.

\section{SAND}

Sand has all the advantages of earth and clay but will not pack to a solid floor. It will drain more readily than dirt or clay. Unfortunately, it has the same disadvantages in that it dries and becomes dusty. Stalls with dirt, clay or sand may get wet spots from urine.

\section{WOOD}

Wood flooring is preferred by some horsemen because it is easy to clean. It can, however, be extremely slippery when wet, and it retains odors. It will wear and rot so it must be replaced periodically. Wood floors can also harbor infestations of rodents. Although wood flooring is expensive, using treated plywood or native softwoods can bring the cost down.

\section{BRICK}

The traditional material for stable floors in Europe is brick. Brick floors are expensive and may be damaged by heavy horses with caulked shoes. Interlocking or ordinary bricks laid on edge can be used but ones specially made for stable floors may be available in some areas. They can be laid on an incline to assist drainage and some are grooved for this purpose.

They are easy to clean but can be very slippery when wet. When laid on sand, they may need to be relevelled periodically.

\section{ASPHALT}

Asphalt floors are inexpensive. They can be laid on an incline, are easy to clean and have some give. While asphalt is not usually slippery, care must be taken when it is wet. When very cold, asphalt becomes hard and brittle, but in a heated barn this should pose no problem. When hot, asphalt may become sticky. Although it has a long life it may need resurfacing after years of continuous hard use. Various mixtures of asphalt are available to provide different textures. A horse not used to asphalt flooring may scrape his hocks when getting up. Occasional applications of lime keep asphalt odor free. Most of the disadvantages associated with this flooring can be overcome by deep bedding.

\section{CONCRETE}

Concrete is very hard wearing, easy to clean, and can be laid on a slope. It is not slippery if finished with a rough surface, e.g., a wood float or broom finish. Smooth finished concrete is very slippery and should be avoided. Adequate bedding is essential to prevent urine from accumulating in low areas.

\section{RUBBER MATS}

Rubber mats can be used with concrete, asphalt or wood to add traction to the floor. The mats have some insulating value and are very easy on the horses' feet. Although expensive, the saving in stall cleaning labor and bedding, plus the added comfort they provide to the horse may be worth it.

\section{RED ASH (Coal Slag)}

Red ash (coal slag) is an alternative flooring material available in coal mining country. Its red color adds to the appearance of alleys and driveways. It drains well and retains little odor. Horses are less prone to paw or dig ash than earth. It does add some dust to the air but it is firm and easier to clean than earth, sand or clay. It also has the advantage of not being slippery when wet. 


\section{BOX STALLS}

Box stalls allow a horse the freedom to move around and lie down. They provide a place of relaxation for horses in rigorous work or training sessions. However, a horse maintained in a box stall may become bored and develop bad habits. Stall weaving and cribbing are two that commonly arise. Box stalls require more space and bedding than tie stalls. They also require more labor to clean and maintain.

A well planned box stall should have a smooth inner finish, with no projections to injure the horse. It should be well ventilated and have sufficient light. The minimum recommended size for a box stall is $9 \mathrm{~m}^{2}$ per horse. The ceiling should be at least $2.4 \mathrm{~m}$ high. Foaling and sick stalls should be larger than average.

Box stall fittings can include a manger, grain trough, water, and cross tie rings (Figure 14). An auxiliary overhead heater could be used for supplementary heat in foaling stalls.

Doors entering stalls should be a minimum of $1200 \mathrm{~mm}$ wide and solidly built. Sliding and swinging doors are common. Swinging doors should open into the alley. Dutch doors or doors with open tops are traditional, but a full door is more practical. A horse will put his head into the alley and paw and strain against the door, especially at feeding time. If an opening is desired, it it better to leave the top part of the wall open. A wall is better able to take the strain of a horse leaning against it than a door.

For easy cleaning it is best to have a system that allows the whole front of the stall to open. A metal panel is ideal for this. A wide door will permit machinery to enter and operate easily. This will cut down on the need for hand labor. A wide opening will also let in more air and light. The side walls can be solid to provide some seclusion. All door hardware should be solid with no sharp edges. Latches should be chosen and placed so that the horses will not be able to open them themselves.

Windows add light to the barn and give a feeling of openness. They are aslo a major source of heat loss, but they can be used for ventilation. A horse can look out of a window, but a stall is a place to relax. A high window above the horses's line of vision may be better.

Tense horses may gaze out the window instead of eating and relaxing. Foaling stalls should be especially secluded. Windows with solid shutters but no glass, which can be opened in the summer and on warm winter days, may be another choice. Skylights may be used instead. They are out of a horse's reach and cannot be broken. Skylights add plenty of natural light and do not require much cleaning. In a barn with good air mixing, heat loss is not any greater through skylights than through windows. Skylights or windows may actually add up to 2.5 watts $/ \mathrm{m}^{2} /$ hour of heat when the sun is shining.

Stall partitions can be several different styles. If solid from floor to ceiling, they can impede ventilation. Kick walls should be solid, 1200 to $1300 \mathrm{~mm}$, with grates or screens to a height of $2100 \mathrm{~mm}$. bottom of the kick wall to aid in ventilation, such as Figure 15a. Leave $38 \mathrm{~mm}$ spaces between boards to allow air movement. For horses that are normally pastured together and hold no animosity for each orher, metal pipe panels $1500 \mathrm{~mm}$ high make an open, airy low maintenance facility. Panels can be movable to allow for changes in the physical set-up for different situations. Commercial panels are available with this capability, e.g. with a removable partition, to make a double stall for foaling.

Various materials can be used to build partitions. Wood is the most common. If lumber is used, $38 \mathrm{~mm}$ planking is required. Plywood panels (18 $\mathrm{mm}$ thick) with metal reinforcing are available commercially. All exposed wooden edges should be metal covered to prevent chewing. Metal panels are strong and maintenance free. Hollow masonry brick partitions, such as those in Figure 15b should be filled with sand or concrete to resist punctures from kicks. Solid stall partitions similar to Figure $15 \mathrm{c}$ can be built of laminated $38 \times 140$ lumber especially when using this type of building wall construction. Latches should not project into the stalls. They should be designed to prevent horses from opening them. The main points to remember are to keep inner surfaces smooth and to make partitions strong.

Some partition types and construction details are shown in Figure 16. Those with open tops and bottoms facilitate ventilation. Stalls with solid walls and closed fronts can be difficult to ventilate adequately. 
Figure 14: Alternative box stall layouts
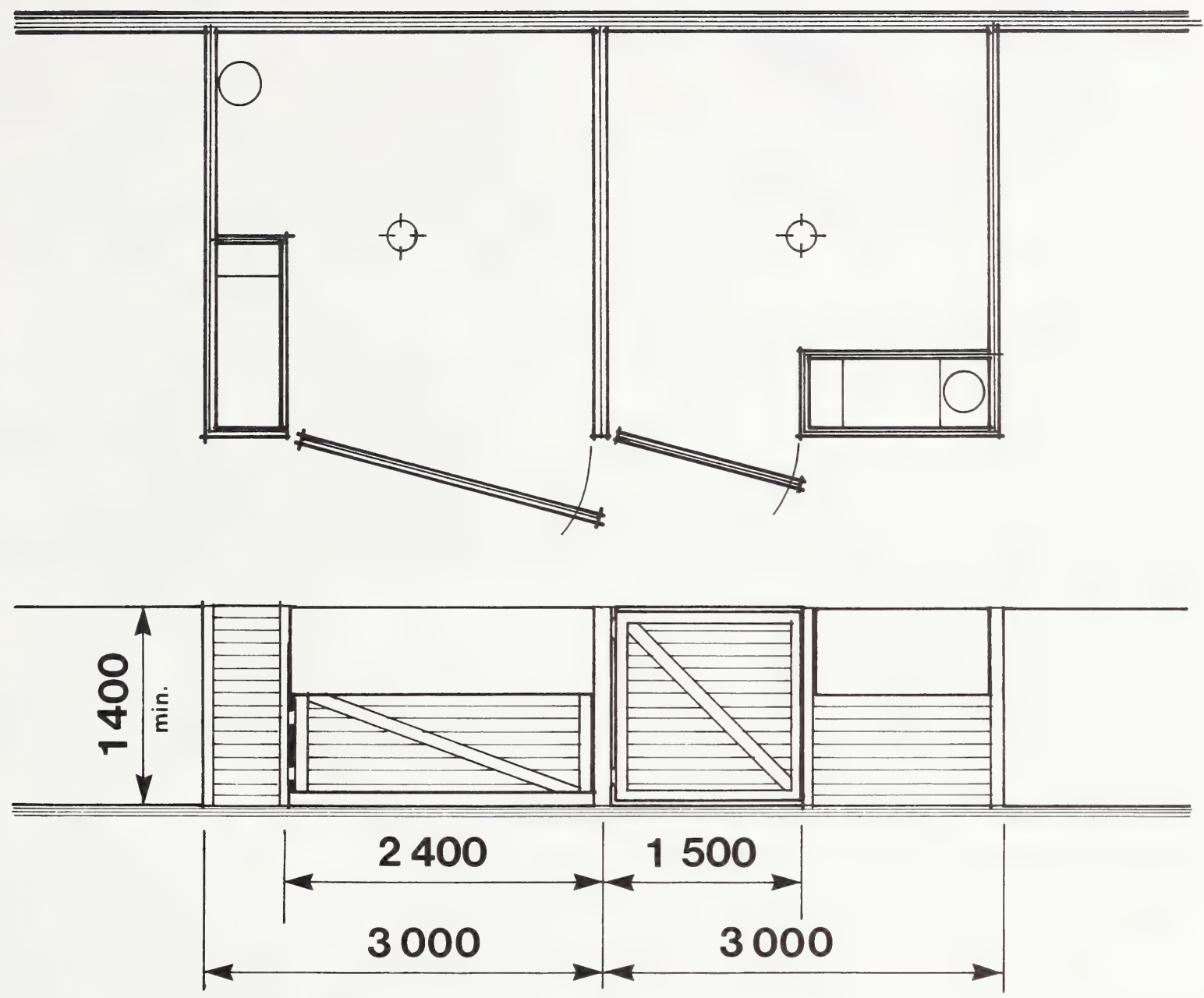

Feeding can be accomplished without entering the stall or opening the gate. Absence of a grill simplifies feeding and watering. 
Figure 15: Box stall construction alternatives

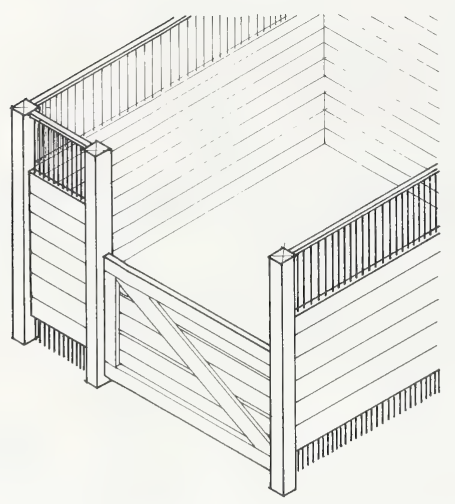

Figure 15a:Plank and grate partition

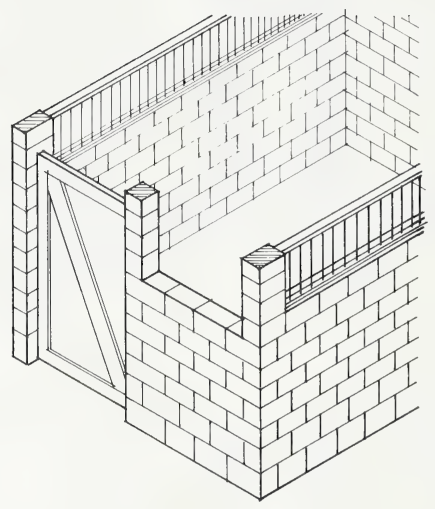

Figure 15b:Masonry partition

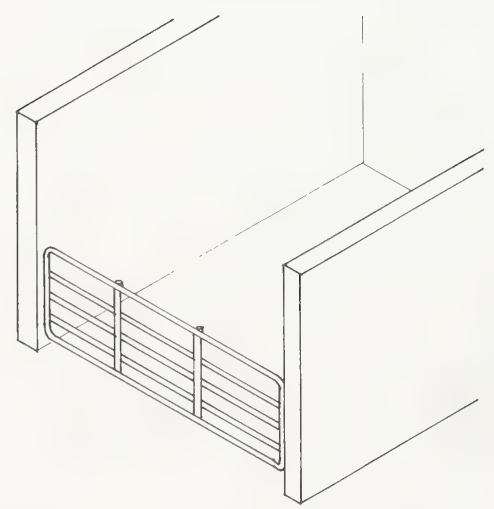

Figure 15c: Solid wall partition 

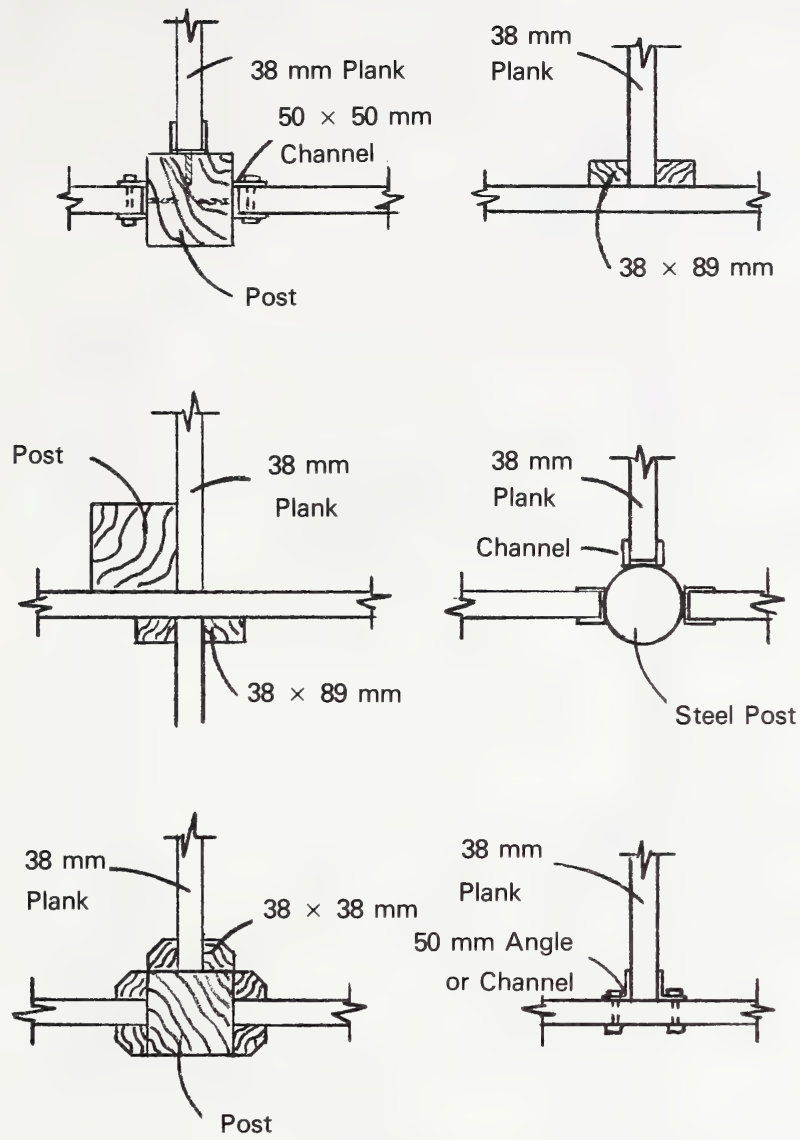

Figure 16: End anchors for stall partitions and walls

\section{TIE STALLS}

Tie stalls are suitable when horses are only brought in twice a day for grain feeding and occasionally for overnight. They are ideal for horses which are kept in paddocks or worked during the day. They take less space than box stalls, use less bedding, and are easier to clean. Horses which are restless can learn to stand still and relax in tie stalls. They can also become used to having people moving about them. Pillar reins can be used to cross tie horses facing out. This will prevent them from drinking or eating just before being worked.

Mangers, grain boxes and, occasionally, waterers are built into tie stalls. Feed alleys may be run in front of the stalls to supply service, but feeding can also be done from the alley behind the horses. Partitions at the front of the stalls should be high enough ( $2 \mathrm{~m}$ minimum) to prevent animals from fighting. Rear partition posts should either run from floor to ceiling, or they should be cut flush with the top of the partition. A horse turning out of a stall can injure his face on a projecting post. Details of construction are shown in Figures 17 and 18 respectively. 
Floor Plan
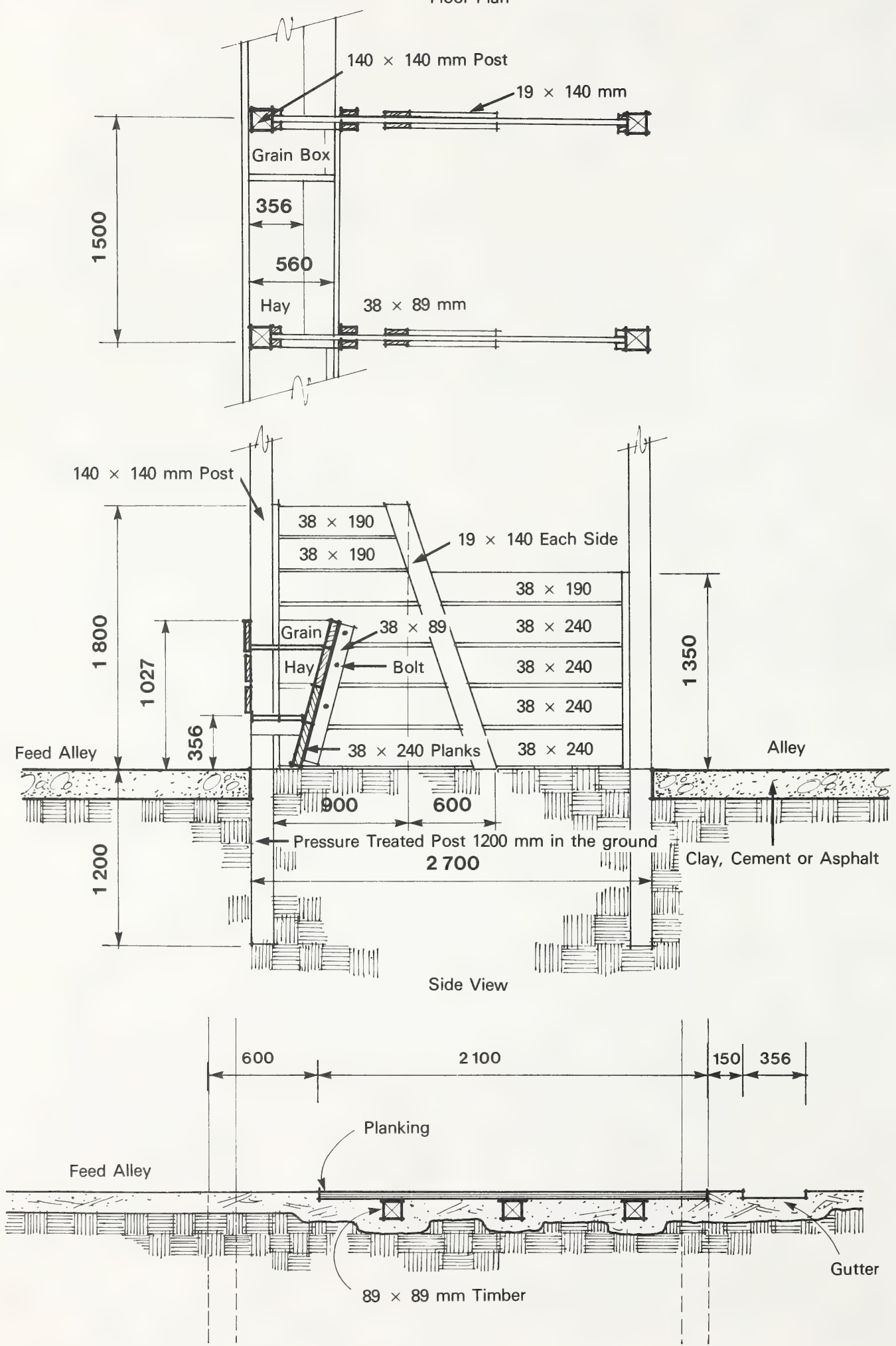

Figure 17: Tie stall construction 


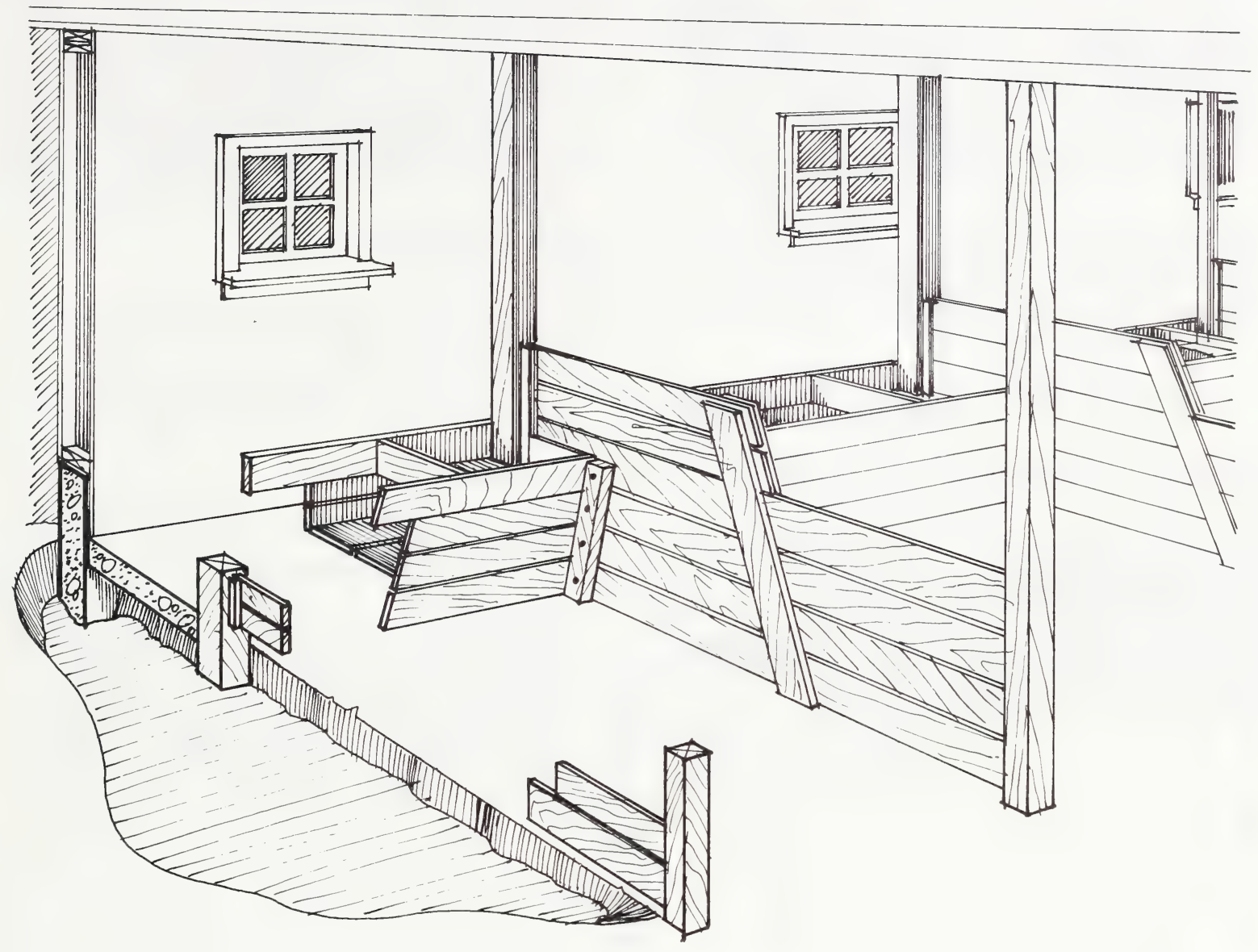

Figure 18: Tie stall arrangement 


\section{LIGHTING}

Good lighting prevents accidents, speeds chores and aids livestock inspection.

The cost of lighting includes the cost of electric power, lights and lighting equipment, and the labor involved in the installation and maintenance of the system.

Lighting can be provided by different systems. Incandescent lights are the most common. Fluorescent lighting gives good light intensity and is energy efficient, but is not suitable for very humid conditions. Mercury-vapor lights range in power from 125 to 1000 watts, with an expected life of 20,000 hours. High pressure sodium lighting has a high initial cost, but very low operating costs. Variable intensity control is possible.

The distance between incandescent lamps should be no more than 1.5 times their height above the floor. Fluorescent fixtures in 1200, 1800 or $2400 \mathrm{~mm}$ lengths can be run in continuous rows with each row hooked to an outlet box. This is often the most economical system.

Walls should be flat white or at least of a flat texture in a light color. This increases reflection and prevents dark corners.

Vapor proof fixtures should be used. They are usually also dust proof which helps reduce the fire hazard.

Lights can be run in rows down the edges of alleys thereby illuminating both stalls and alley. In completely enclosed stalls it will be necessary to hang a light in each stall.

Lighting in the stable should be a minimum of 4320 lumen $/ \mathrm{m}^{2}$. Lighting requirements, as stated in the Canadian Farm Building Code, 1977, are as follows:

\section{HORSE STABLES (TIE STALLS)}

\section{Lighting Outlets}

- One outlet should be provided at the rear of every other tie stall on the centre line of the alley.

- One outlet should be provided for every $4800 \mathrm{~mm}$ on the centre line of the feed alley.

- One outlet should be provided for each room and box stall.

\section{Convenience Outlets}

- One outlet should be provided at the rear of every other tie stall.

- In barns having a centre litter alley, one outlet will serve two to four stalls depending upon the structure.

- Two outlets should be provided for each tack room and feed room.

\section{HORSE STABLES (BOX STALLS)}

\section{Lighting Outlets}

- One outlet should be provided every $4800 \mathrm{~mm}$ on the centre line of feed alleys.

- One outlet should be provided for each box stall.

- One outlet should be provided for each tack room and feed room.

\section{Convenience Outlets}

- Outlets should be provided in the feed alley so that one serves every four stalls.

- One outlet should be provided for each tack room and feed room.

- Adequate controls on lights are needed. It should be possible to light up a foaling stall or tack room without setting the whole stable ablaze. It is best to control the lights across the barn, not down the length of the barn. That is, light up one end, then the middle, and then the other end, as opposed to one side of stalls, the alley, and the other side of stalls. 


\section{WATERING SYSTEMS}

Many horse barns are equipped with manually filled plastic water buckets in each stall. Labor can be reduced with individual automatic waterers such as depicted in Figure 19. An automatic waterer such as this should have a valve for cutting the waterers off as well as a means of keeping the water from freèzing. Electrically heated waterers must be properly grounded to prevent electric shock from harming the operator or animal.

Large automatic, electrically heated waterers (Figure 20) can be used for corral or paddock facilities. These waterers can be placed on a fenceline to serve two pens. They should be located on a well drained site surrounded by a concrete apron 1.8 to $3 \mathrm{~m}$ wide to provide a dry area around the waterer and a solid base for the waterer itself.

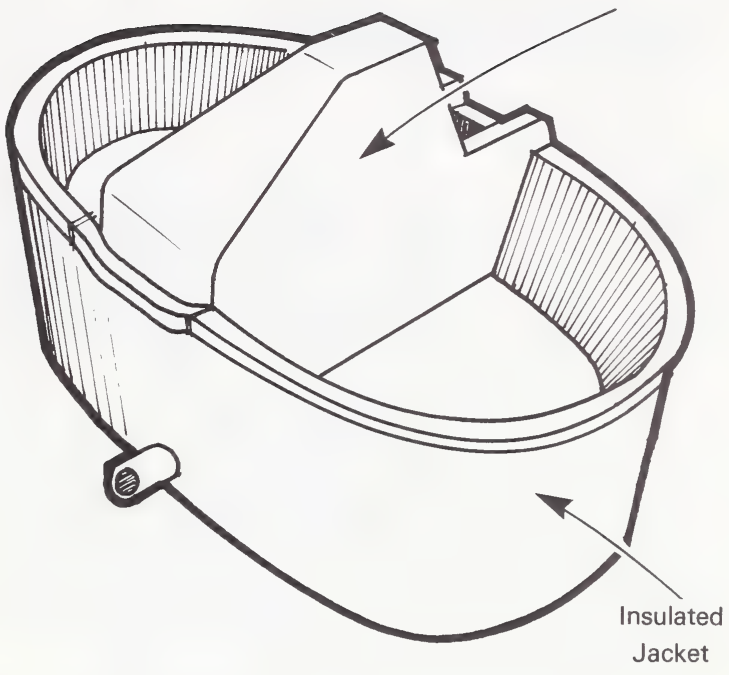

Figure 19: Two bowl waterer

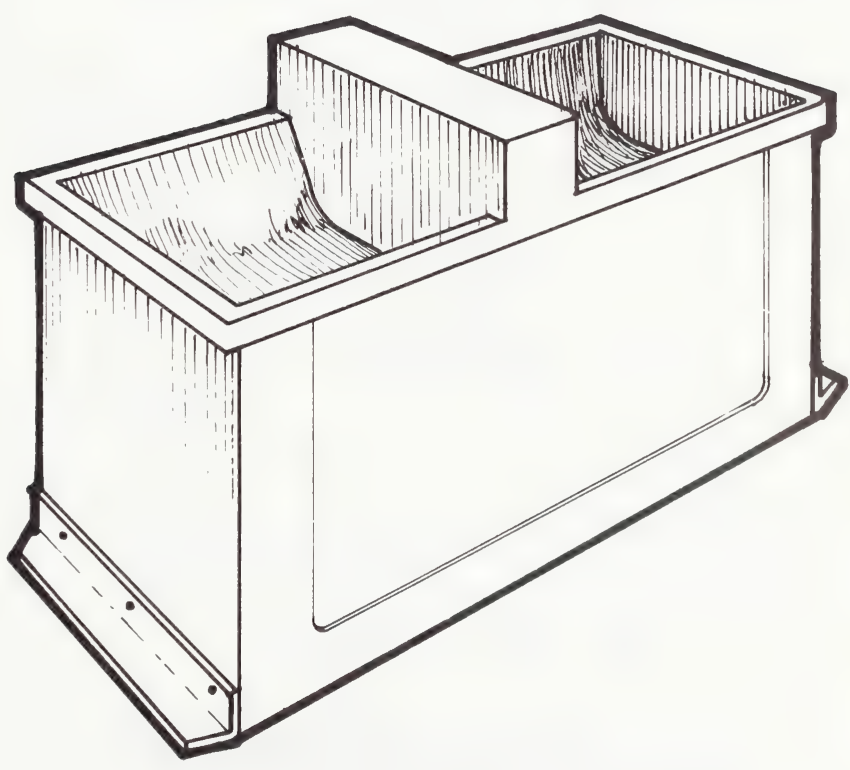

Figure 20: Automatic waterer 


\section{HEATING AND VENTILATION}

Ventilation is one of the most neglected, yet one of the most important aspects of stabling. Moisture and foul air contribute to poor animal health. Condensation from lack of ventilation can cause rapid deterioration of the building structure. Proper planning and construction can produce comfortable, healthy structures where the environment can be controlled.

As outside air is brought in and heated, its ability to carry moisture is increased. The colder the air is to start with, or the more the air is heated, the greater its moisture holding capacity. The amount of air required to remove the moisture produced determines the ventilation rate. The rates given in Table 2 were calculated on the assumption that a horse produced 527 to 703 watts ( 1800 to $2400 \mathrm{BTU}$ ) of heat per hour, and 4500 to 5000 grams of moisture at $-30^{\circ} \mathrm{C}$.

In winter, ventilation is a critical factor. Enough air must pass through the structure to keep it dry, yet it must be kept to a minimum to prevent heat loss. More air movement is required in spring and fall when the temperature differential is less. In summertime, as much air movement as possible is desired to keep the inside as cool as possible.

\section{NATURAL VENTILATION}

Natural ventilation is the ventilation of a livestock building without the aid of fans. It utilizes convection currents. Convection systems only work if there is a difference between the inside barn temperature and the outside temperature. Ventilation outlets should be at or near the highest point of the building. The air inlets should be placed as low on the wall as possible without causing drafts in the stalls. For ease of construction and adjustment, the inlets are usually located near the top of the walls, or under the eaves and over the top plate.

A long narrow slot inlet with an adjustable baffle is the most satisfactory. This slot should be about 25 to $100 \mathrm{~mm}$ and should be continuous down both eaves of the bar. A $150 \mathrm{~mm}$ wide opening will be required to cool the barn in the summer. A maximum opening of $75 \mathrm{~mm}$ will be adequate for most other conditions.

Types of ventilation outlets are the continuous ridge opening type (Figure 21) or the cupola. The continuous ridge opening type is usually $100 \mathrm{~mm}$ wide and runs the full length of the barn (except for $2.4 \mathrm{~m}$ on either end). One or two cupolas of a comparable size can be used instead (Figure 22).

Table 2 - Ventilation requirements for Horse Barns.

\begin{tabular}{|lccr|}
\hline & Winter & Spring \& Fall & Summer \\
\hline $\begin{array}{l}\text { Ventilation Rate } \\
\text { Required per } 454 \mathrm{~kg} \\
(1000 \mathrm{lb}) \text { of horse }\end{array}$ & $12 \mathrm{~L} / \mathrm{sec}$ & $75 \mathrm{~L} / \mathrm{sec}$ & $125 \mathrm{~L} / \mathrm{sec}$ \\
\hline
\end{tabular}

Ventilation systems can be natural or use forced air. Forced air is easier to control but will incur the expense of purchasing, maintaining and operating fans. Natural ventilation needs to be watched more closely, and vent openings need to be changed frequently to maintain the desired inside conditions.

Cold housing provides shelter from the environment but does not provide supplemental heat. This is an acceptable method of housing animals, if adequate ventilation is provided.

Animals will need more feed to maintain body heat.

Warm housing requires an insulated building and a heating system. Effectively insulated buildings require less added heat, and are, therefore, less expensive to maintain. With the high humidity prevalent in livestock buildings, a vapor barrier becomes a critical part of an insulation system. A vapor barrier is placed on the warm side of the wall to prevent moisture from infiltrating into the insulation and building materials. This protects against loss of insulating value, rotting and structure failure. 


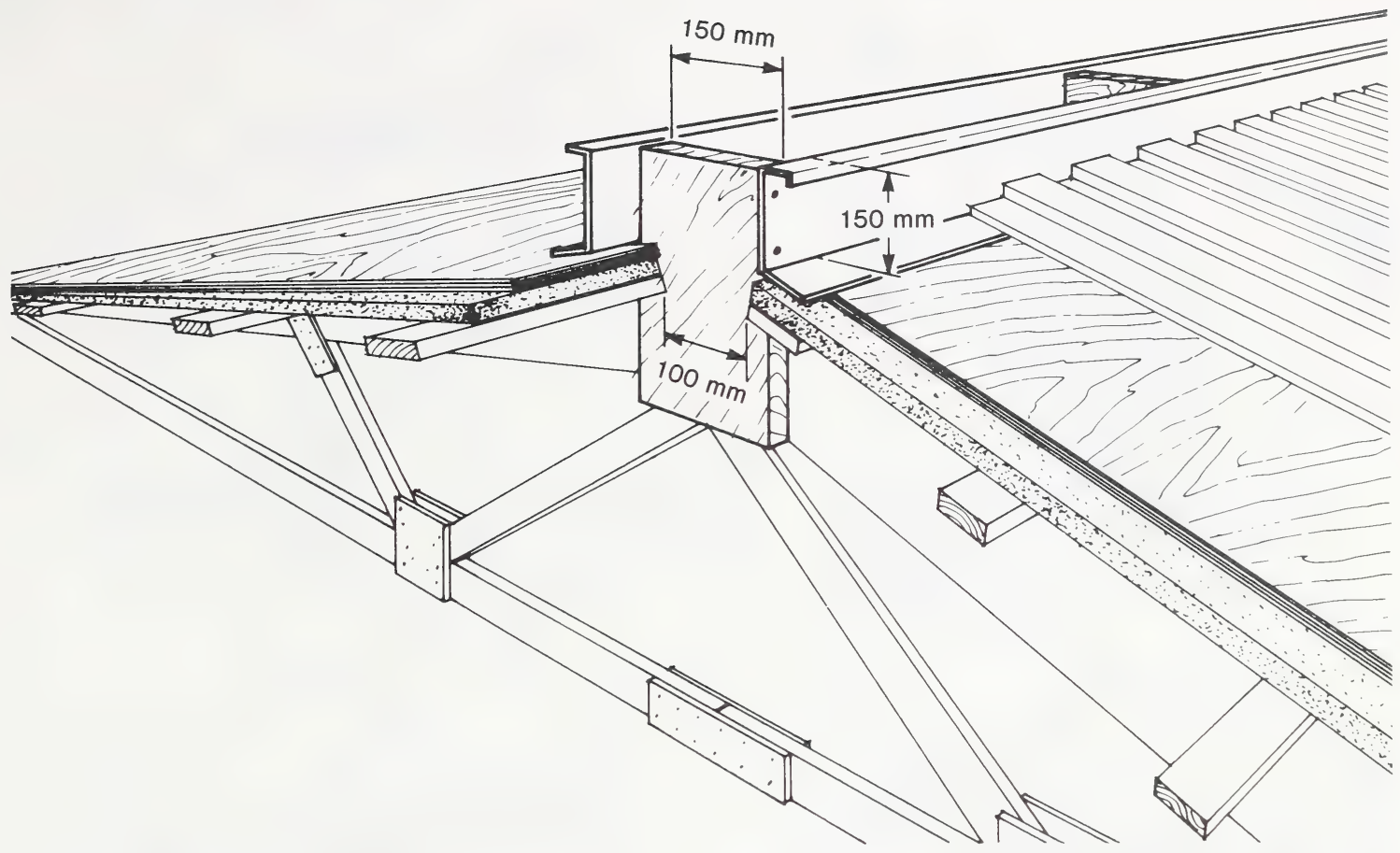

Figure 21: Continuous ridge ventilation opening
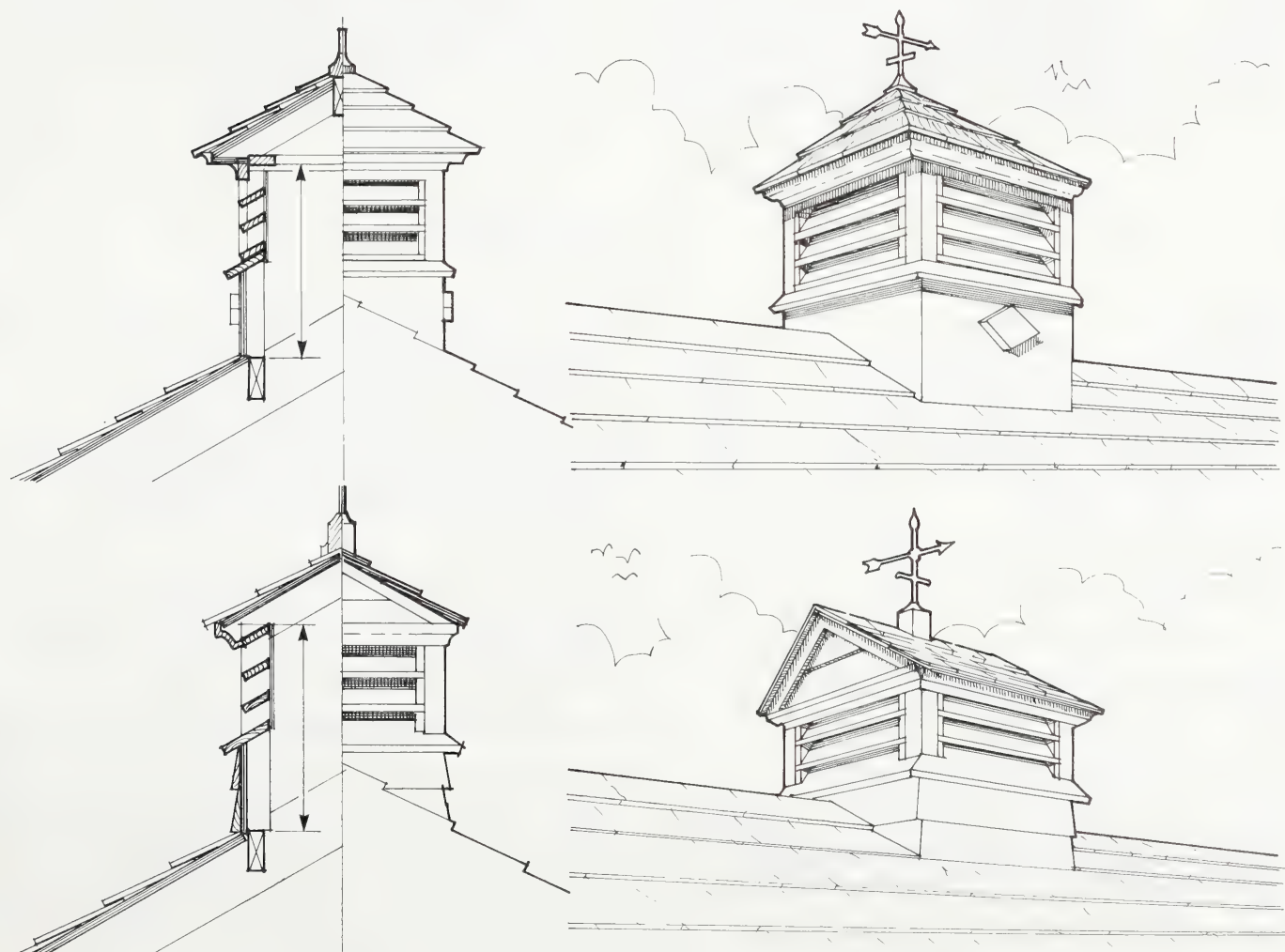

Figure 22: Ventilation cupolas 

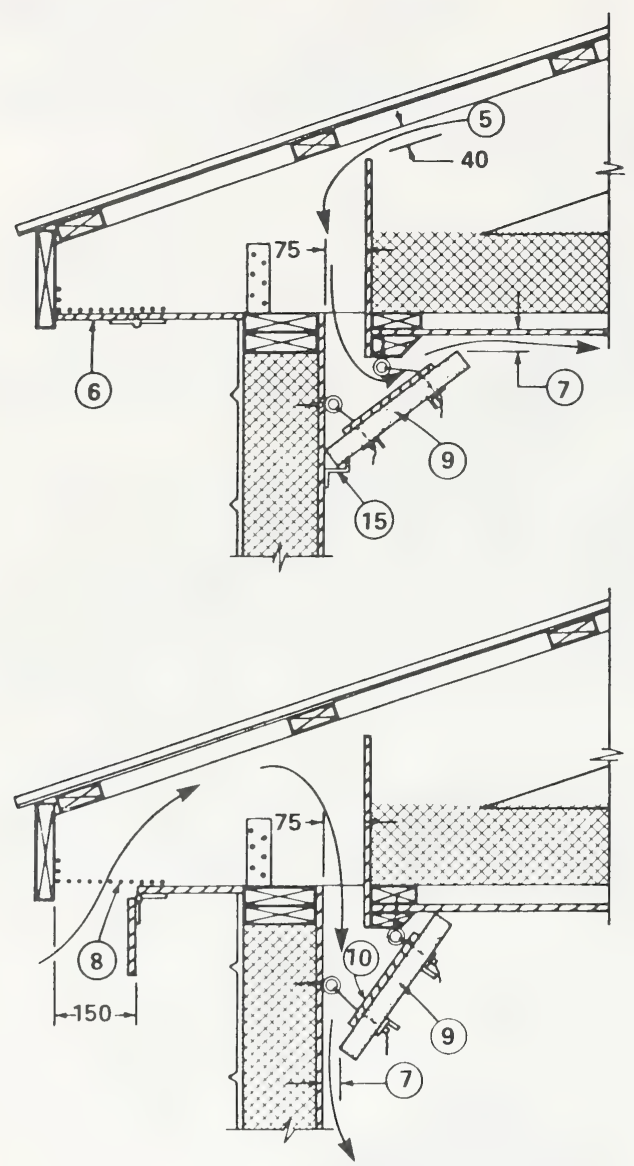

(3)

\section{STUD WALL SECTION}

1. NORMAL SETTING

2. EMERGENCY HOT WEATHER SETTING

3. STUD FRAME WALL INLET

4. POLE FRAME WALL INLET

5. WINTER VENTILATION FROM ATTIC

6. HINGED SOFFIT CLOSED FOR WINTER

7. SLOT ADJUSTABLE $0-50 \mathrm{~mm}$

8. SCREENED SOFFIT INLET OPEN FOR SPRING , SUMMER AND FALL

9. $38 \times 300$ (or $400 \mathrm{~mm}$ ) EXTRUDED HIGH-DENSITY POLYSTYRENE BOARD CONTINUOUS

10. $6 \times 75 \mathrm{~mm}$ PLYWOOD STRIPS @ ENDJOINTS OF (9). BOLT THRU (9)TO (11).
(1)

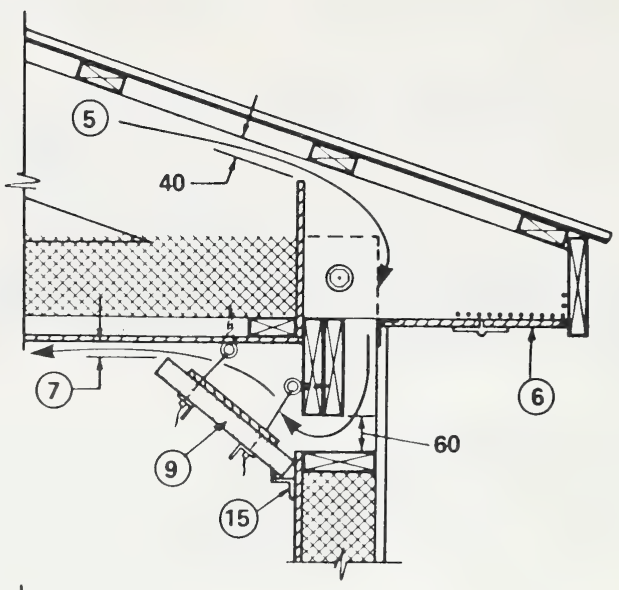

(2)

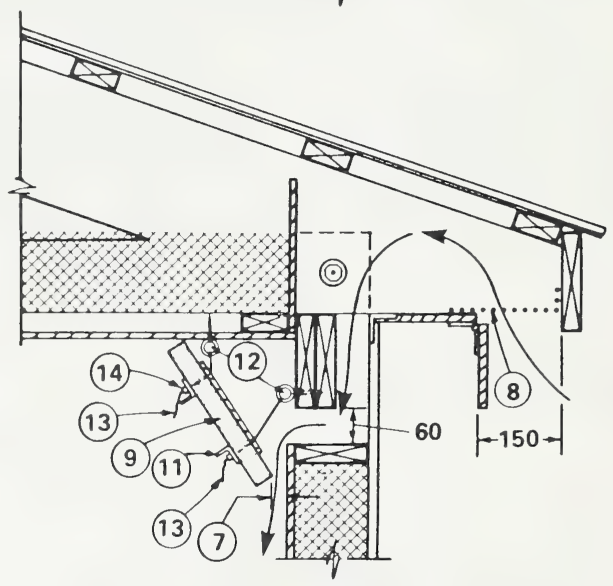

(4)

11. GALV. SHEET STEEL ANGLE STIFFENER, $0.4 \times 25 \times 25$ $X 2400 \mathrm{~mm}$ LENGTHS, PRE-DRILL FOR BOLTS \& CORD (13) AT CENTER \& $25 \mathrm{~mm}$ FROM ENDS

12. $5 \mathrm{~mm}$ VINYL-COVERED STEEL MARINE CONTROL CABLE RUNS THRU SCREW EYES TO WINCH CONTROL AT ONE END AND RETURN SPRING AT OTHER END

13. HEAVY $(2 \mathrm{~mm})$ NYLON CORD,CLAMPED TO CONTROL CABLE WITH ELECTRICAL MARR CONNECTOR THRU SCREW EYE AT (12), THRU HOLE IN (9). (10) AND (11). ADJUST WITH ANOTHER MARR CONNECTOR

14. MARR ELECTRICAL CONNECTOR TO ADJUST CORD 13

15. FOR FARROWING AND WEANLING, ADD GALV. STEEL Z-STRIP TO HINGE AND SUPPORT (9), OMIT LOWER CONTROL 

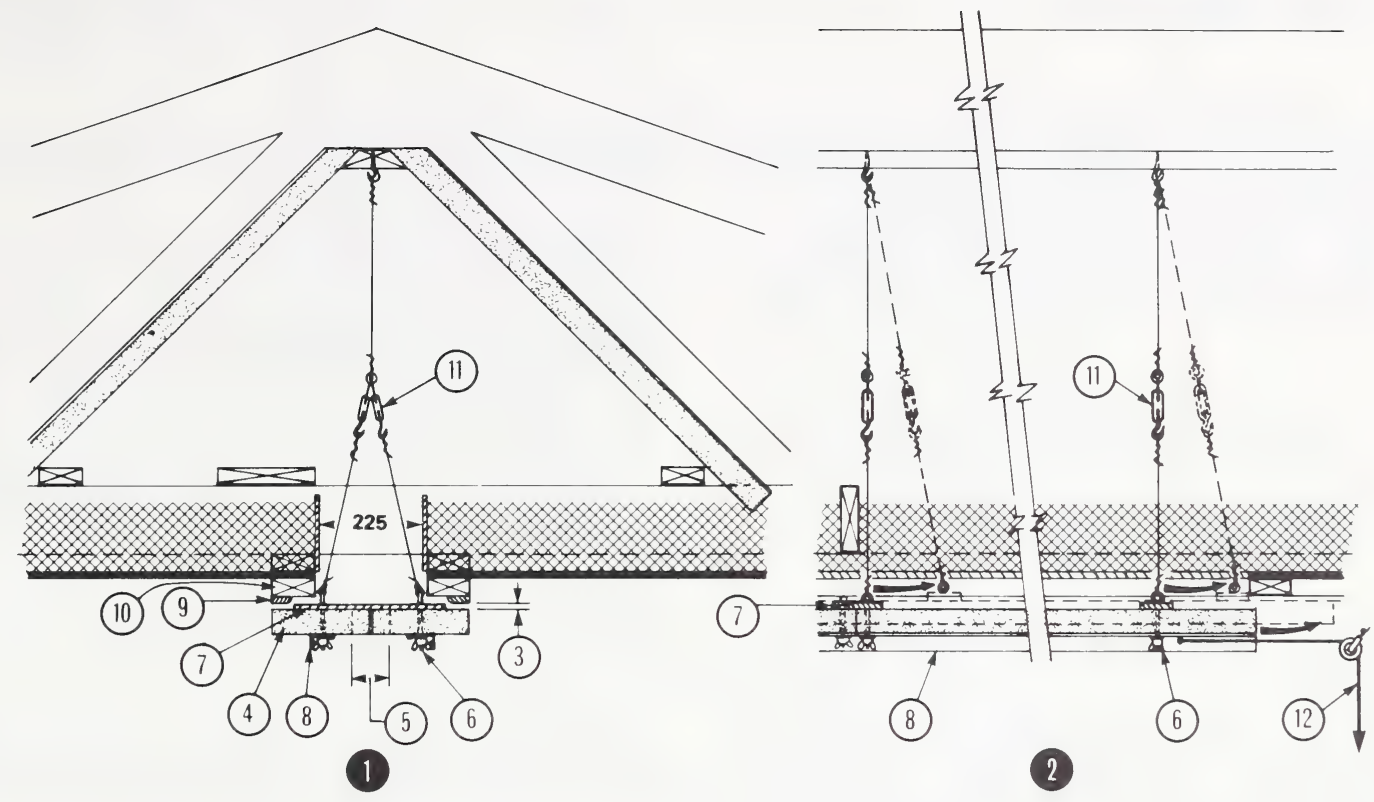

1. CROSS SECTION THRU INSULATED ATTIC DUCT \& CEILING

2. LONGITUDINAL SECTION AT CONTROL END OF INLET

3. CEILING SLOT, ADJUSTABLE $0.50 \mathrm{~mm}$

4. $38 \times 200 \times 2400 \mathrm{~mm}$ SLABS OF HIGH-DENSITY EXTRUDED POLYSTYRENE BOARD

5. OPTIONAL SLOT $0.50 \mathrm{~mm}$ WIDE FOR VENTILATION TO FLOOR DURING HOT DAYS:

6. PLATED EYEBOLTS $1200 \mathrm{~mm} \propto c$, WASHERS, WING NUTS, GALV SUSPENSION WIRE
7. PLYWOOD STRIPS $9 \times 75 \times 267 \mathrm{~mm} @ 1200 \mathrm{~mm}$ OC, PRE.DRILLED FOR (6)

8. $0.4 \times 25 \times 25 \mathrm{~mm}$ GALV. STEEL ANGLES $1200 \mathrm{~mm}$ LONG FOR STIFFENNG, PRE-DRILLED FOR (6) AND (7) AT CENTER AND $25 \mathrm{~mm}$ FROM ENDS

9. SHOE MOULD, ALL AROUND

10. DOUBLE $38 \times 89 \times 4800 \mathrm{~mm}$ JOINS STAGGERED $2400 \mathrm{~mm}$ OC

11. FURNACE CHAIN OR $2 \mathrm{~mm}$ WIRE, ADJUST TURNBUCKLES FOR EQUAL SLOTS 3 ALL AROUND

12. PULLEY AND CONTROL ROPE TO BOAT WINCHCONTROL

Figure 24: Adjustable centre ceiling air inlet
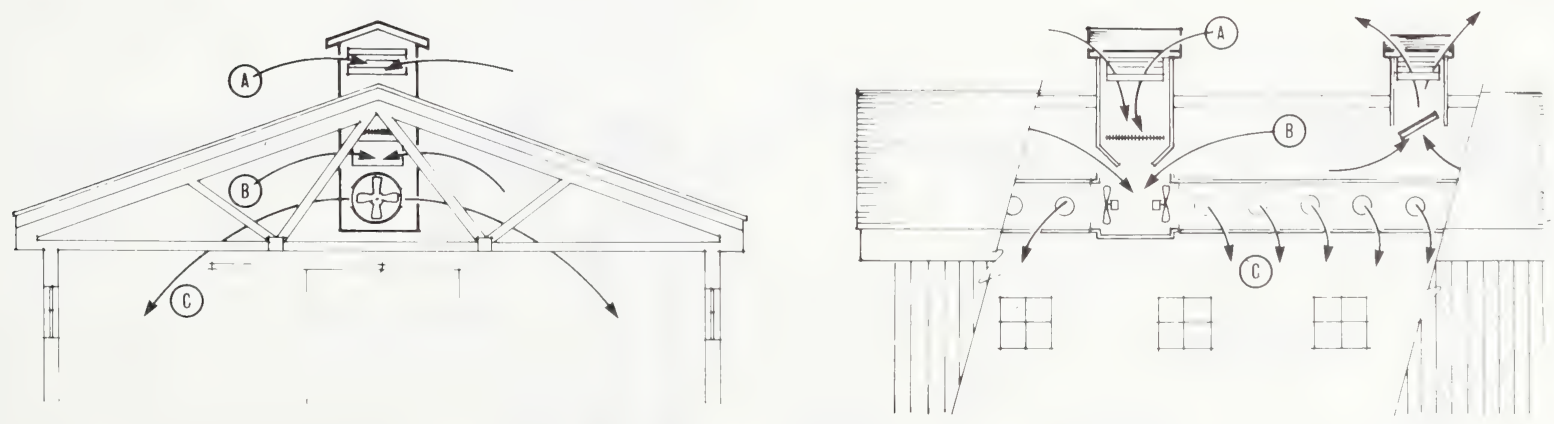

Figure 25: Positive pressure ventilation system

Fresh air is drawn through the fresh air intake cupola, (A) and forced into ductwork by fans. As outside temperatures drop, causing stable temperatures to drop also, the automatic or manually controlled baffle doors, (B) open, allowing for the recirculation of stable air. The amount they are opened is directly related to outside temperature. When fully opened, fresh air is still allowed to enter. That is, the doors do not completely seal the inlet duct. The outlet baffle, (C) is made of a light material, (e.g. $25 \mathrm{~mm}$ polystyrene board) and is equipped with an offset hinge. Air pressure forces the door open, allowing exhaust air to escape. Supplemental heat can be added by a hot water radiator placed in the duct as shown, (D) or by a forced air duct blowing air into the ventilation duct above the recirculation baffles. 
Fans should be selected for their certified rating, based on 3 $\mathrm{mm}$ static pressure. They should have enclosed motors to protect them from dust and moisture, and sealed bearings to assure proper lubrication. Overload protection is necessary to prevent motor burn-out. Automatic shutters and wire mesh guards should also be installed to prevent drafts and to keep birds out.

Fans should be located away from prevailing winds. They should be placed in a tight wall away from loose fitting doors and windows. Air flow in a building is controlled mostly by inlet placement. Fan location has very little influence on air flow patterns.

\section{INLETS AND OUTLETS}

Inlets should be designed to prevent drafts. Long, narrow inlets promote air mixing in open truss sytems. In a forced air system, $900 \mathrm{~cm}^{2}$ of inlet should be allowed for each 1260 $\mathrm{m}^{3} / \mathrm{h}$ of fan capacity. Inlets should be installed where they will draw fresh air and be located well away from manure storage areas. In winter, tempered air can be drawn from the attic. In the summer, air should be drawn directly from outside. Careful placement of inlets and outlets is required since they are the major factors in controlling air mixing.

A negative pressure ventilation system (exhaust fans creating a vacuum inside the barn, causing air to be drawn into the barn) is practical in a stable. Inlets can then be placed in every stall to ensure good ventilation. Stall partitions can cause ventilation dead spots if this is not done. Inlets in unused stalls can be closed, and others opened wider, to promote ventilation where needed.

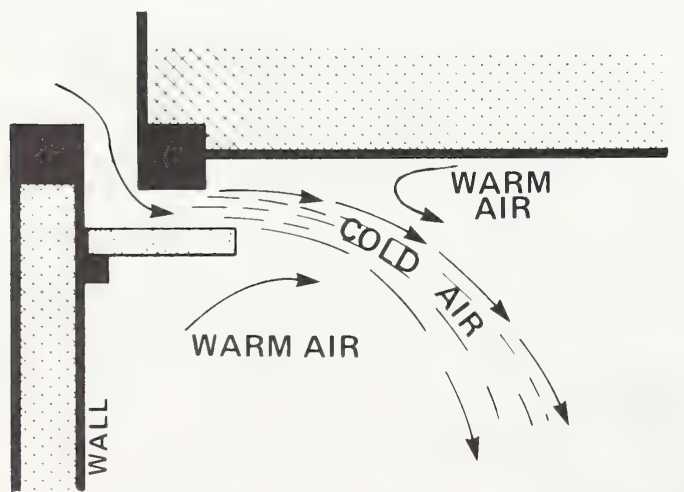

A. WITH INLET OPEN TOO WIDE, LAZY STREAM OF COLD AIR SINKS TO FLOOR CAUSING COLD DRAFT

Figure 26: How the size of an inlet slot affects the jet of cold air
Figures 23 and 24 show how to install negative pressure inlets either on the walls or in the centre of the ceiling.

A positive pressure ventilation system (fans forcing fresh air into the barn) can also be used. Forced inlet systems require some duct work to ensure good air mixing although in a small barn a square baffle below the fan will adequately distribute the air. Heat distribution can be optimized in a heated building with the use of forced air systems for ventilation. The main disadvantage of a positive pressure system occurs with an inadequate vapor barrier. This could result in moisture being forced into the walls and insulation by the positive pressure system.

Figure 25 shows a workable positive pressure ventilation system using a plastic tube for air distribution.

Both negative and positive systems can work, but many attempts to combine them in a single structure have proven unsatisfactory. A great deal of care must be taken to make sure that one system does not fight against the other.

To prevent drafts, incoming air should be directed across the ceiling by a baffle system. If inlets are placed high on a wall and are correctly adjusted, air mixing potential is optimized (Figure 26). The various ventilation alternatives are summarized in Figure 27 which shows the various options of air inlet and outlet locations.

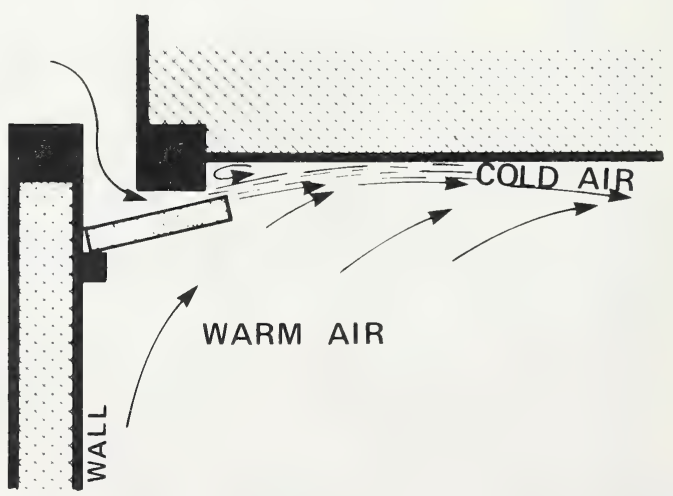

B. WITH INLET

ADJUSTED CORRECTLY, HIGH.VELOCITY COLD AIR SWEEPS THE CEILING AND MIXES WITH WARM AIR 
Figure 27: Ventilation alternatives

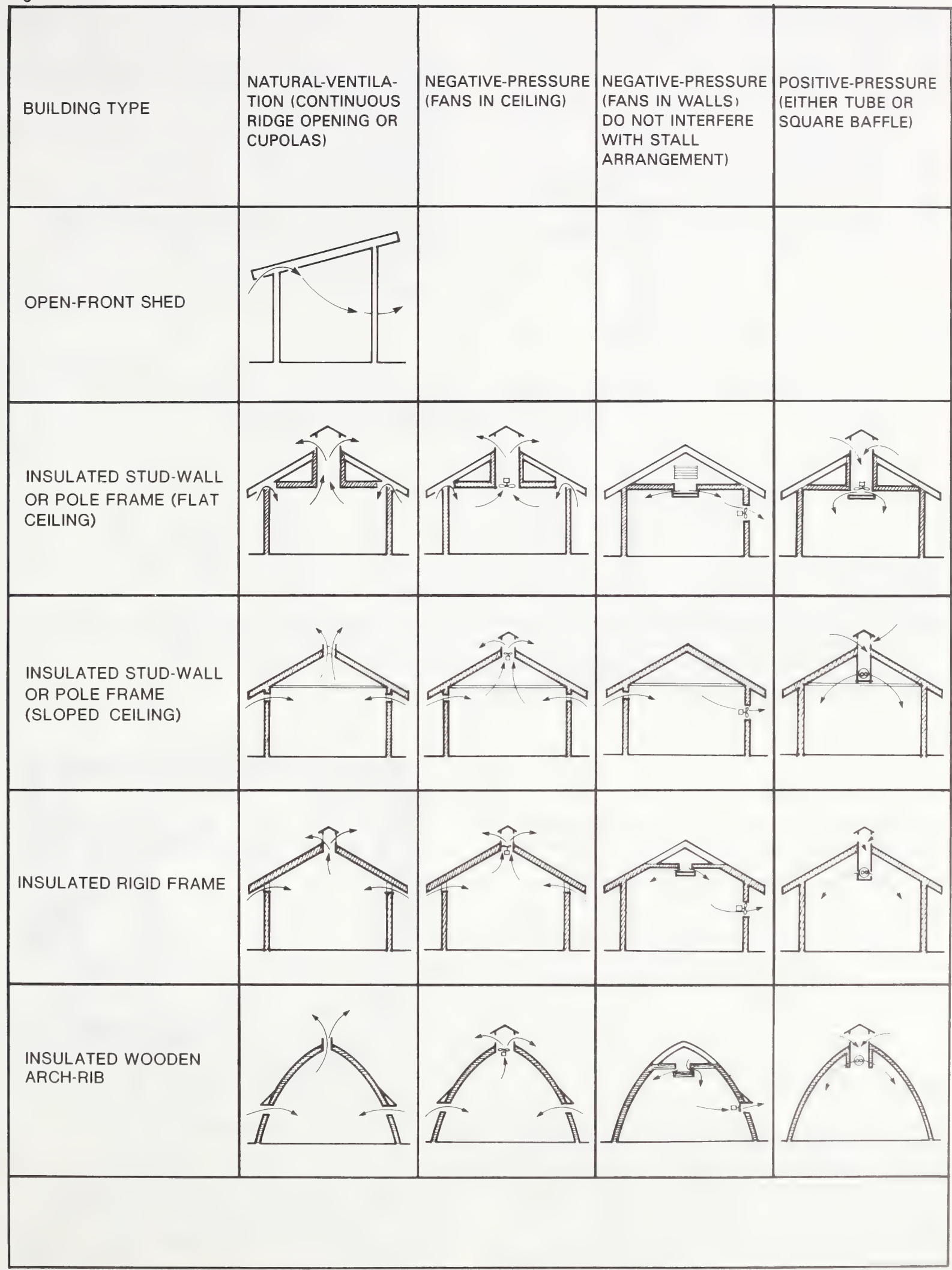




\section{HEATED FACILITIES}

Before any livestock facility is heated, it must be insulated and sealed against air leaks. The degree to which added heat is needed must also be decided. In general, a cold barn which is dry and well ventilated is healthier than a humid warm barn. The higher the desired temperature, the higher the cost of running the facility. Sale and show barns are often heated to discourage winter coat growth or to encourage shedding of hair. The operator's comfort is usually the deciding factor in normal stabling. The only advantage of keeping the temperature above freezing is that it simplifies watering systems.
Heating rates in Table 3 were taken from a barn that housed horses in box stalls. The building was of average construction with R20 insulation in the roof and R18 in the walls.

Allowance was made for $0.5 \mathrm{~m}^{2}$ of window per horse. These figures can be treated as a general guideline but actual heat requirements may vary depending on the type and construction of the facility.

Three common types of heating systems can be used for heating horse facilities: hot water boilers, forced air furnaces, and electric radiant heaters.

Table 3 - Heating requirements for horses.

\begin{tabular}{|crrrrrrrrrr|}
\hline $\begin{array}{c}\text { Inside Barn } \\
\text { Temperature }\end{array}$ & \multicolumn{7}{c|}{$\begin{array}{c}\text { Supplemental Heat Required at Various Outside Design Conditions } \\
\text { Given in watts per }\end{array}$} \\
\hline${ }^{\circ} \mathrm{C}$ & -40 & -35 & -30 & -25 & -20 & -15 & -10 & -5 & 0 \\
\hline-7 & 880 & 675 & 440 & 205 & 0 & 0 & 0 & 0 & 0 \\
\hline 2 & 1465 & 1201 & 880 & 733 & 586 & 293 & 117 & 0 & 0 \\
\hline 4 & 1524 & 1289 & 1025 & 820 & 645 & 380 & 234 & 117 & 0 \\
\hline 7 & 1553 & 1318 & 1055 & 880 & 703 & 440 & 264 & 146 & 0 \\
\hline 10 & 1699 & 1465 & 1230 & 996 & 791 & 557 & 322 & 234 & 0 \\
\hline
\end{tabular}

NOTE: Heating rates given are taken from a barn that houses horses in box stalls. It is of average construction with RSI 3.5 insulation in the roof and walls. There is allowance made for $0.5 \mathrm{~m}^{2}$ of window per horse. Depending on the type and construction of the facility, heat required may be either higher or lower than the guideline given.

NOTE: Appendix 2 contains the same information in Imperial units.

\section{HOT WATER HEATING}

Hot water heating is very efficient as well as clean and dry (Figure 28). Pipes for hot water heating require less space than forced air ductwork and once the system is installed, requires little maintenance. This type of heating does not interfere with a ventilation system because there is no forced air movement and no drafts. In a pressure ventilation system, careful placement of radiators minimizes piping. Even heat distribution is ensured if an element is placed where ventilating air enters the system. The main disadvantage to hot water heating is the high initial cost.

\section{FORCED AIR HEATING}

A forced air furnace heating system (Figure 29) has a lower initial cost but has several disadvantages. The least expensive installation uses an ordinary household furnace with normal aluminum heat exchangers. The furnace, like the hot water boiler, has to be placed in a separate room to prevent backdrafting of the flue gases. The furnace circulates the air from the interior of the barn the same way it does in a house. Problems arise from the fact that barn air carries a lot of dust

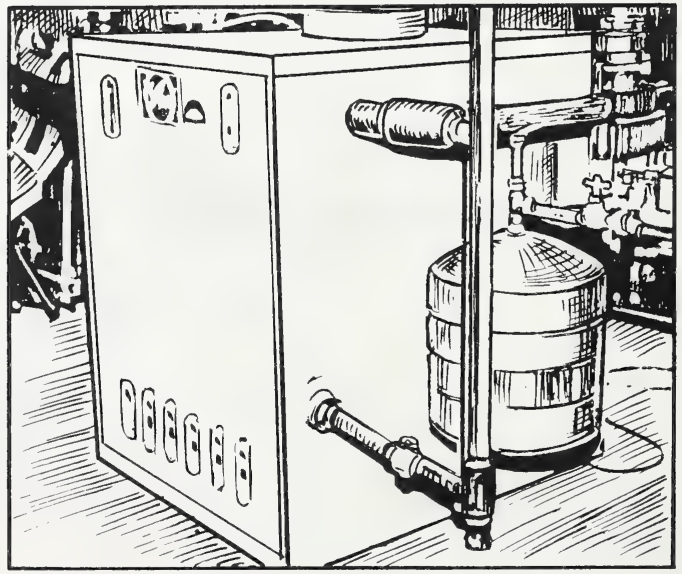

Figure 28: Hot water boiler

and moisture so a large filter is required. This filter must be cleaned daily to allow for proper operation. If the filter is removed, rapid corrosion of the heat exchanger may occur and a potential fire hazard will be created in the furnace by the build-up of dust. 
Some fresh air can be added via the required cold air duct from the outside, but this will not be enough to maintain oxygen supplies within the barn. A ventilation system must be added to provide fresh air and moisture control. The combination must be managed properly or excessive amounts of heat may be wasted. Cold air being brought in through the ventilation system must be kept to a minimum.

An alternative forced air heating unit is a more expensive make-up air unit with a stainless steel heat exchanger. This type of unit is capable of heating outside cold winter air to about $20^{\circ} \mathrm{C}$ which would be adequate to provide fresh air and enough heat to keep the barn above freezing. These furnaces can be equipped with modulating flame control and a continuously running fan. This way they will help provide a pressurized ventilation-heating system.

Another disadvantage of a forced air heating system is the large heat duct required to distribute the heat evenly throughout the barn. In a horse barn with stalls on both sides, the best location for the heat duct is down the middle of the barn which means it may interfere with head room.

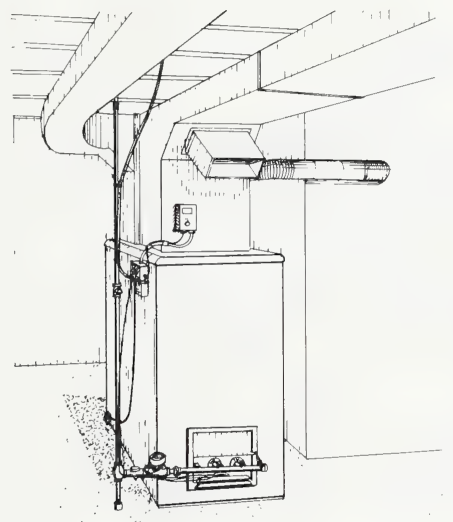

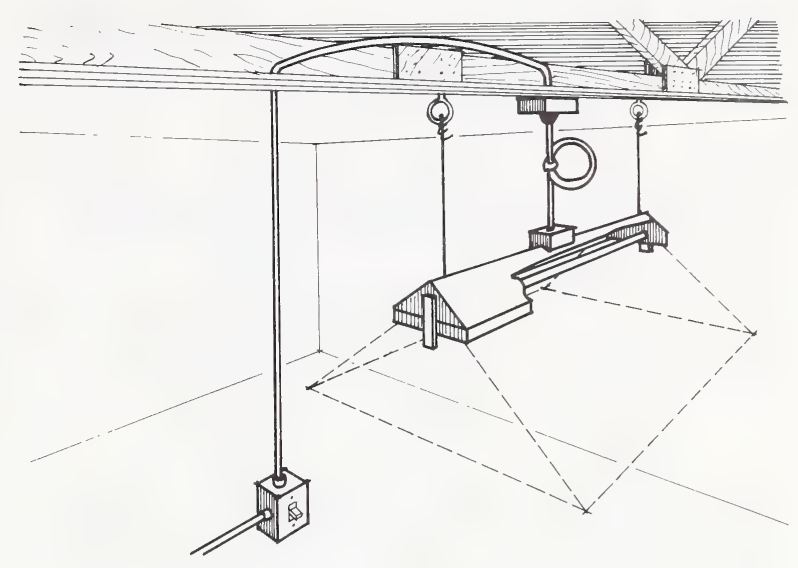

Figure 30: Infrared heat unit installation

\section{RADIANT HEATING}

Electric radiant heaters are expensive to operate but are well suited to areas where localized heat is required such as foaling stalls. Figure 30 shows an example of a 1750 watt infrared heating unit. Table 4 gives approximate sizes of heated areas for various suspension heights. Care must be taken to ensure that the horses cannot come in contact with the unit. A minimum distance of $600 \mathrm{~mm}$ must be maintained between the heater and any combustible material it may radiate onto.

Figure 29: Forced air heating system

Table 4 - Influence of a 1750 watt infrared heater.

\begin{tabular}{|c|c|c|c|}
\hline \multirow[t]{2}{*}{ Mounting Height } & \multirow[t]{2}{*}{ Area } & \multicolumn{2}{|c|}{ Temperature Rise } \\
\hline & & ${ }^{\circ} \mathrm{C}$ & ${ }^{\circ} \mathrm{F}$ \\
\hline $2.1 \mathrm{~m}(7 \mathrm{ft})$ & $2.4 \times 3.3 \mathrm{~m}(8 \times 11 \mathrm{ft})$ & 8 & (46) \\
\hline $1.8 \mathrm{~m}(6 \mathrm{ft})$ & $2.1 \times 3.0 \mathrm{~m}(7 \times 10 \mathrm{ft})$ & 14 & (57) \\
\hline $1.5 \mathrm{~m} \mathrm{(5 \textrm {ft } )}$ & $1.8 \times 2.4 \mathrm{~m}(6 \times 8 \mathrm{ft})$ & 19 & (66) \\
\hline $1.2 \mathrm{~m} \mathrm{(4ft)}$ & $1.5 \times 2.1 \mathrm{~m}(5 \times 7 \mathrm{ft})$ & 28 & (82) \\
\hline $0.9 \mathrm{~m}(3 \mathrm{ft})$ & $1.2 \times 1.8 \mathrm{~m}(4 \times 6 \mathrm{ft})$ & 44 & (110) \\
\hline
\end{tabular}




\section{MANURE HANDLING}

A mature horse will produce up to 9 tonnes of manure per year. The collection and disposal of this manure is a major problem for horse owners.

Labor can be saved if alleys, doors, and gates are wide enough for a truck or manure spreader to pass through. Manure can then be loaded directly onto the vehicle.

Storage areas must be situated where they will not contaminate water supplies. In rural areas, given a sufficient land base, manure can be spread on the land not being used as pasture. Manure can also be disposed of by burning, but this may not be allowed by local regulations, and is environmentally undesirable.
Composting using nitrogen pellets may be necessary in crowded areas where odors from spreading and burning may be ojectionable. One can use $46-0-0$ or $34-0-0$ fertilizer to supply nitrogen to aid the breakdown process. When manure is piled it breaks down, reducing the odor. This makes it more acceptable to the public when it is spread on the land.

Fresh manure and bedding requires $0.05 \mathrm{~m}^{3}$ of storage space per animal per day. Composting will reduce this to about 0.03 $\mathrm{m}^{3}$. Spreading is the most satisfactory solution. Horse manure is worth $\$ 5.95 /$ tonne at present day prices for its fertilizer value. Table 5 shows the chemical composition of horse manure.

Unless composted, horse manure should not be spread on horse pastures because it can contain large concentrations of internal parasite eggs.

Always check local regulations before proceeding with any method.

Table 5 - Composition (on a wet-weight basis) of fresh manure.

\begin{tabular}{|c|c|c|c|c|c|c|c|c|}
\hline \multirow[t]{2}{*}{ Components of Manure } & \multicolumn{2}{|c|}{ Proportions } & \multicolumn{2}{|c|}{$\begin{array}{l}\text { Nitrogen } \\
\text { (as N) }\end{array}$} & \multicolumn{2}{|c|}{$\begin{array}{c}\text { Phosphorous } \\
\text { (as } \mathrm{P}_{2} \mathrm{O}_{5} \text { ) }\end{array}$} & \multicolumn{2}{|c|}{$\begin{array}{c}\text { Potassium } \\
\text { (as } \mathrm{K}_{2} \mathrm{O} \text { ) }\end{array}$} \\
\hline & $\%$ & $\begin{array}{c}\mathrm{kg} / \mathrm{t} \\
\text { of manure }\end{array}$ & $\%$ & $\mathrm{~kg}$ & $\%$ & $\mathrm{~kg}$ & $\%$ & $\mathrm{~kg}$ \\
\hline Horse Feces & 60 & 600 & .055 & 2.99 & 0.30 & 1.36 & 0.40 & 2.18 \\
\hline Urine & 15 & 150 & 1.35 & 1.86 & \multicolumn{2}{|c|}{ trace } & 1.25 & 1.72 \\
\hline Bedding (straw) & 25 & 250 & 0.50 & 1.13 & 0.20 & 0.45 & 1.00 & 2.27 \\
\hline Total mixture 1 tonne & & & 0.66 & 5.99 & 0.23 & 2.09 & 0.68 & 6.17 \\
\hline
\end{tabular}

NOTE: Appendix 3 contains the same information in Imperial units of measurement. 


\section{FEED STORAGE AND HANDLING}

Hay is most efficiently stored in a shed built specifically for that purpose. While hay traditionally has been stored in the stable loft, there are several reasons for not doing so. It is usually cheaper to build a hay shed (Figure 31) than to build a two-storey building and strengthen it to support a loft full of hay. Hay can be machine stacked or unloaded in a shed, while loft storage uses hand labor. The fire risk is lower when feed is not stored in the stable. Air circulation in a shed helps prevent heating and the danger of spontaneous combustion. With the increasing cost of construction and labor, hay lofts are becoming obsolete.

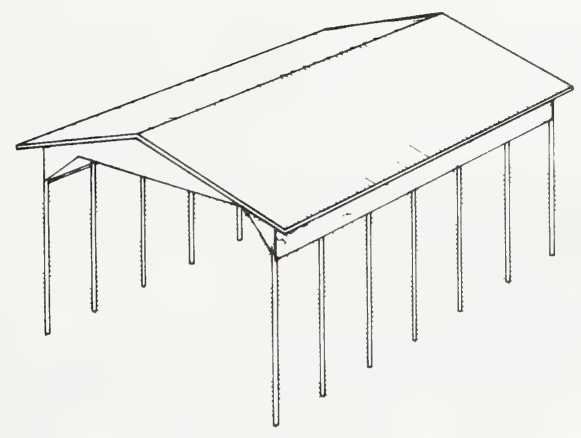

Figure 31: Hay storage CPS plan 7601

Hay can also be stored outside, preferably under a tarp.

Grain should be stored away from moisture in rodent-proof bins if possible, either outside the stable (Figure 32) or in grain storage bins incorporated into the barn. Figure 33 illustrates a hand dip storage bin that will hold a ton of grain.

One tonne of hay takes $7 \mathrm{~m}^{3}$ of space, and grains weigh up to $973 \mathrm{~kg} / \mathrm{m}^{3}$. Storage facilities should be planned accordingly.

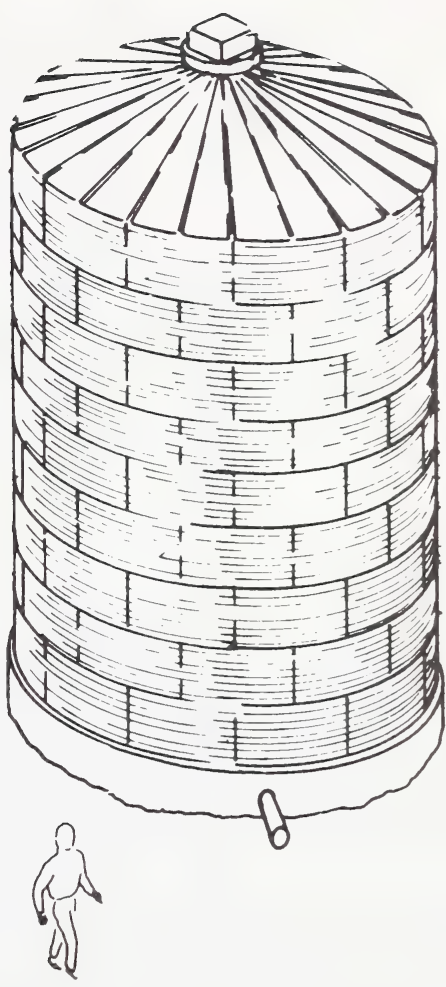

Figure 32: Commercial grain bin 


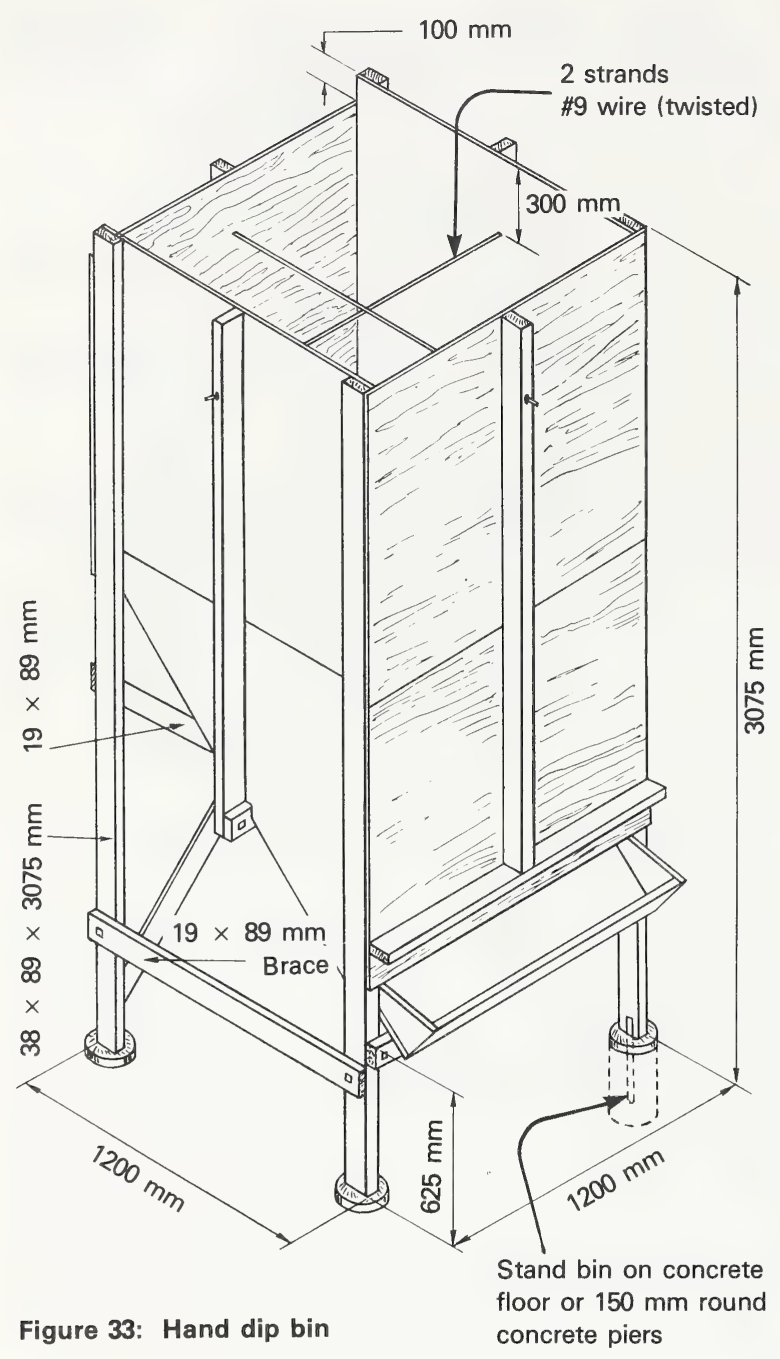

\section{HAY FEEDERS}

Pasture mangers should be sturdy and portable. Some types are available commercially, but most are built on the site.

One type is built with two $90 \times 90 \mathrm{~mm}$ skids running the length of the manger, a $28 \mathrm{~mm}$ lumber floor, and laminated 38 x $99 \mathrm{~mm}$ walls (Figure 34). The manger can be lined with tin to prevent horses from chewing and damaging it.

A practical hay feeder $1200 \times 1800 \mathrm{~mm}$ and $600 \mathrm{~mm}$ high can be built from two pieces of plywood and $2 \times 4$ framing, as in Figure 35 . To prevent horses from chewing the wood, the edges of the manger can be lined with drywall corners.
A very practical, long lasting manger can be made from a used tractor tire (Figure 36). The sidewall is cut out of one side and plywood bolted to the other. This type of manger is inexpensive and inedible, and it greatly minimizes the chances of injury. Once built, it requires a minimum of upkeep.

Commercial racks are available with pans in the bottom (Figure 37). Wooden edges are protected by pipe to prevent chewing. They withstand a lot of abuse and can be used in crowded conditions. The elevated head position required by this type of feeder may result in dust and hay particles falling into a horse's nose and eyes.

Fence line bunks (Figure 38) offer an efficient method of feeding large numbers of loose horses. By feeding from permanent stacks along bunks, or feeding with side-chute equipped vehicles, labor is minimized. Pellets or grain can also be fed in these bunks. At least $1500 \mathrm{~mm}$ of bunkspace should be allowed for each mature horse, $900 \mathrm{~mm}$ for each young horse.

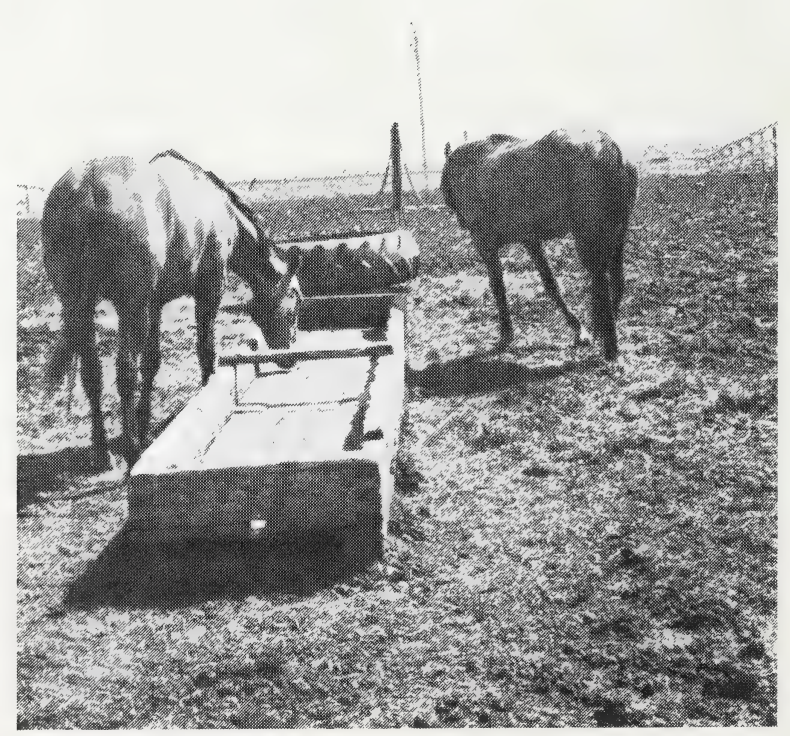

Figure 34: Laminated hay feeder 


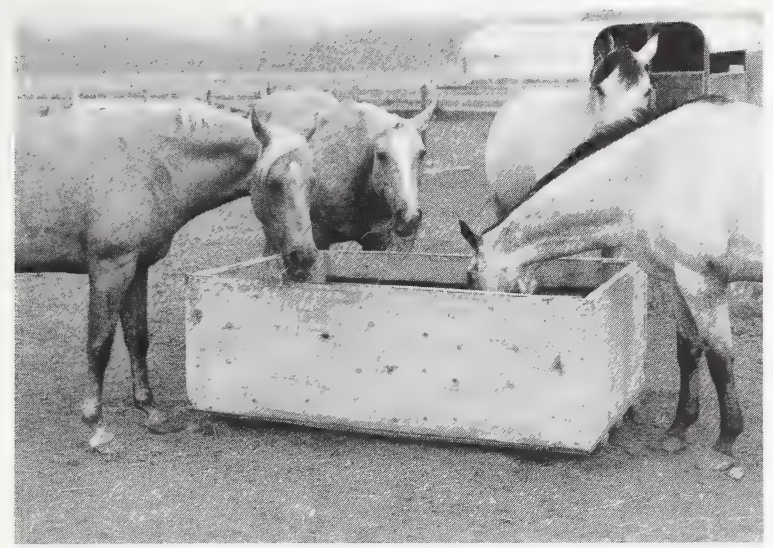

Figure 35: A plywood hay feeder

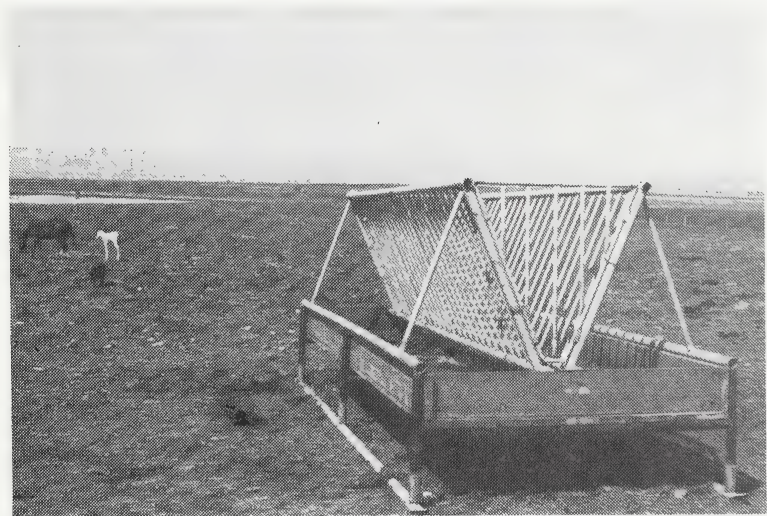

Figure 37A (above): Commercial feeder with bottom pans

Figure 37B (right): Farm built hay feeder with bottom pans

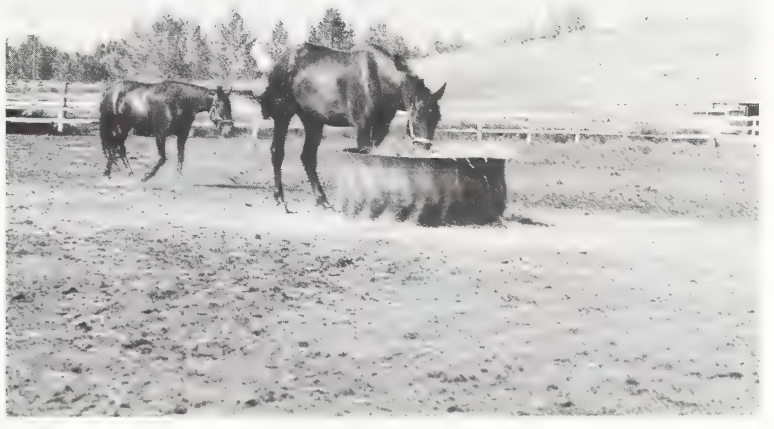

Figure 36: A tractor tire hay feeder

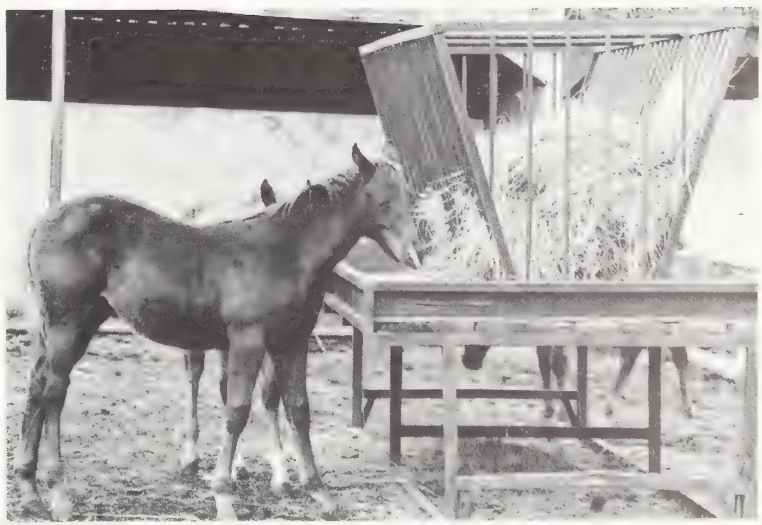



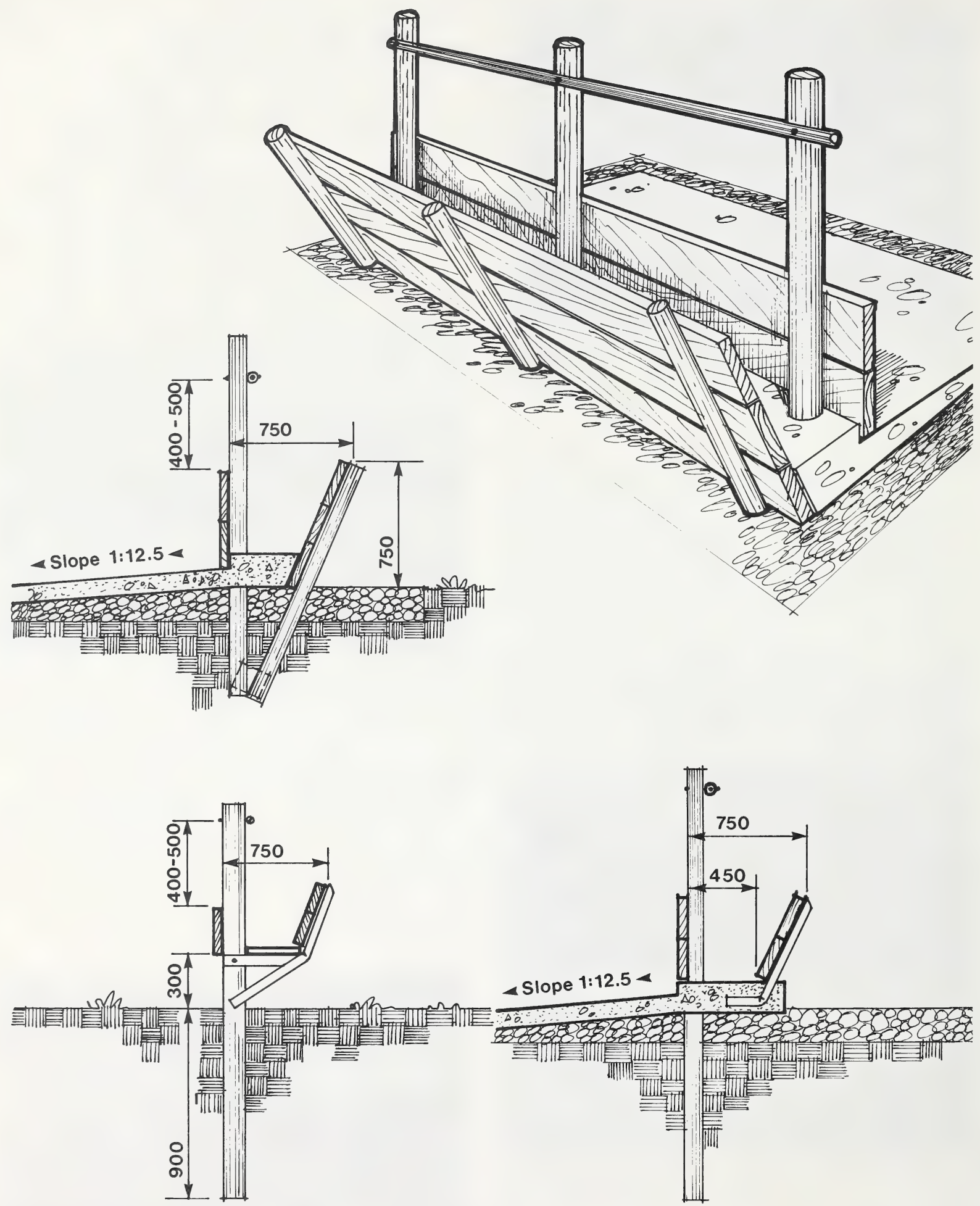


\section{CREEPS}

Creeps should be located where mares are inclined to congregate. A creep should entice foals to enter it. It should be dry when rainy, shaded when the weather is warm, and be big and open so foals will spend time in the creep. It should be at least $3 \mathrm{~m} \times 5 \mathrm{~m}$ for one or two foals. For greater numbers, an additional $2.5 \mathrm{~m}^{2}$ of creep should be allowed per foal.
Entrance to creeps can be restricted to foals by three methods: narrow opening (Figure 39), low openings (Figure 40 ), or troughs with small muzzle openings (Figure 41). In most cases, openings $50-60 \mathrm{~cm}$ wide will keep mares from entering the creep. To restrict by height, openings should be $15 \mathrm{~cm}$ shorter than the shortest mare measured at the withers. Restrictive creep troughs should be shallow with bars spaced $9-10 \mathrm{~cm}$ apart. Allow $46 \mathrm{~cm}$ of feeder per animal.
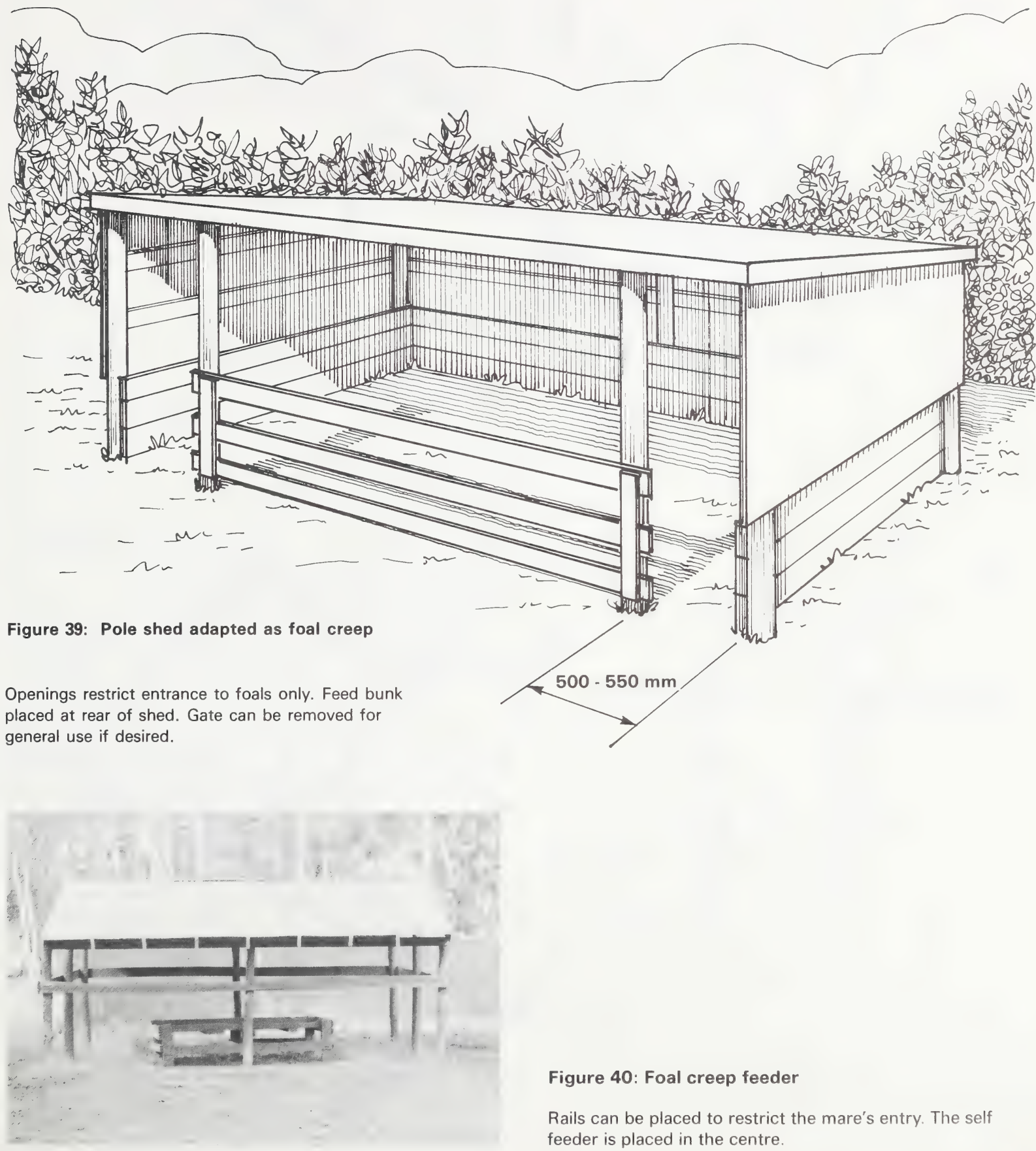

Figure 40: Foal creep feeder

Rails can be placed to restrict the mare's entry. The self feeder is placed in the centre. 


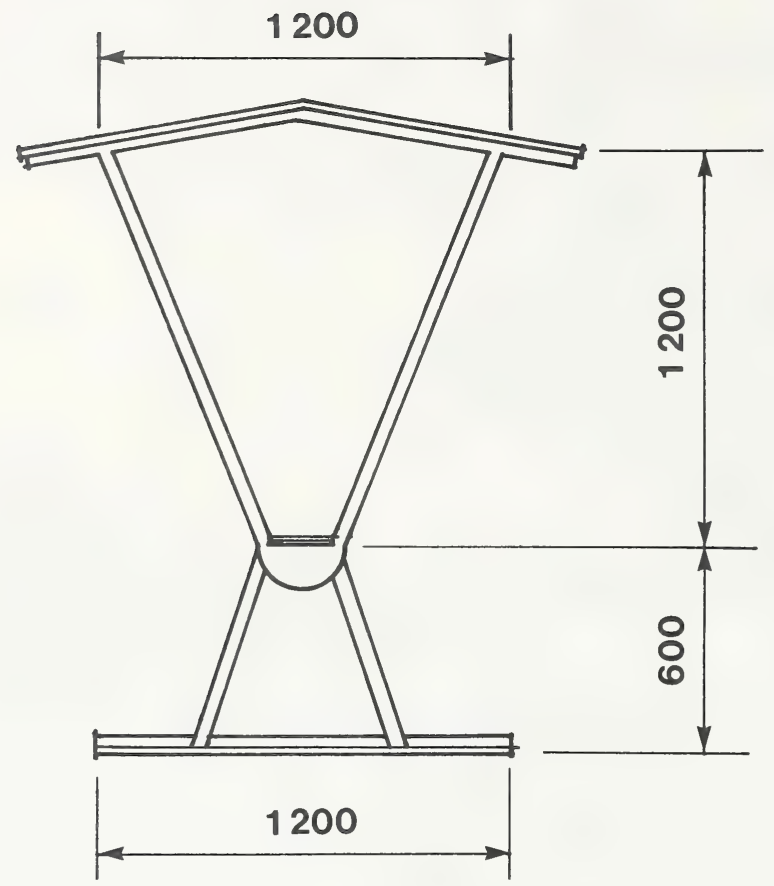

Figure 41A: Free standing creep feeder for foals

Figure 41B: Another view of the free standing creep feeder for foals

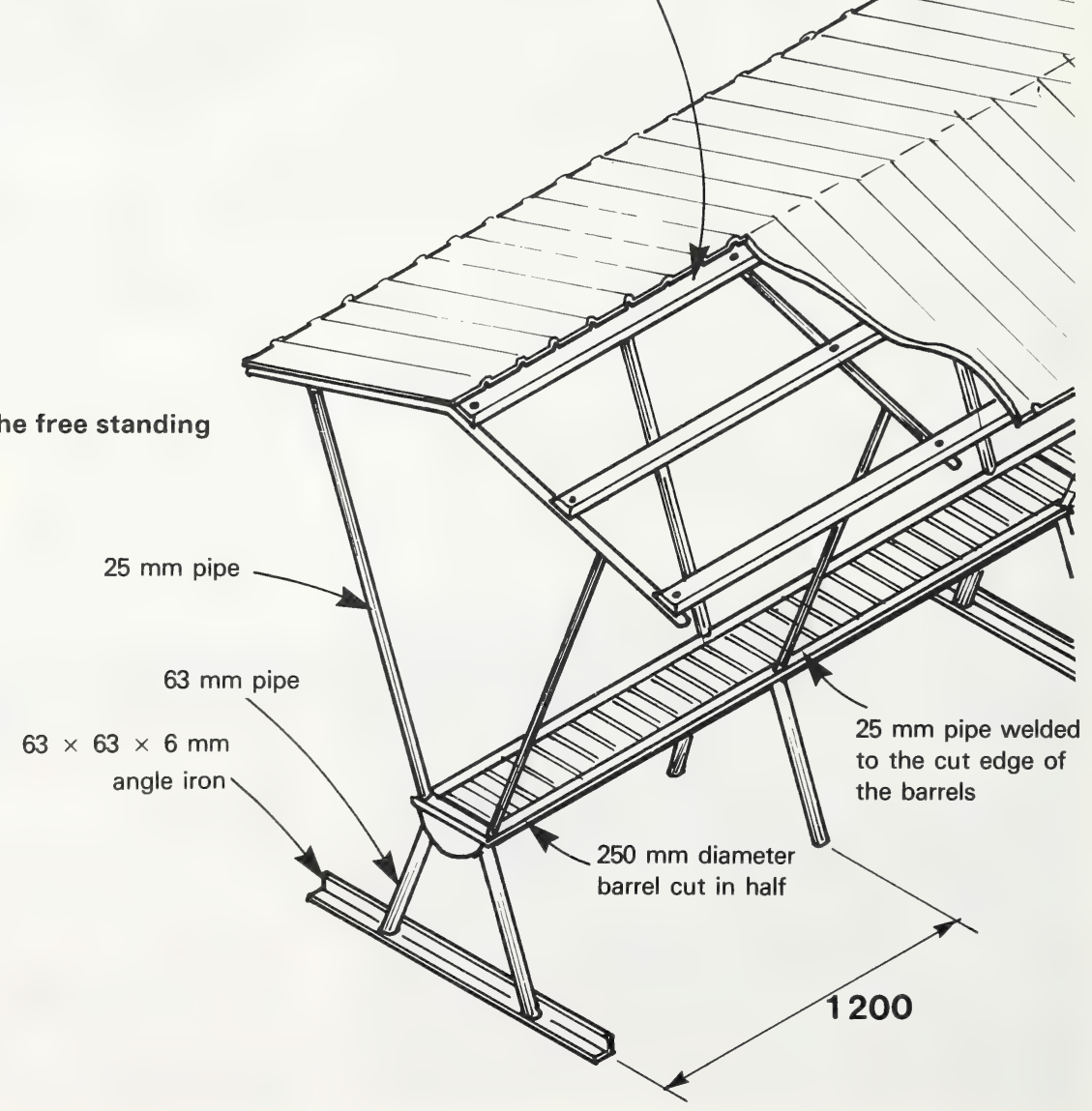




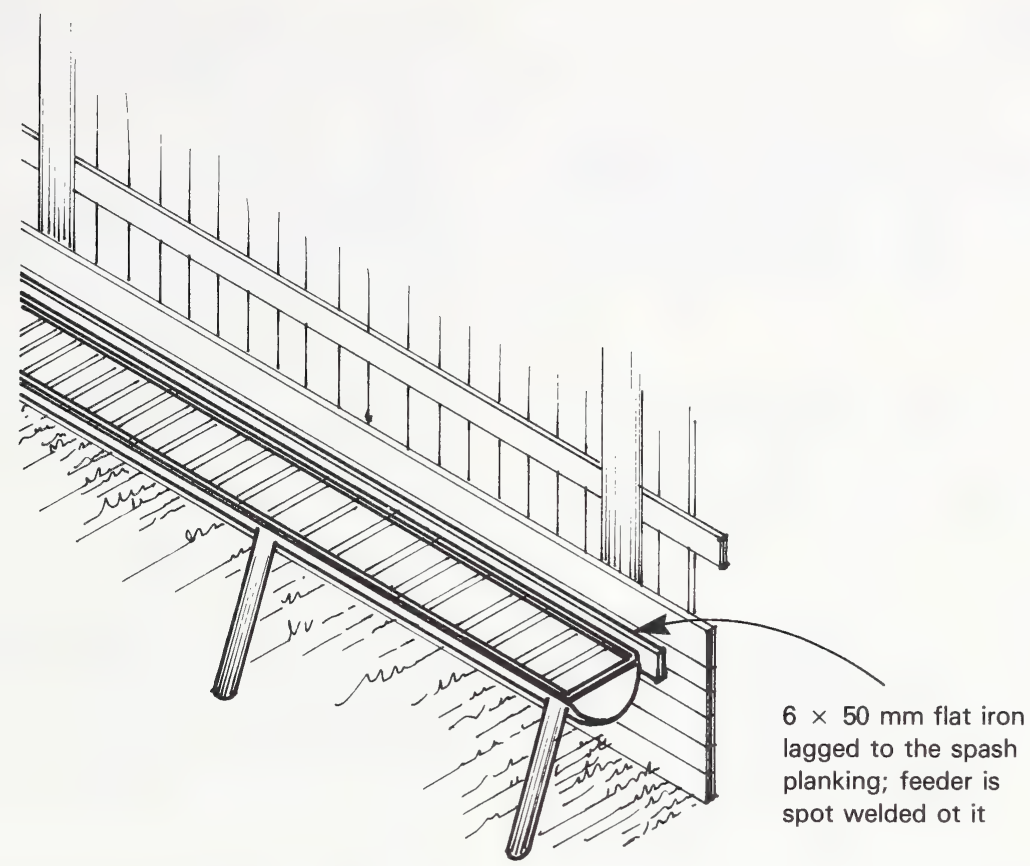

Figure 41C: Foal creep feeder for shed wall

\section{MINERAL FEEDERS}

A sturdy weatherproof mineral feeder (Figure 42) can be built from two fenceposts, two sheets of exterior $12.5 \mathrm{~mm}$ plywood or Aspenite, $9600 \mathrm{~mm}$ of $38 \times 39 \mathrm{~mm}$ lumber and some asphalt roofing. For better durability, pressure-treated posts and galvanized nails can be used. Line all exposed edges with metal to prevent horses from chewing the wood.

The plywood and framing should not be painted. A good penetrating wood stain will look better in the long run and requires less maintenance. The feeder is best located in the pasture with the opening facing away from the direction of most rainstorms.

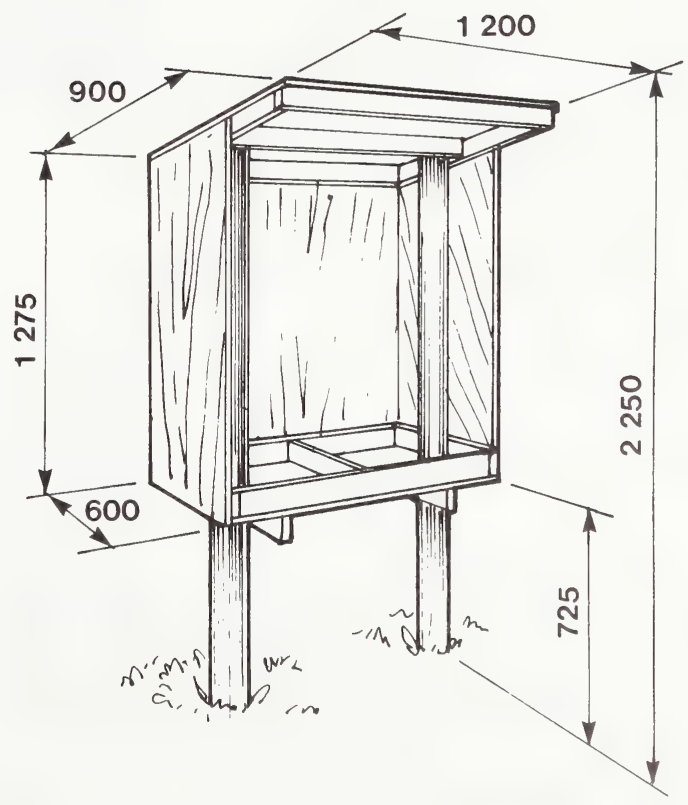

Figure 42: Mineral feeder for horses 


\section{FENCING}

It is important when building a fence to ensure that adequate construction techniques and materials are used. Fences must be effective. The property owner is liable for any damage to crops or for automobile accidents that his animals might cause should they escape. As the saying goes, "good fences make good neighbors".

\section{CHAIN LINK FENCES}

Chain link fencing is highly effective and long lasting. However, it is also very expensive. If properly erected, it should have a low maintenance requirement. It will give if a horse runs into it, but it may be permanently stretched by horses leaning against it.

\section{POST BOARD FENCES}

Post board fences are strong and highly visible. Kept painted and in good repair, they can add to the appearance and value of one's property. Board fences require a lot of maintenance. Horses may lean over them and loosen boards and posts. Setting the posts in concrete will help keep fences tight. Larger posts should be used in high-density, high-use areas such as corrals. Staining may be a longer lasting alternative to painting. Lead based paints are poisonous and should not be used on livestock facilities. Some horses will chew lumber, especially if they are confined in small areas. Some paints contain a chewing preventative that may help this problem. Using creosote-treated lumber also reduces chewing.

\section{PIPE FENCES}

Pipe fences with metal posts are expensive initially, but their endurance potential pays off in the long run. Pipe makes a strong, safe and attractive fence. If the posts are set in concrete, a pipe fence will be there for life. No maintenance other than an occasional coat of paint is needed.

\section{WIRE MESH FENCES}

Wire mesh fences are less expensive to construct. Wire will give easily if a horse runs into it or leans against it which means it will need frequent restretching. Boards may be needed on the top and bottom of the fence to keep horses from pushing or walking it down. This obviously will add substantially to the cost of the fence. A well tightened and stapled strand of barbed wire run along the top of the fence can help to keep horses from leaning too heavily on the wire mesh.

\section{DIAMOND MESH FENCES}

Diamond mesh is more expensive than standard mesh. It has more and heavier stay wires. It is resistant to curling and less stretchable than standard mesh. Horses cannot walk it down or put their feet through it. Boards and barbed wire are not needed for this type of fencing.

\section{RUBBER RAIL FENCES}

Rubber rail fences with wooden or metal posts are durable and easy to maintain. The rubber strapping is expensive but long lasting. It is strong and safe for horses. Some types have all their edges sealed and others do not. Raw edges should be sealed with a rubber compound, or singed to burn off the loose threads. If the edges are left raw, horses may pull the threads out and swallow them.

\section{ELECTRIC FENCES}

Although electric fences are inexpensive and effective in fence training horses, there is a risk of physical injury to the animals when more than 12 volts are used. If built with smooth wire using a low voltage, they are fairly safe. Electric fences are sometimes difficult to see. Strips of cloth can be tied to the wires to increase their visibility. The wire stretches easily and can be broken by horses, cows or wild animals. Fences need to be kept free of weeds and bushes to prevent short circuiting. Electric fences are sometimes used in conjunction with board fences.

\section{BARBED WIRE FENCES}

Most horses spend their lives inside barbed wire fences. The fact that barbed wire is inexpensive and quick to erect will keep it popular. A strong tight barbed wire fence can safely be used in large pastures. Barbed wire fences usually have high maintenance requirements. These can be minimized with good construction. This type of fence should not be used to enclose stallions, or for corrals.

Fence maintenance can be simplified by starting with a well built fence. A well built fence starts with good posts, properly set in the ground. When one post along the length of a fence fails, it can be replaced relatively simply. If a corner post fails on a barbed or woven wire fence, the whole thing will need to be restretched.

Therefore, special care must be taken in the setting and bracing of corner posts. Setting posts in concrete adds to the stability of the fence but is not necessary. A good job of tamping will be adequate in most situations. Treated wooden posts are more expensive than untreated but they last substantially longer and so are recommended.

A sturdy fence can be made with $4800 \mathrm{~mm}$ planks set at 2400 $\mathrm{mm}$ intervals. The planks should be staggered so that only some of the planks end on each post. Planks may have to be drilled to prevent them from splitting when nailed. For a rail or plank fence, the posts need to be carefully spaced. This is not as critical for wire fences.

Wire fencing should not be tightened around a corner sharper than 45 degrees. It is better to tighten to the corner, cut the wire, and start stretching from that point. Woven wire should be rolled out, propped up and stretched evenly, then stapled to the posts. Overstretching can be more harmful than understretching. Staples should be driven in snugly without burying the wire in the post. There should be enough wire left to complete the tie around the post before the cut is made.

Livestock have often been killed by lightning carried along wire fences. In areas of frequent thunderstorms, it is a good idea to ground such fences. This can be done by driving a 9 to 12 $\mathrm{mm}$ diameter rod into the ground deep enough to reach some permanent moisture. Fence wires are fastened to this rod with heavy galvanized wire.

Figure 43 shows fencing alternatives. Figure 44 gives construction details for fence corners. 


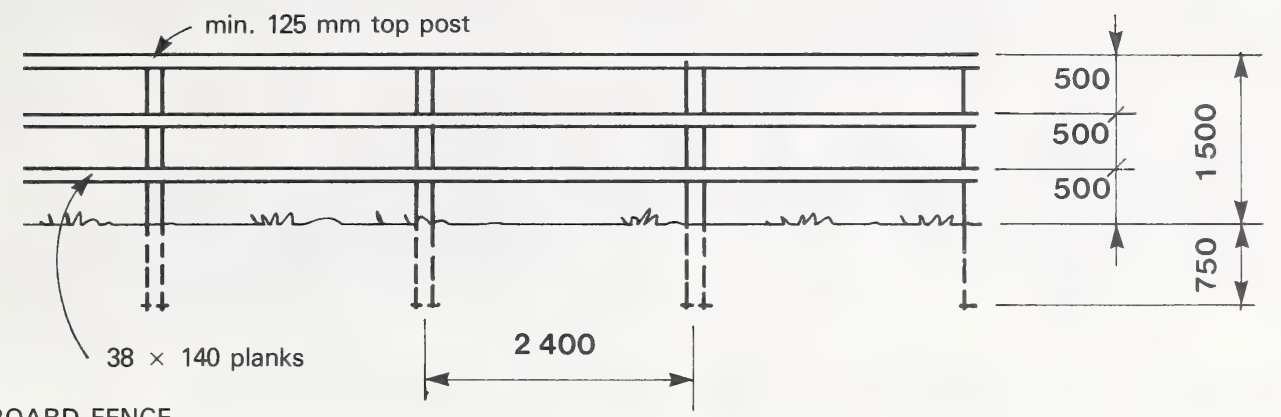

BOARD FENCE
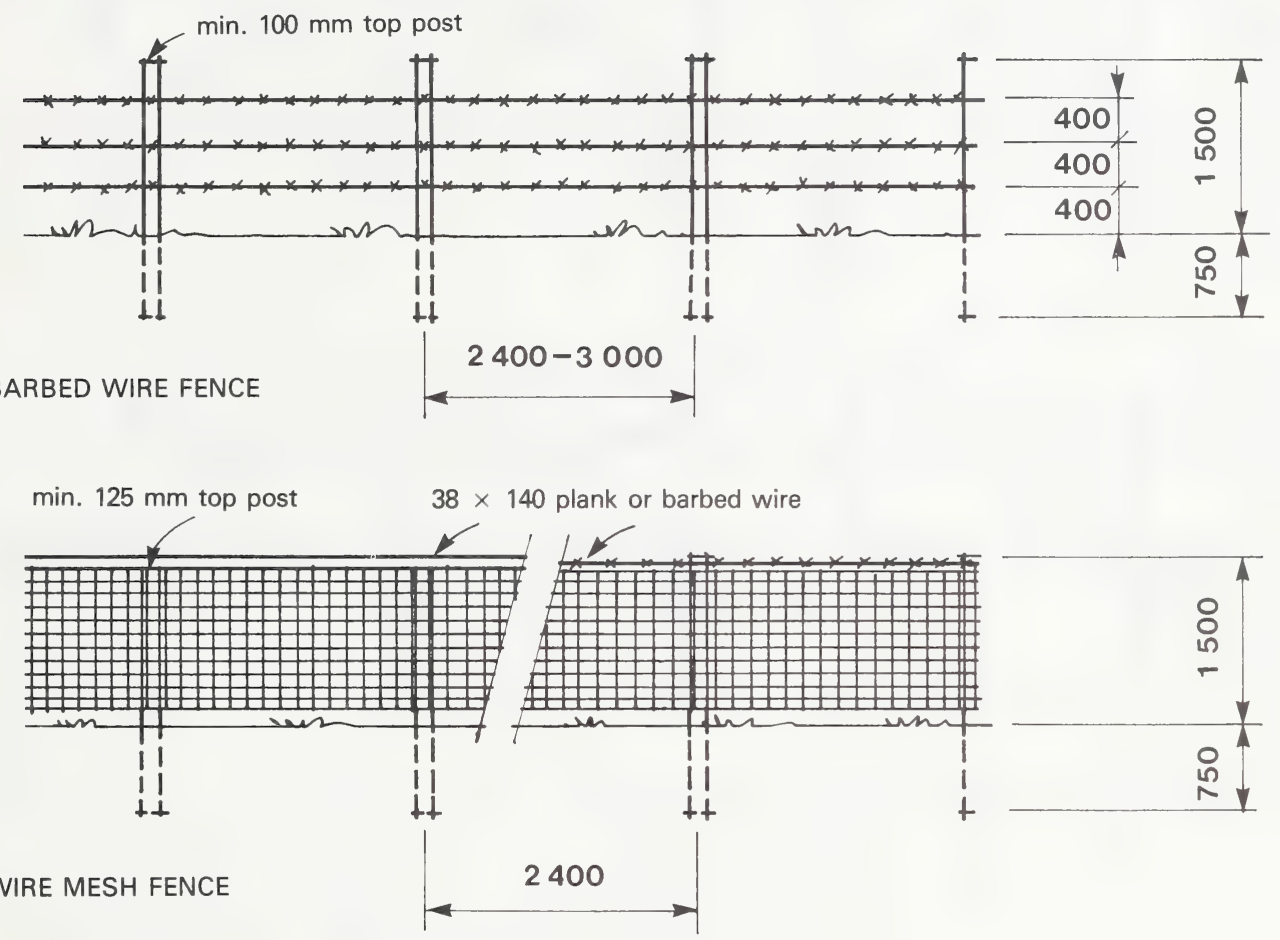

min. $125 \mathrm{~mm}$ top post

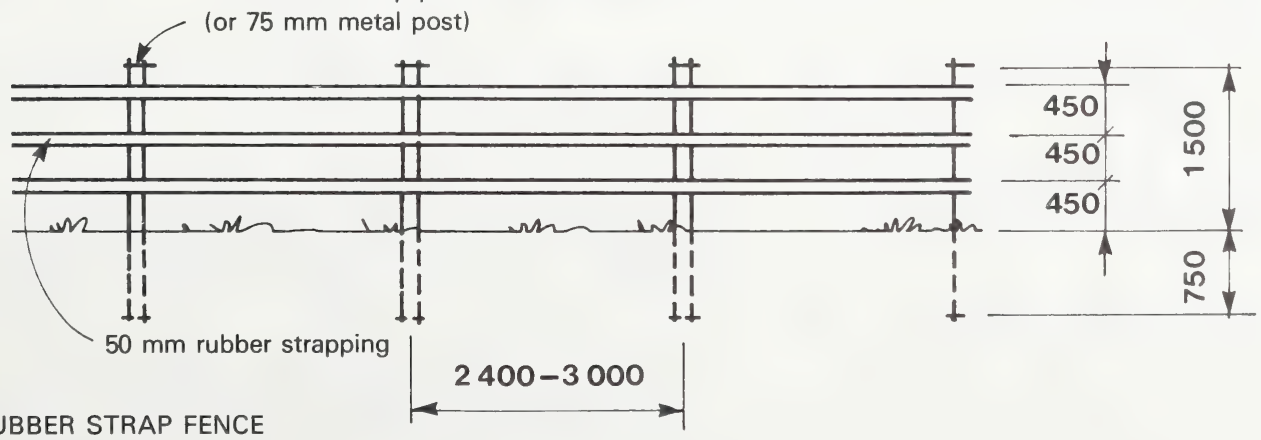

Figure 43: Fencing alternatives 

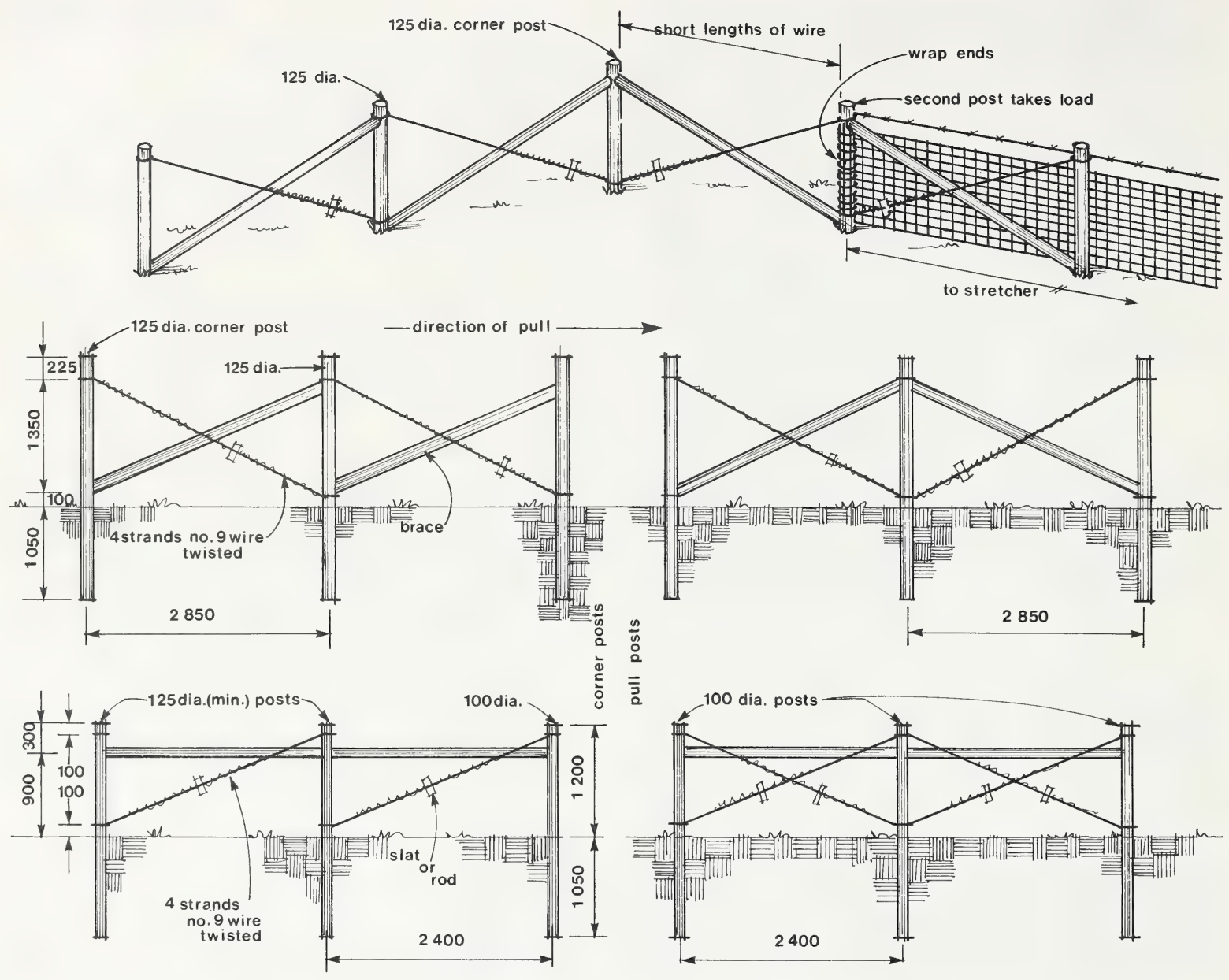

Figure 44: Construction details for fence corners

\section{CORRAL HOUSING}

Corral Housing for Stallions-Fences of stout construction 2.4 to $2.7 \mathrm{~m}$ high will be needed (Figure 45 ) if stallions are to be run side by side. If there is only one stallion, a $1.8 \mathrm{~m}$ fences will be adequate. The fences should not be solid. The horse should be able to see through it.

Corral Housing for Geldings, Mares, and Mares with Foals-Fences 1.5 to $1.8 \mathrm{~m}$ high that the horses can see through will be suitable (Figure 46).

Horse Runs provide a convenient way to house stock. Isolation is easy. On a breeding establishment which has visiting mares, they offer a safe and efficient method of housing, especially if foals are at foot. Runs should be built on a base of compacted gravel to aid in drainage. In some situations, it may be necessary to floor runs with concrete. Waterers and mangers should be situated along the fence, or in a shed, in a position which can be serviced from outside the run.
If a corral is to be used regularly, it should be built on a bed of compacted gravel. Compacted pit run with a sand or clay cover will give good footing and drainage.

Water and salt should be made available in the corral. If horses get into the habit of coming to the corral for these necessities, they will be easier to catch.

Handling Corrals - Corrals used for training horses should have tall, strong fences. A height of about $1.8 \mathrm{~m}$ will help prevent the horse from escaping or being distracted. Heavy 50 $\mathrm{mm}$ planks or pipe will provide fences with adequate strength.

The solid lines in Figure 47 represent a minimum corral set-up for working horses. It is small enough to make it possible to catch difficult horses, yet large enough to allow space for breaking and training. A loading chute set up with a cutout gate is shown in broken lines. When working and handling a large number of horses, a loading chute is a necessity. When horses are unschooled to the point where ordinary restraining stocks are inadequate, a horse squeeze may be needed. A 
round corral and horse squeeze are also shown in broken lines to make a complete set of working corrals.

Details of the horse squeeze are shown in Figure 48. Gate 1 and wall $A$ can be the same thing, but have been shown separately for clarity. Gates and walls should be made of rails or heavy planking. The flat side of the gate should always go toward the horse. The height of the structure should be a minimum of $1950 \mathrm{~mm}$. Heavy hinges and hardware must be used throughout. There must be no projecting corners to injure the horses.

When a horse is loaded into the squeeze, his head must always point toward the hinge end, as shown. A chain or rope tie can be used to hold the squeeze shut.

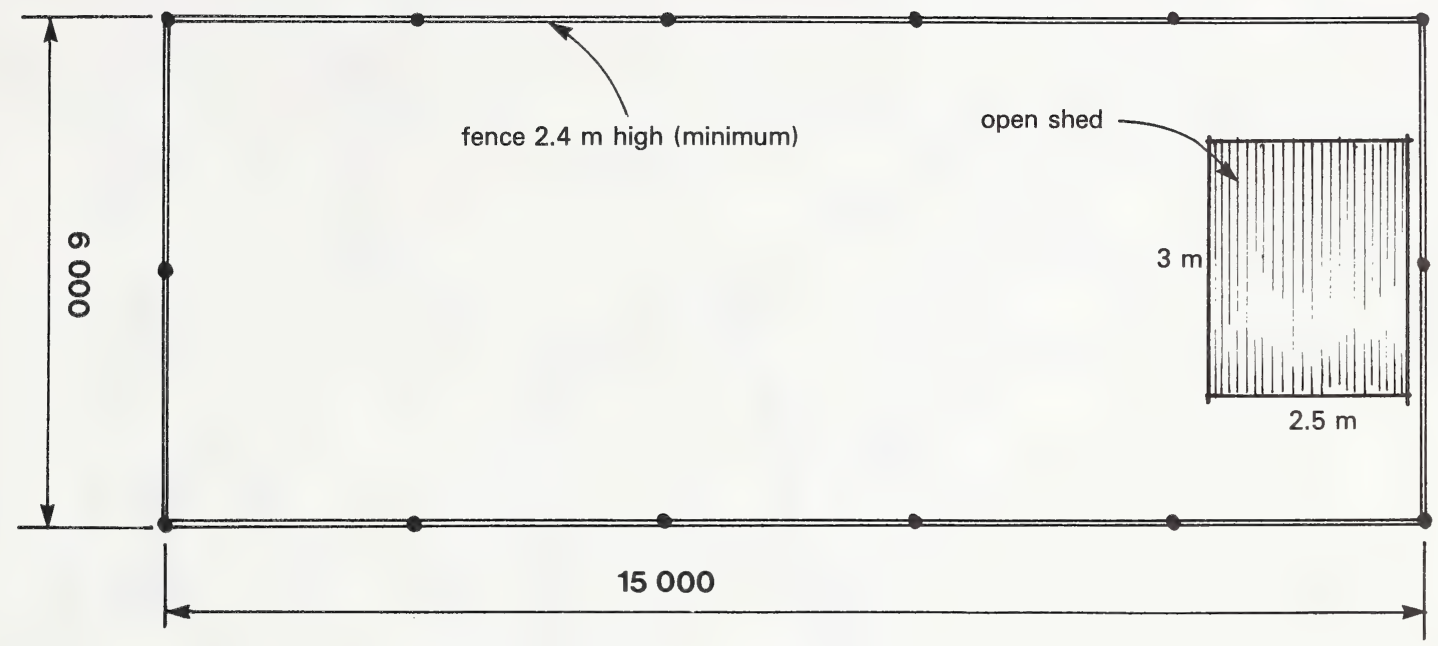

Figure 45: Corral housing for stallions

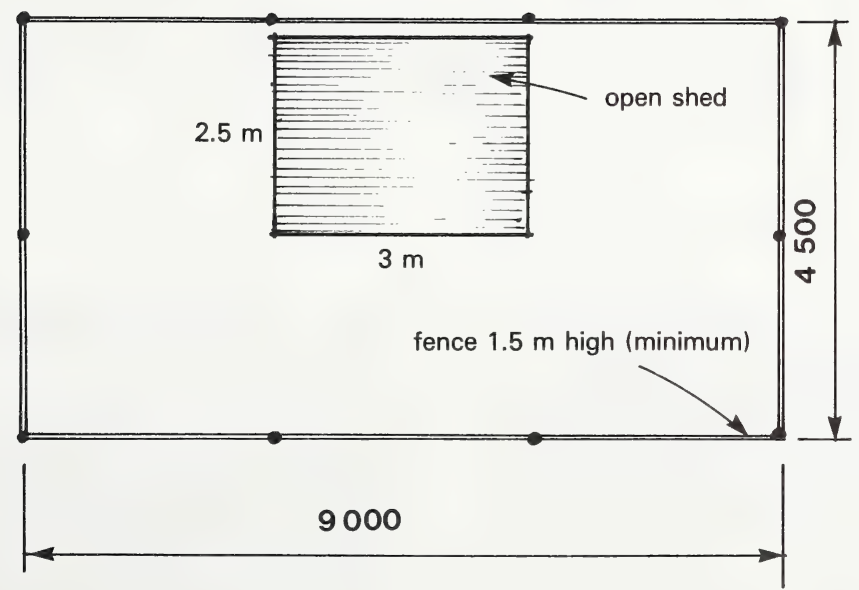

Figure 46: Corral housing for geldings and mares 


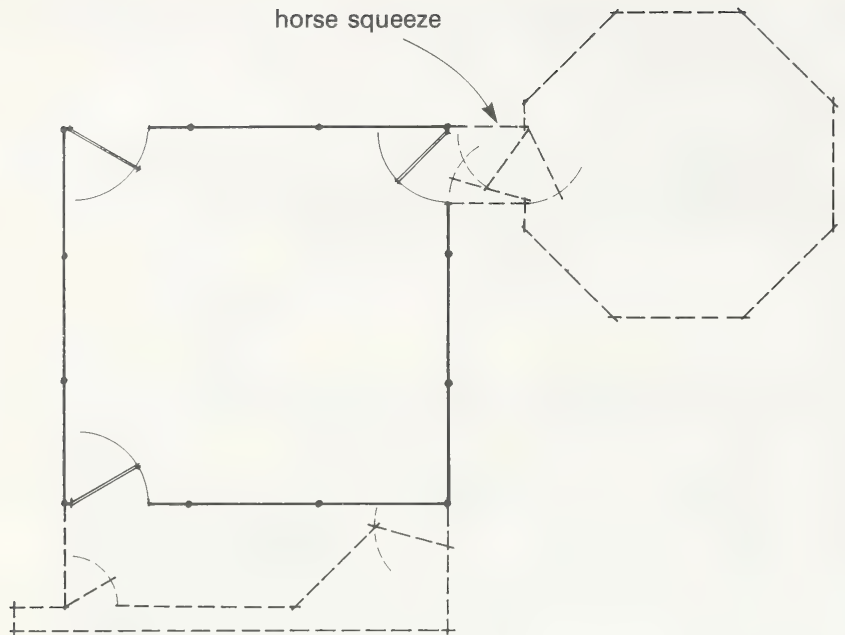

Figure 47: Handling corrals

Figure 48: Horse squeeze

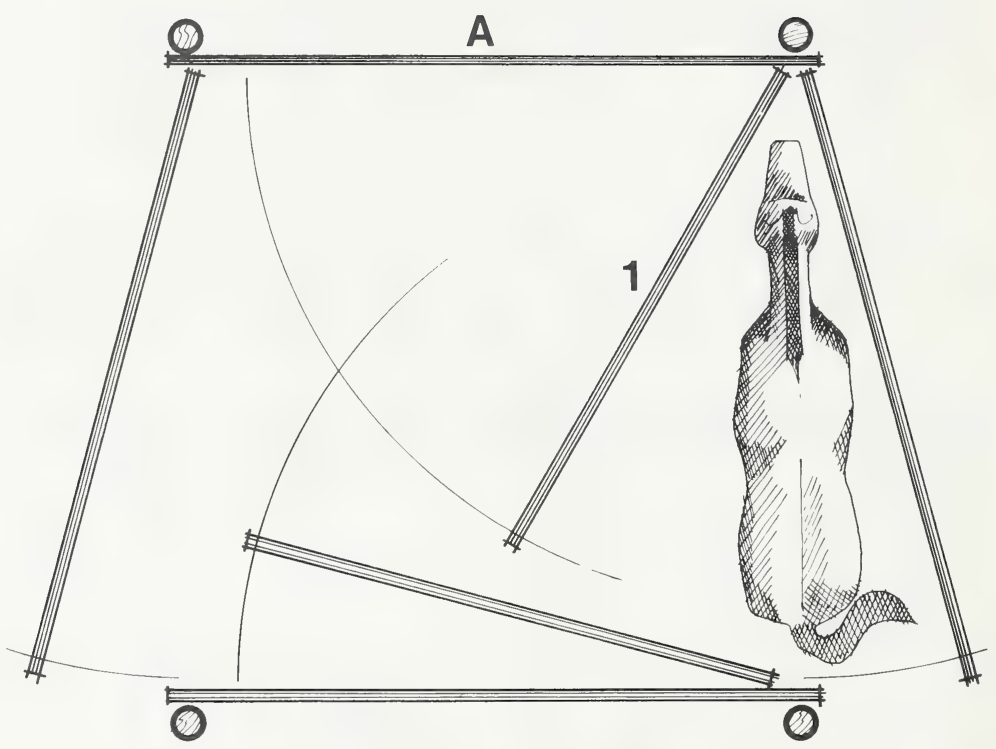

\section{RESTRAINING STOCKS}

Restraining stocks are necessary for artificial insemination breeding programs or where veterinary services are often required. The stock is sized to allow the horse to be led through. There is a restraining bar in front of the horse and a restraining gate behind. The top edge of the rear gate should be between 750 and $800 \mathrm{~mm}$, but no more than $900 \mathrm{~mm}$ high. These gates should be solid to prevent horses from kicking the people working on them.

The size of the stock, $800 \times 1800 \mathrm{~mm}$, may be reduced for smaller horses. In some operations it may be desirable to have the stall $300 \mathrm{~mm}$ longer and $150 \mathrm{~mm}$ wider, with a solid front so that the foal can be placed in front of the mare in the stock. If this is the situation, solid stock walls are preferred. It is advisable to have a small alley in front of the walk-through stocks so foals can move without leaving the mares' view.
Stocks can be built side by side so a number of horses can be restrained at one time for purposes of artificial insemination, pregnancy checks, worming, etc.

The stocks should be made of pipe or treated $90 \times 90 \mathrm{~mm}$ posts, $38 \mathrm{~mm}$ lumber or $19 \mathrm{~mm}$ plywood, The posts should be secured to the floor to prevent the stock from tipping or shifting. Figure 49 shows the dimensions and some construction details for a pipe frame, open sided restraining stock, and a wood-frame solid sided stock. 


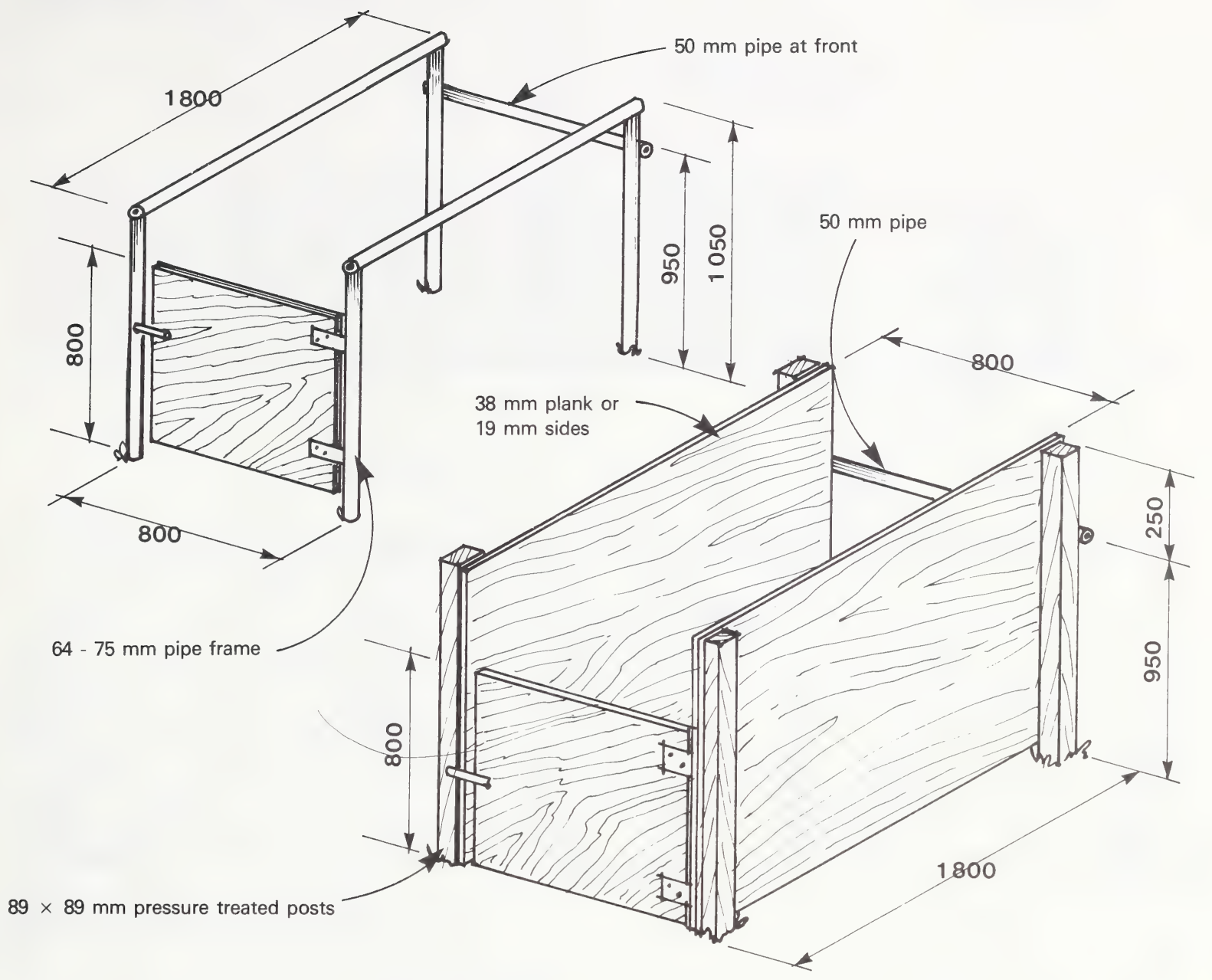

Figure 49: Restraining stocks

\section{TEASING AND BREEDING FACILITIES}

\section{TEASING CHUTE}

The tease chute in Figure 50 is a wooden alley 70 to $82 \mathrm{~cm}$ wide, $1.5 \mathrm{~m}$ high on one side and $1.2 \mathrm{~m}$ high on the other. The length of the chute can vary, allowing 5 metres per mare. If the chute were to accommodate nine mares, for instance, it would be 45 metres long. Gates should be located one at each end with one or two in the side. Mares are placed in the chute and tied 5 metres apart. A stallion is led to the low side of the chute and allowed to tease each mare individually to determine their stages of estrus (heat). It is important to keep the stallion from savaging mares when teasing in this method or the mares may become refractory and not show heat. This method is only good for dry mares handled as a band. Estrual mares (in heat) can be separated from diestrual mares (not in heat) via side gates of the chute. One stallion handler can tease many mares in a short time using a tease chute. 


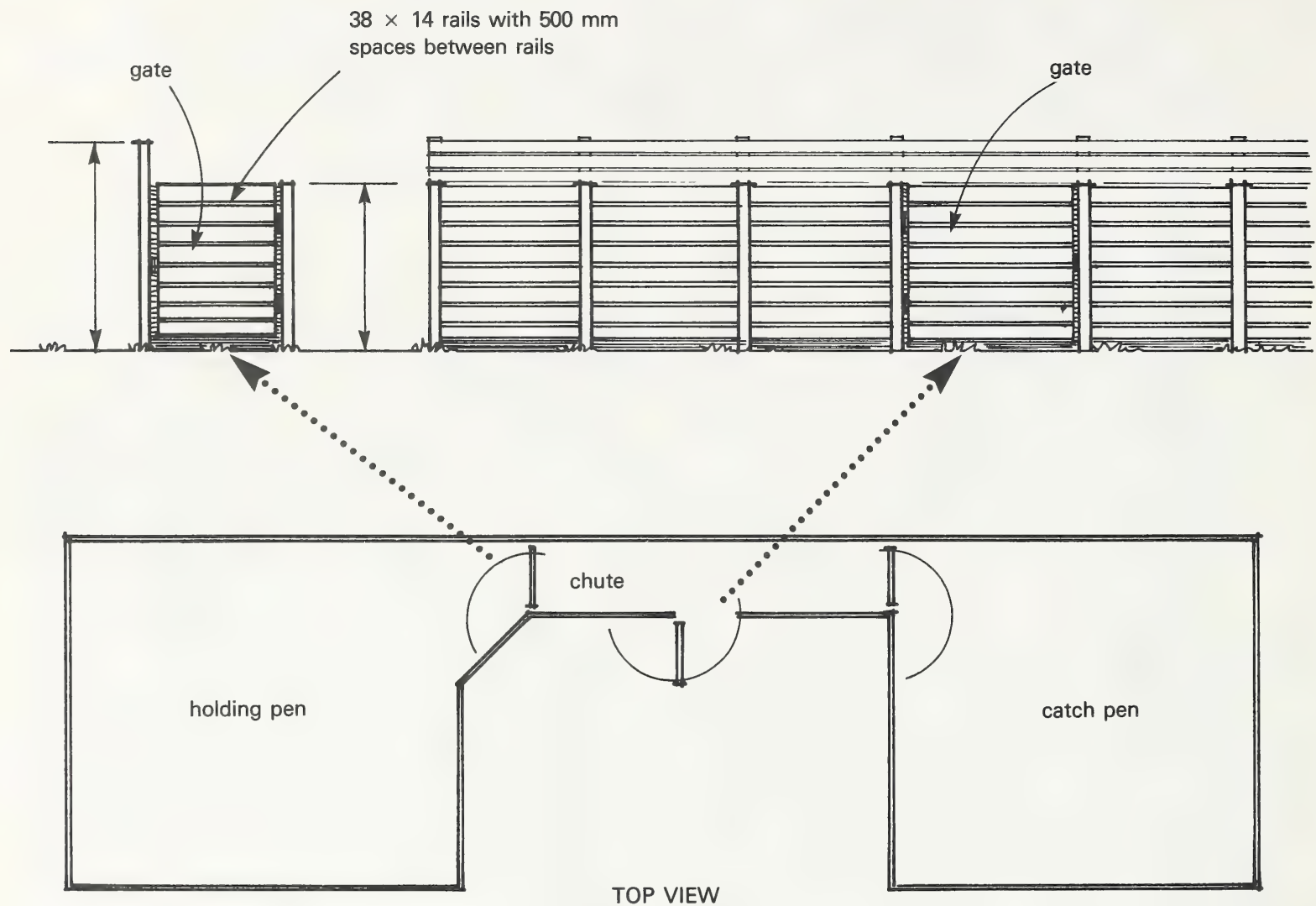

Figure 50: Tease chute

\section{TEASING CAGE OR PEN}

This method of heat detection involves holding a stallion in a cage or pen in the centre of a larger pen (Figure 51). The mares are allowed into the larger pen. Most estrual mares will go to the stallion cage and exhibit the signs of estrus. The moment a mare has demonstrated that she is in estrus, she should be removed from the group so the stallion can concentrate on other mares. It is advisable to lead each mare that does not show signs of estrus up to the stallion once the other mares are removed, as some shy or timid mares will not exhibit signs unless actively teased. This method can be used for both mares with foals and dry mares. The main advantages are that little labor is required and mares can be maintained as a band.

\section{T-BAR}

This method involves leading the stallion to one side of a rail, and the mare to the other (Figure 52). The stallion is allowed to tease the mare over the rail. This method requires two people and a considerable amount of time. It is a very effective means of detecting heat as each mare is individually teased. The method is very safe for the mare, stallion and the handlers, and so is ideal for most small breeders.

\section{BREEDING STALLS}

Breeding stalls (Figure 53) serve to control the mare to a large extent. This allows one mare to handle breeding in a safer manner. 

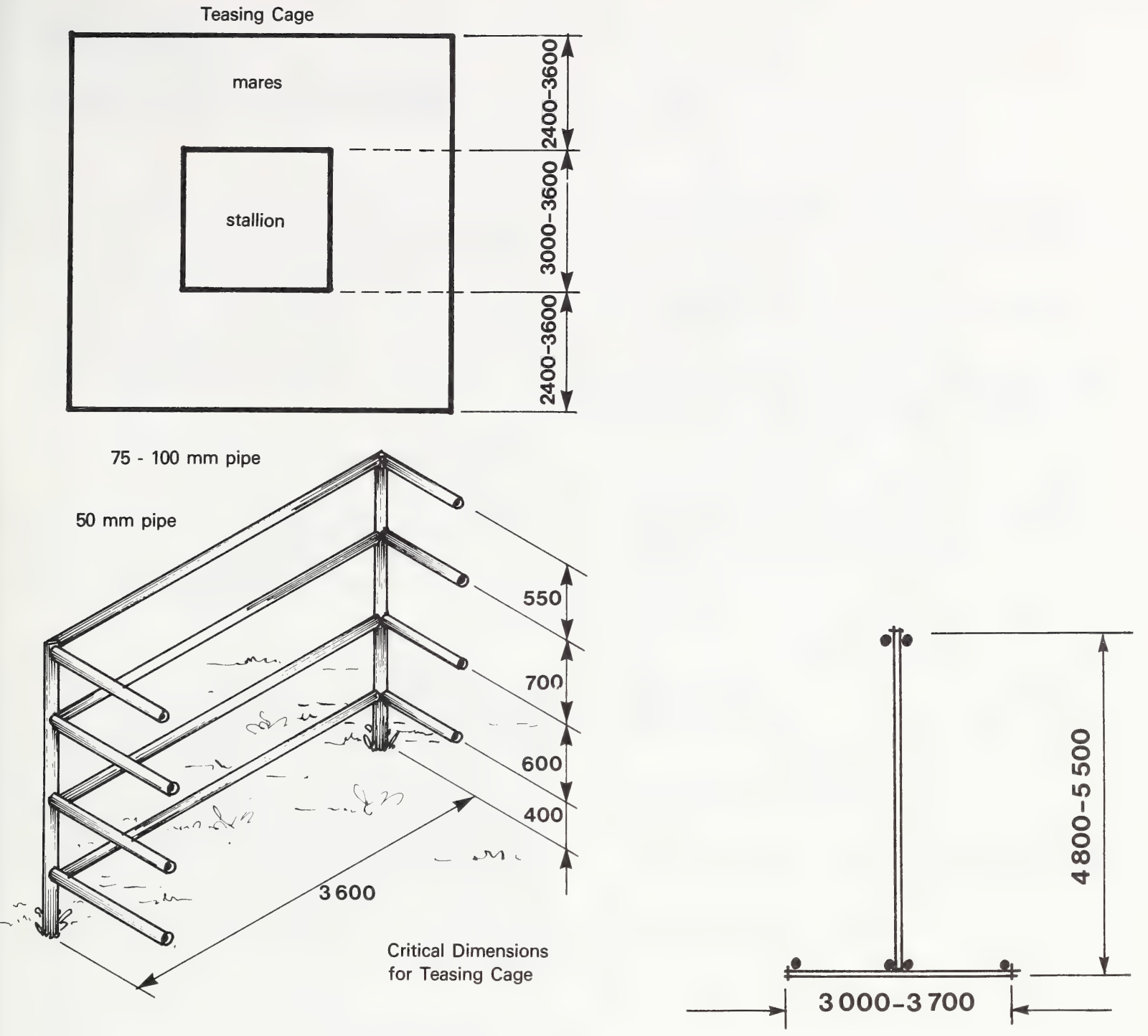

Figure 51: Teasing cage

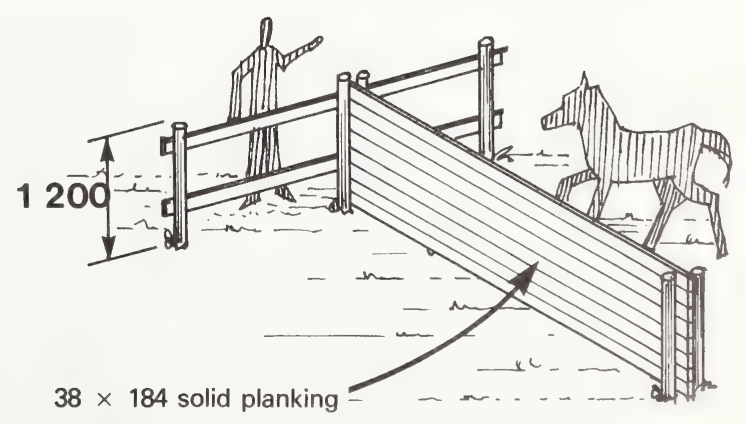

Figure 52: T-Bar 


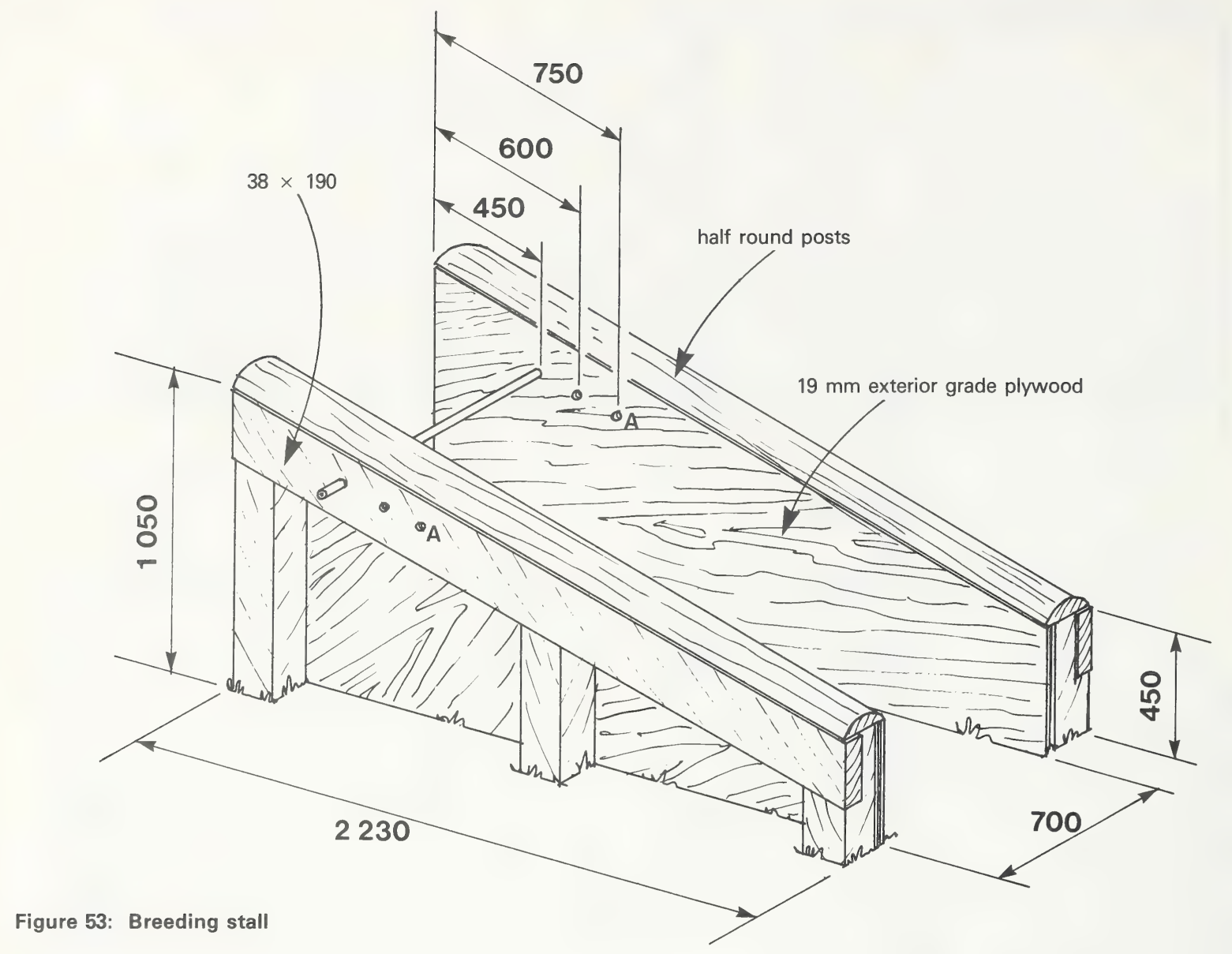

Figure 53: Breeding stall

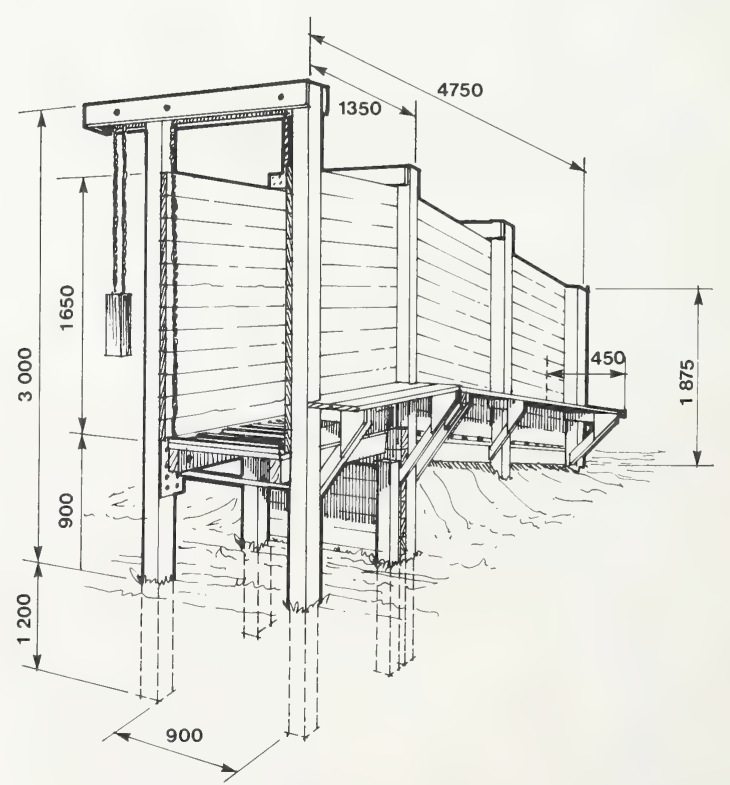

Figure 54: Adjustable stationary loading chute 


\section{ARENA}

\section{CONSTRUCTION}

Footing is one of the most important aspects of arena construction. The usual practice is to rototill the existing soil. A good all-weather surface can be constructed as shown (Figure 55). This surface is good for dressage and jumping, but a firmer surface may be needed for reining or for working cow horses. This can be obtained by reducing the top layers of sand and shavings to $25 \mathrm{~mm}$ each. The surface may be crowned slightly, but very little crown is desired. Only unwashed gravel should be used.

The minimum size for an arena is $18 \times 36 \mathrm{~m}$. The most common and more versatile size is $30 \times 60 \mathrm{~m}$ (Figure 56).

Having the entrance and exit at opposite ends of the arena makes it easy to move horses in and out of the ring. Gates should extend right from the floor to the full height of the fence. Openings under the fence might allow pets to enter or

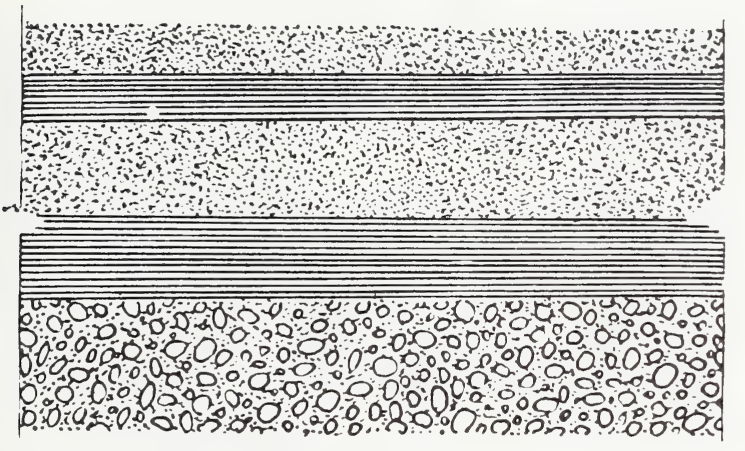

$50 \mathrm{~mm}$ of sand

$50 \mathrm{~mm}$ of shavings

$100 \mathrm{~mm}$ of compacted sand

$100 \mathrm{~mm}$ of shavings, wetted and compacted to $50 \mathrm{~mm}$

$150 \mathrm{~mm}$ of unwashed, compacted road gravel feet to protrude, possibly causing a horse to shy. Gates should also match the rest of the fence to make them less distracting.

A vertical arena fence may be satisfactory, but riders might bump their feet and legs against the wall.

An arena fence with an excessive slant away from the ring can be very dangerous. A horse travelling close to the wall may hit the wall with his feet, lose his balance, and fall into the wall trapping the rider.

A slight slope of the fence (away from the ring) offers some protection to the rider. A fence with a slope of between 2:12 and 2.5:12, attached to a vertical support is best. It will allow a horse to travel against the wall safely without endangering the rider.

Harrow top two layers together

Figure 55: Riding arena surface

$36 \mathrm{~m}$ minimum
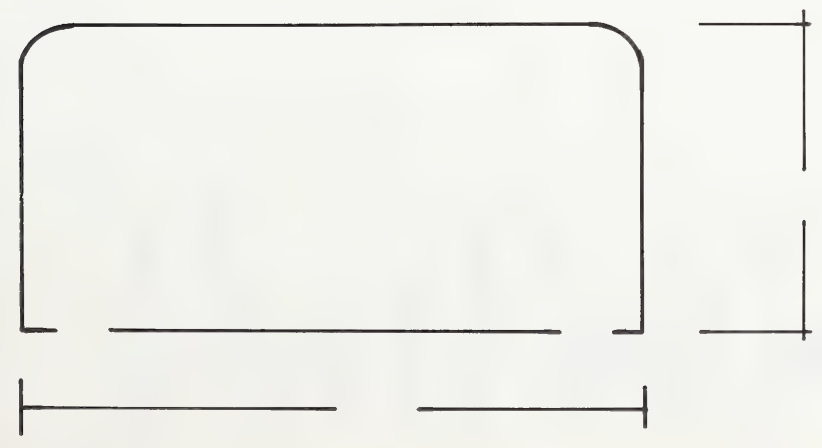

18 m minimum

Figure 56: Arena size and shape 


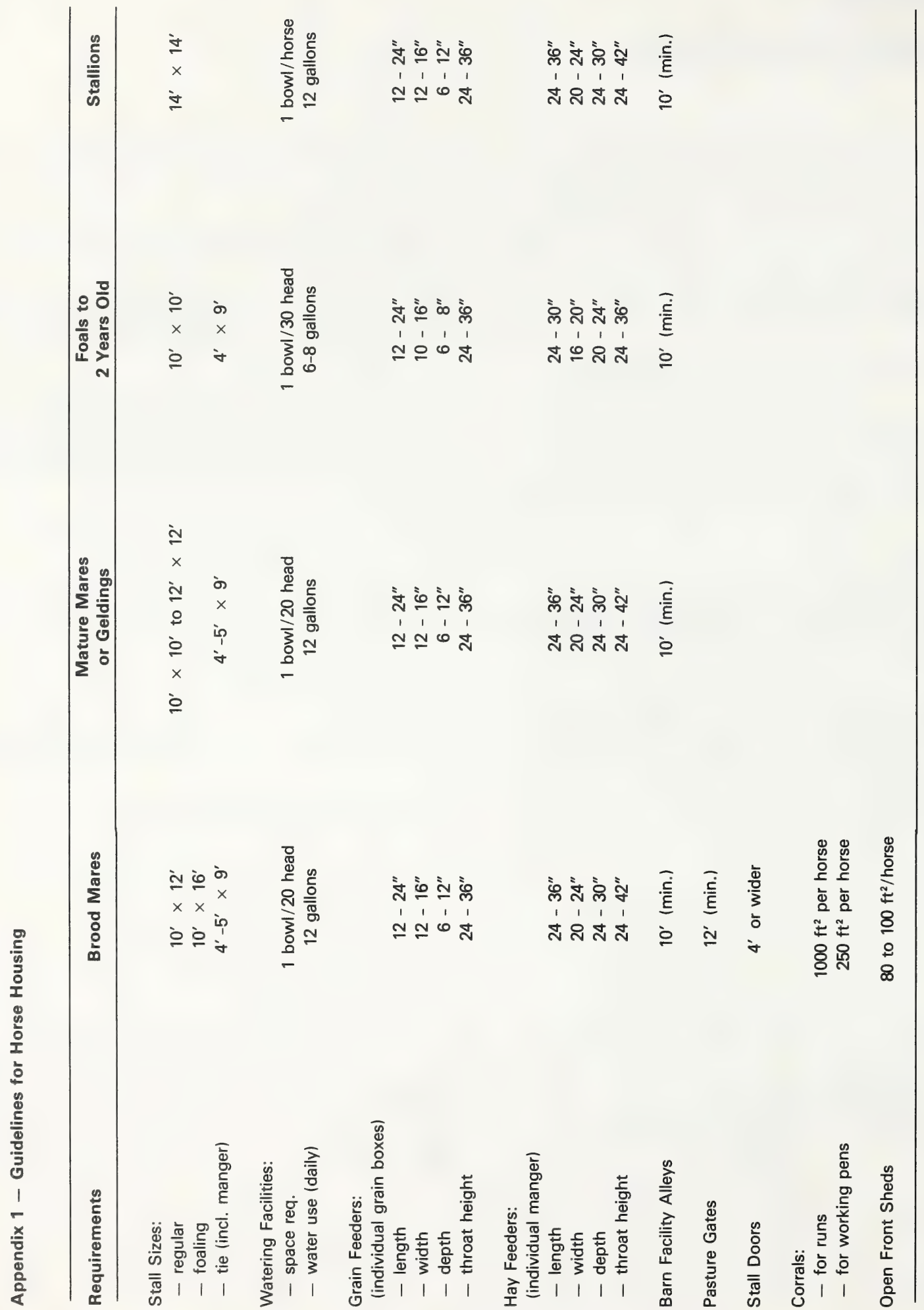


Appendix 2 - Heating requirements for horses.

\begin{tabular}{|crrrrrrrrrr|}
\hline $\begin{array}{c}\text { Inside Barn } \\
\text { Temperature }\end{array}$ & \multicolumn{7}{c|}{$\begin{array}{c}\text { Supplemental Heat Required at Various Outside Design Conditions } \\
\text { Given in BTU/hr. }\end{array}$} \\
\hline${ }^{\circ} \mathrm{F}$ & -40 & -32 & -21 & -12 & -4 & 4 & 13 & 23 & 32 \\
\hline 20 & 3000 & 2300 & 1500 & 700 & 0 & 0 & 0 & 0 & 0 \\
\hline 35 & 5000 & 100 & 3000 & 2500 & 2000 & 1000 & 400 & 0 & 0 \\
\hline 40 & 5200 & 4400 & 3500 & 2800 & 2200 & 1300 & 800 & 400 & 0 \\
\hline 45 & 5300 & 4500 & 3600 & 3000 & 2400 & 1500 & 900 & 500 & 0 \\
\hline 50 & 5800 & 5000 & 4200 & 3400 & 2700 & 1900 & 1100 & 800 & 0 \\
\hline
\end{tabular}

NOTE: Heating rates given are taken from a barn that houses horses in box stalls. It is of average construction with R20 insulation in the roof and walls. There is allowance made for $5 \mathrm{ft}^{2}$ of window per horse. Depending on the type and construction of the facility, heat required may be either higher or lower than the guideline given.

Appendix 3 - Composition (on a wet-weight basis) of fresh manure.

\begin{tabular}{|c|c|c|c|c|c|c|c|c|}
\hline \multirow[t]{2}{*}{ Components of Manure } & \multicolumn{2}{|c|}{ Proportions } & \multicolumn{2}{|c|}{$\begin{array}{c}\text { Nitrogen } \\
\text { (as N) }\end{array}$} & \multicolumn{2}{|c|}{$\begin{array}{c}\text { Phosphorous } \\
\text { (as } \mathrm{P}_{2} \mathrm{O}_{5} \text { ) }\end{array}$} & \multicolumn{2}{|c|}{$\begin{array}{l}\text { Potassium } \\
\text { (as } \mathrm{K}_{2} \mathrm{O} \text { ) }\end{array}$} \\
\hline & $\%$ & $\begin{array}{c}\mathrm{lb} / \mathrm{t} \\
\text { of manure }\end{array}$ & $\%$ & lb & $\%$ & lb & $\%$ & lb \\
\hline Horse Feces & 60 & 1,200 & .055 & 6.6 & 0.30 & 3.6 & 0.40 & 4.8 \\
\hline Urine & 15 & 300 & 1.35 & 4.1 & \multicolumn{2}{|c|}{ trace } & 1.25 & 3.8 \\
\hline Bedding (straw) & 25 & 500 & 0.50 & 2.5 & 0.20 & 1.0 & 1.00 & 5.0 \\
\hline Total mixture 1 ton & & & 0.66 & 13.2 & 0.23 & 4.6 & 0.68 & 13.6 \\
\hline
\end{tabular}



Imperial units

\section{LINEAR}

inch

foot

yard

mile

AREA

square inch square foot acre

\section{VOLUME}

cubic inch

cubic foot

cubic yard

fluid ounce

pint

quart

gallon

\section{WEIGHT}

ounce

pound

short ton $(2000 \mathrm{lb})$

\section{TEMPERATURE}

degrees Fahrenheit

\section{PRESSURE}

pounds per square inch

\section{POWER}

horsepower

\section{SPEED}

feet per second

miles per hour

\section{AGRICULTURE}

gallons per acre

quarts per acre

pints per acre

fluid ounces per acre

tons per acre

pounds per acre

ounces per acre

plants per acre

25
$\times \quad 30$
$\times \quad 0.9$
$\times \quad 1.6$

$\times 6.5$

$\times 0.09$

$\times 0.40$

$\times 16$

$\times 28$

$\times 0.8$

$\times 28$

$\times 0.57$

$\times 1.1$

$\times 4.5$

$\times 28$

$\times \quad 0.45$

$\times 0.9$

$\begin{array}{r}6.9 \\ \hline\end{array}$

$\times 0.30$

$\times 1.6$

$\times 2.8$

$\times 1.4$

$\times 70$

$\times 2.24$

$\times 1.12$

$\times 70$

$\times 2.47$
Approximate

conversion factor

( $\left.{ }^{\circ} \mathrm{F}-32\right) \times 0.56$ or

$\left({ }^{\circ} \mathrm{F}-32\right) \times 5 / 9$

kilopascal

(kPa)

watt

(W)

kilowatt

(kW)

$\times 11.23$ metres per second

kilometres per hour

$(\mathrm{m} / \mathrm{s})$

$(\mathrm{km} / \mathrm{h})$

litres per hectare

litres per hectare

litres per hectare

millilitres per hectare

tonnes per hectare

kilograms per hectare

grams per hectare

plants per hectare
(L/ha)

(L/ha)

(L/ha)

(mL/ha)

(t/ha)

( $\mathrm{kg} / \mathrm{ha}$ )

(g/ha)

(plants/ha) 
National Library of Canada
hatheque nationale du Canada

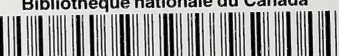

33286525460511 